\title{
Performance evaluation of exhaust aftertreatment devices used for emissions control on diesel engines employed in underground coal mines
}

Daniel K. Carder

West Virginia University

Follow this and additional works at: https://researchrepository.wvu.edu/etd

\section{Recommended Citation}

Carder, Daniel K., "Performance evaluation of exhaust aftertreatment devices used for emissions control on diesel engines employed in underground coal mines" (1999). Graduate Theses, Dissertations, and Problem Reports. 1038.

https://researchrepository.wvu.edu/etd/1038

This Thesis is protected by copyright and/or related rights. It has been brought to you by the The Research Repository @WVU with permission from the rights-holder(s). You are free to use this Thesis in any way that is permitted by the copyright and related rights legislation that applies to your use. For other uses you must obtain permission from the rights-holder(s) directly, unless additional rights are indicated by a Creative Commons license in the record and/ or on the work itself. This Thesis has been accepted for inclusion in WVU Graduate Theses, Dissertations, and Problem Reports collection by an authorized administrator of The Research Repository @ WVU. For more information, please contact researchrepository@mail.wvu.edu. 


\title{
Performance Evaluation of Exhaust Aftertreatment Devices Used for Emissions Control on Diesel Engines Employed in Underground Coal Mines
}

\author{
Daniel K. Carder \\ Thesis submitted to the \\ College of Engineering and Mineral Resources \\ at West Virginia University \\ in partial fulfillment of the requirements \\ for the degree of \\ Master of Science \\ in \\ Mechanical Engineering \\ Mridul Gautam, Ph.D., Chair \\ Greg Thompson, Ph.D. \\ W. Scott Wayne, Ph.D.
}

Department of Mechanical and Aerospace Engineering

Morgantown, West Virginia

1999

Keywords: Coal Mining, Diesel Emissions, Exhaust Aftertreatment 


\title{
Performance Evaluation of Exhaust Aftertreatment Devices used for Emissions Control on Diesel Engines Employed in Underground Coal Mines

\author{
Daniel K. Carder
}

\begin{abstract}
This study was initiated to assist the WV Diesel Equipment Commission in its promulgation of initial rules, requirements, and standards governing the operation of diesel-powered equipment in underground coal mines. Four different engines and various exhaust aftertreatment devices that represent current levels of in-use technology were selected for performance evaluation. Both eddy-current and water-brake dynamometers were used to load the engines according to an ISO 8-Mode test cycle. Experimental emissions data, sampled from a full-flow dilution tunnel, suggests that particulate traps can reduce the mass emission rates of particulate matter (DPM) by nearly $90 \%$, while reductions in fuel sulfur content ( $0.04 \%$ compared to $0.37 \%$ by mass) can reduce DPM mass emissions by as much as $22 \%$. The study concluded that the singular usage of catalytic converters is not recommended for the confined spaces of a mining environment, due to their tendency to enhance particulate matter sulfate production and possibly increase overall exhaust toxicity.
\end{abstract}




\section{ACKNOWLEDGEMENTS}

As the final chapter to a very lengthy master's career draws to a close for me, I feel compelled to give thanks to all of those who have made this journey end. In addition and for the record, it looks as if I will indeed graduate before Macy.

First and foremost, I would like to thank God. Without Him none of this would be possible. So many times He is forgotten, thankfully He does not forget us.

Next, I would like to express my appreciation of the West Virginia State Legislature and the West Virginia Diesel Commission for funding the research activities that provided the basis for this thesis. Not only have their efforts and funding provided a research opportunity for me, but, more importantly, they have answered necessary questions and posed new ones regarding the implementation of diesel engines in underground mining environments.

I next need to mention the people that have done more for me than anyone else ever could - my family. I know your continued support was always there, even when I doubted myself. Dad, if there was ever an engineer who missed his calling, I am certain it is you. You have provided me with so much insight into the physics of everyday life I am eternally grateful for the spark that ignited an inquisitive mind. Mom, thanks for teaching me patience and providing spirituality - two of the most necessary intangibles of life. Hillarey, you truly are the light of my life. Thank you for all that you are, and all that you've done. Macy, thanks for being daddy's girl. God has truly blessed me. Dennis \& Gwynne - the row is hoed. I've accomplished the mission; it's just that the "G's" were in the wrong sequence. Diz \& Susan - thanks for being there. Thanks to Beck, Dan, and little Shelby. Finally, thanks to Ashley and Erin - now hurry up and give Macy some playmates.

Thank you, Dr. Mridul Gautam. You've been an excellent advisor, but more importantly, you and your family have been good friends. Thanks for taking the time to

educate this Appalachian American. More importantly, thanks for grading that final, and still believing that there are some honest students left. 
Next, I need to offer my sincere gratitude for the extraordinary efforts and assistance of the crew - Bret Rankin, Sriram Popuri, Ryan Barnett. Who said that slavery was abolished? No one could ever ask for a better group of engineers, or, more importantly, a better bunch of friends. Mr. Cliff Judy, thanks for everything, especially for finally realizing the importance of a good pair of rubber boots. Thanks to my contemporaries - Don Ferguson, Rob Smith, Tim Chasey, Tony McKenzie, Brian Kelly, Mark Stablein, Eric Miller, Deepak Gupta, Murali Durbha, Avula Sreenath, Wes Riddle, and Ben Shade. When you finally break McKenzie's record, you accumulate a lot of friends. Thanks are also in order to Sandeep Mehta, whose help in the laboratory and data reduction assistance is greatly appreciated.

Thanks are also in order for the support provided by Rohmac, Inc., and, in particular, Mr. Buck Lovern - man those wings were delicious. Goodman industries must also be mentioned. I would also like to thank Richard Atkinson for his helpful guidance, and the remainder of my committee - Drs. Greg Thompson and Scott Wayne. As a side note, thanks Greg - I know "you just shift, alt.-tab, F1, backspace-return."

Last, but certainly not least, I would like to thank Dr. Donald Lyons for giving me the opportunity to attend graduate school at West Virginia University. In addition I would like to thank the United States Department of Energy for funding the construction and providing continuing operation of the Engine and Emissions Research Laboratory (EERL) at West Virginia University. Through their continued support, this research was made possible. 


\section{TABLE OF CONTENTS}

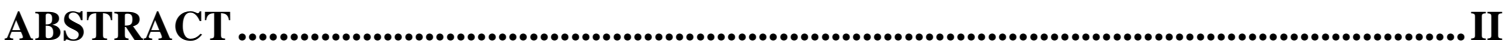

ACKNOWLEDGEMENTS...................................................................................................... III

LIST OF TABLES …........................................................................................ VIII

LIST OF FIGURES ……................................................................................................................IX

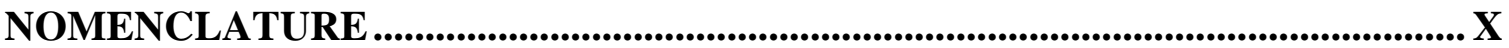

CHAPTER 1 - INTRODUCTION _....................................................................... 1

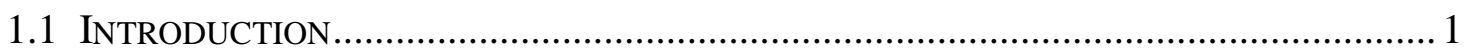

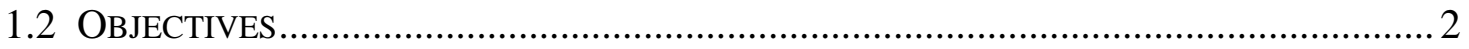

CHAPTER 2 - REVIEW OF LITERATURE.............................................................3

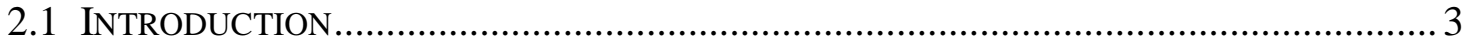

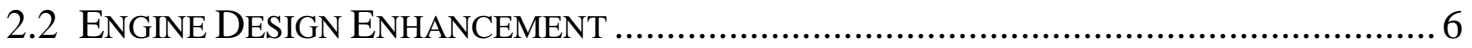

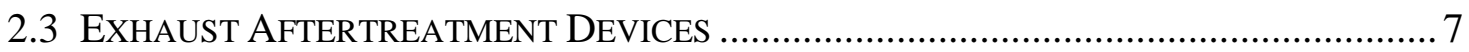

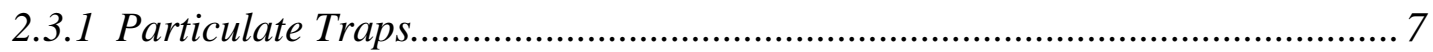

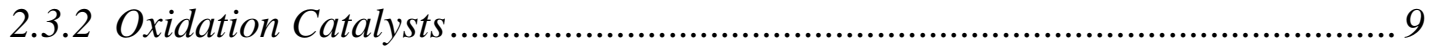

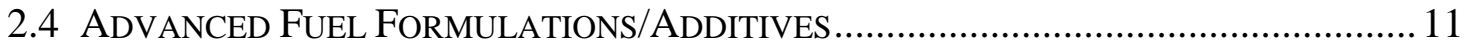

CHAPTER 3 - EXPERIMENTAL EQUIPMENT AND PROCEDURES.................. 13

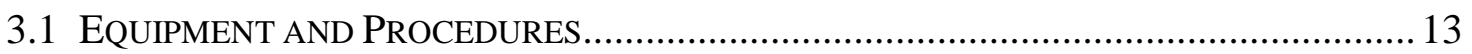

3.2 TEST ENGINES AND EXHaust AftertREATMENT DeVICES ...................................... 13

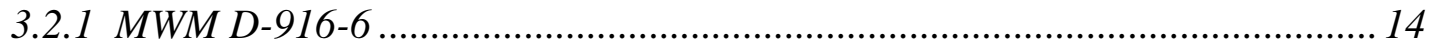

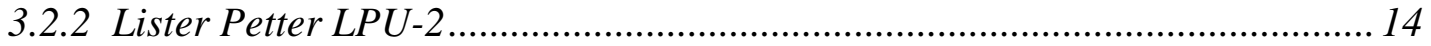

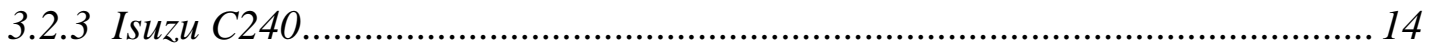

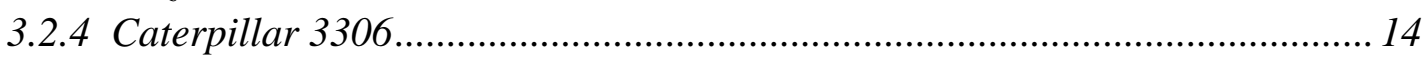

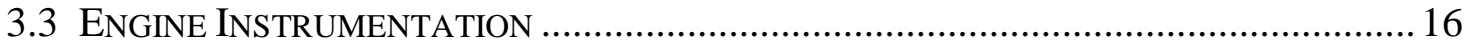

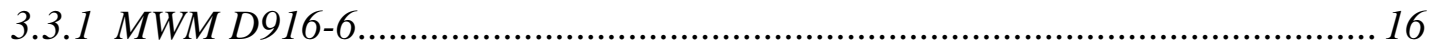

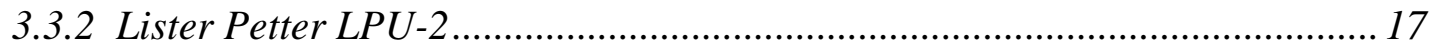

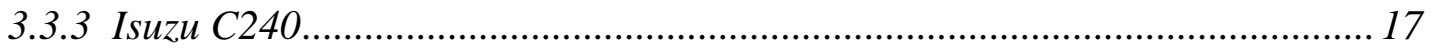

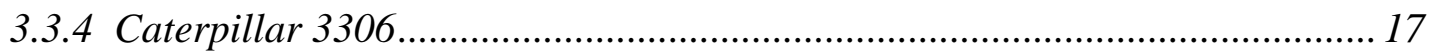

3.4 OPERATING CONDITIONS.......................................................................... 18

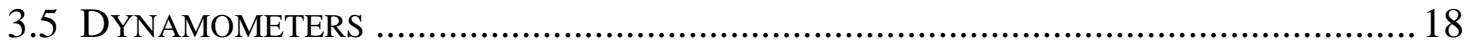

3.5.1 Water-brake Dynamometers ................................................................ 18

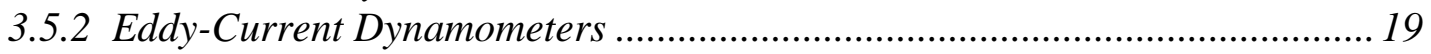

3.5.3 Electric Dynamometers.................................................................... 19

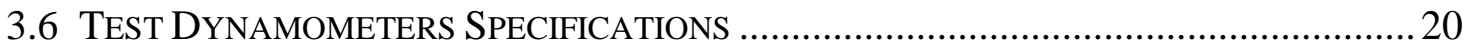

3.6.1 Go-Power D-100 (Lister Petter, LPU-2) ................................................. 20

3.6.2 Mustang Dynamometers EC300 (MWM D916-6 and Isuzu C240) ................ 20

3.6.3 Mustang Dynamometers K-400 (Caterpillar 3306)..................................... 21

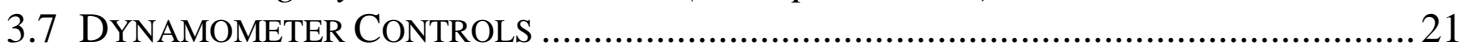




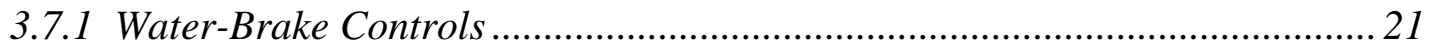

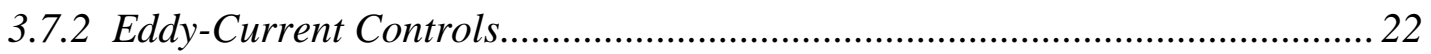

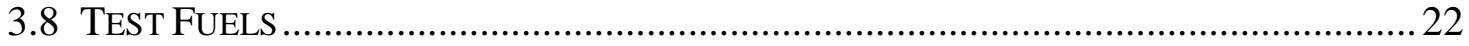

3.9 WEST VIRGINIA UNIVERSITY ENGINE AND EMISSIONS RESEARCH LABORATORY ... 25

3.9.1 Full-Flow Exhaust Dilution Tunnel .............................................................. 25

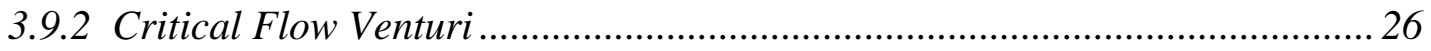

3.9.3 Secondary Dilution Tunnel and Particulate Sampling System ......................27

3.9.4 Gaseous Emission Sampling System ...................................................... 28

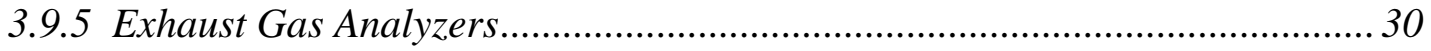

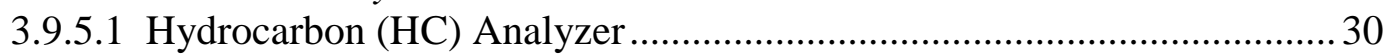

3.9.5.2 Carbon Monoxide (CO)/Carbon Dioxide $\left(\mathrm{CO}_{2}\right)$ Analyzers ....................... 30

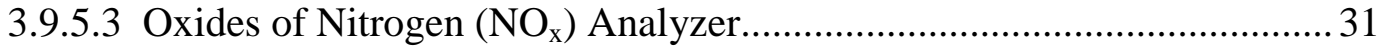

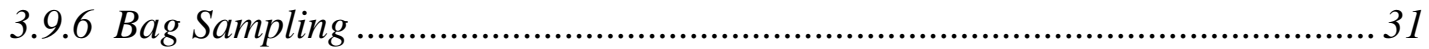

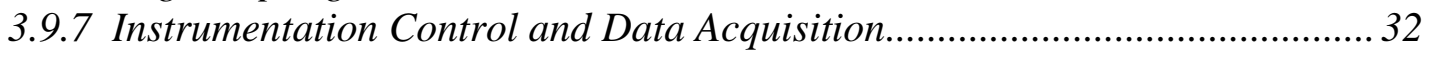

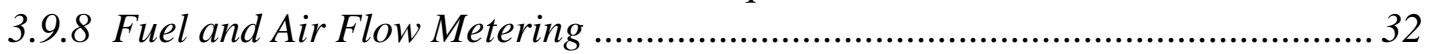

3.10 QuALITY CONTROL AND QUALITY ASSURANCE PROCEDURES ............................ 34

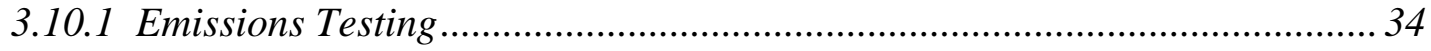

3.10.1.1 Sampling Lines and Probes .............................................................. 35

3.10.1.2 Pumps and Blowers .................................................................... 35

3.10.1.3 Exhaust Transfer Tube ................................................................. 35

3.10.1.4 Exhaust Analyzer Calibration and Calibration Gases ........................... 36

3.10.1.4.1 Hydrocarbon Analyzer ........................................................... 36

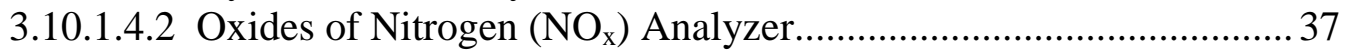

3.10.1.4.3 Carbon Monoxide (CO)/Carbon Dioxide $\left(\mathrm{CO}_{2}\right)$ Analyzers ............. 37

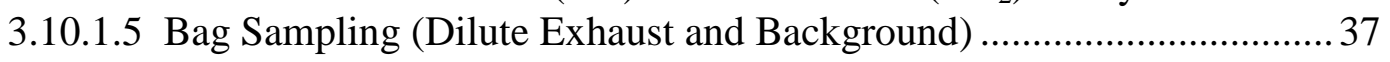

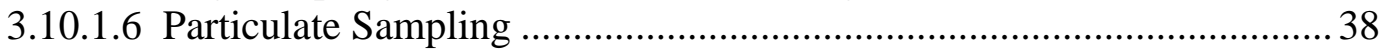

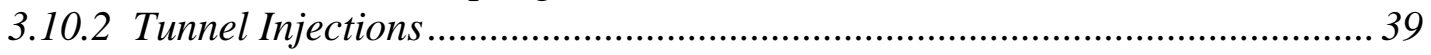

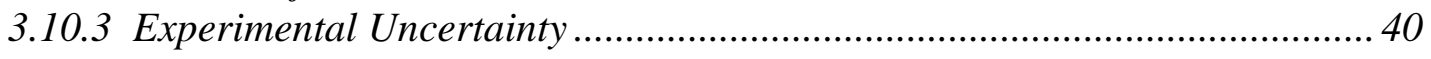

CHAPTER 4 - RESULTS AND DISCUSSION ..................................................45

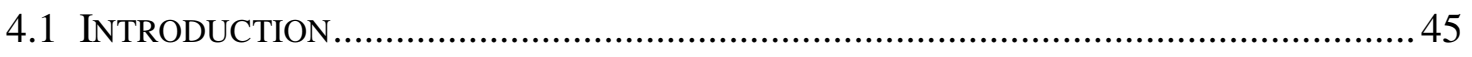

4.2 Considerations Involving the Measurement of Diesel Particulate

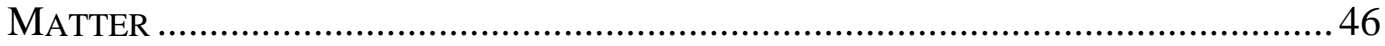

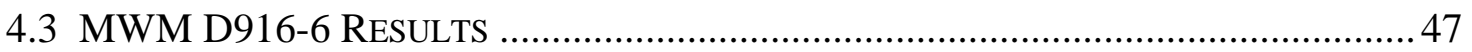

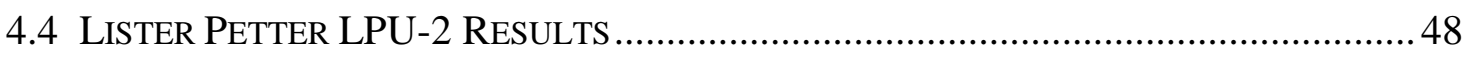

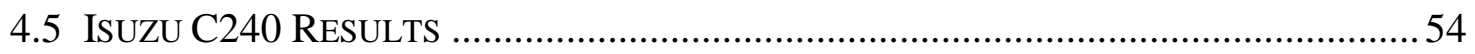

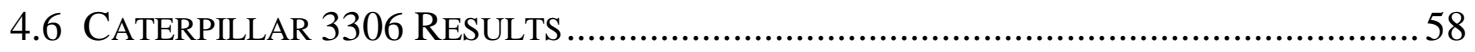

CHAPTER 5 - CONCLUSIONS AND RECOMMENDATIONS ..............................67

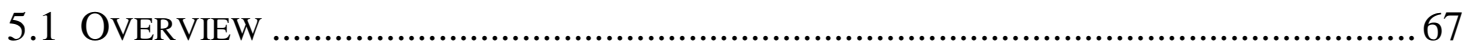

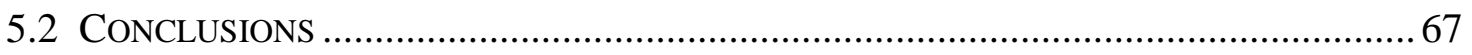

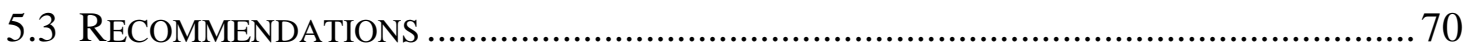

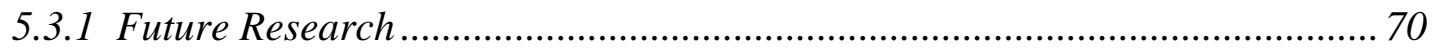

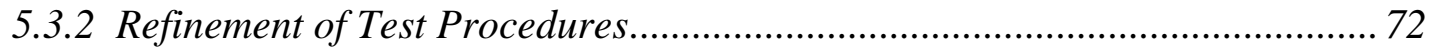

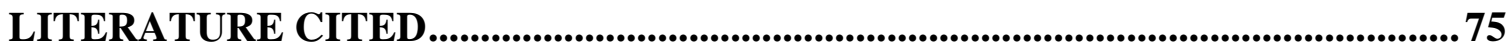


APPENDIX A - EXHAUST MASS EMISSIONS DATA (G/BHP-HR) ................... 79 APPENDIX B - EXHAUST MASS EMISSIONS DATA (G/HR).............................89 


\section{LIST OF TABLES}

Table 1 Test Engine Specifications................................................................. 15

Table 2 Engines and Associated Exhaust Aftertreatment Devices. .............................. 16

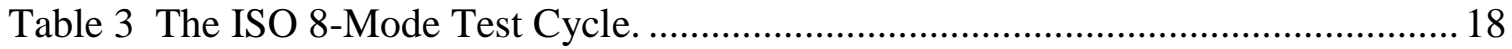

Table 4 Fuel Analysis Results for Low Sulfur Fuel..................................................... 23

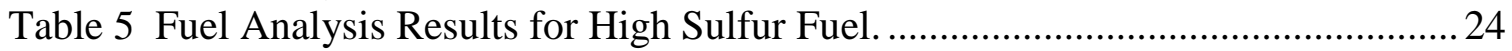

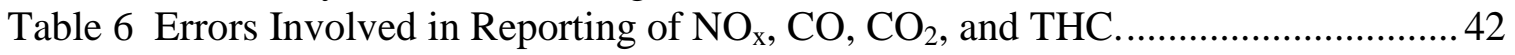

Table 7 Overall DPM Reductions for the MWM D916-6 (g/hr). ................................48

Table 8 Overall DPM Reductions for the Lister Petter LPU-2 (g/hr) ..........................52

Table 9 Overall DPM Reductions for the Lister Petter LPU-2 (g/hr)..........................52

Table 10 Overall DPM Reductions for the Isuzu C240 (g/hr) ....................................57

Table 11 Overall DPM Reductions for the Isuzu C240 (g/hr) ...................................57

Table 12 Overall DPM Reductions for the Caterpillar 3306 - DST I and DST II (g/hr). 63

Table 13 Overall DPM Reductions for the Caterpillar 3306 - DST III (g/hr). ...............63

Table 14 Overall DPM Reductions for the Caterpillar 3306 - Clean Air System (g/hr). 64

Table 15 Observed Exhaust Temperatures $\left({ }^{\circ} \mathrm{F}\right)$ After the DST Flame Arrestor During

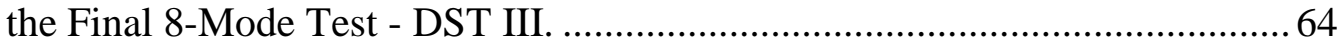




\section{LIST OF FIGURES}

Figure 1 Schematic of the West Virginia University Engine and Emissions Research Laboratory Emissions Analysis System........................................................229

Figure 2 MWM D916-6 Installed on an Eddy Current Dynamometer Test Bed............. 42

Figure 3 Lister Petter LPU-2 with Rohmac/DCL DPM Control System mounted on a Water-Brake Dynamometer Test Bed.

Figure 4 Isuzu C240 Rohmac/DCL DPM Control System Installed on an Eddy-Current

Dynamometer Test Bed.

Figure 5 Caterpillar 3306 with DST Dry Scrubber System Installed on an Eddy-Current Dynamometer Test Bed.

Figure 6 Caterpillar 3306 with Clean Air Systems Catalyzed DPM Trap Installed on an Eddy-Current Dynamometer Test Bed........................................................... 44

Figure 7 Comparison of Particulate Mass Emissions Rates Associated With the LowVersus High-Sulfur Tests Performed on an MWM D916-6.

Figure 8 Comparison of Particulate Mass Emissions Rates Associated With the Various Aftertreatment Devices Evaluated on a Lister Petter LPU-2 ...........................51

Figure 9 Side View of the Rohmac/DCL DPM Control System. ....................................53

Figure 10 Upstream Face of the Rohmac/DCL DPM Control System DPM Trap Prior to

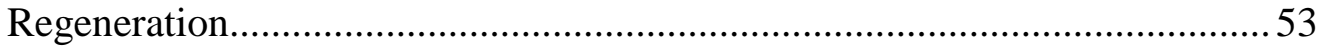

Figure 11 Upstream Face of the Rohmac/DCL DPM Control System DPM Trap Immediately Following Regeneration........................................................54

Figure 12 Comparison of Particulate Mass Emissions Rates Associated With the Various Aftertreatment Devices Evaluated on an Isuzu C240...................................56

Figure 13 Comparison of Particulate Mass Emissions Rates Associated With the Various Aftertreatment Devices Evaluated on an MWM D916-6.

Figure 14 Comparison of Particulate Mass Emissions Rates Associated With the Final DST Configuration Evaluated on a Caterpillar 3306.

Figure 15 Exhaust Temperatures Measured at the Entrance to the Filter Canister of the DST System During the Final DST Evaluation Test on a Caterpillar 3306. .. 62

Figure 16 DST Filter Canister with Signs of Coolant Leakage. 65

Figure 17 Evidence of Leak at Manifold Section of the DST Heat Exchanger.

Figure 18 Manifold Section of the DST Heat Exchanger System Prior to Repair...........66

Figure 19 Evidence of DPM Leakage at the Manifold Section of the DST Heat Exchanger System Prior to Repair. 


\section{NOMENCLATURE}

\begin{tabular}{|c|c|}
\hline $\mathrm{ADC}$ & Analog-to-Digital Conversion (codes) \\
\hline CARB & California Air Resources Board \\
\hline CFR & Code of Federal Regulations \\
\hline $\mathrm{CFV}$ & Critical Flow Venturi \\
\hline CVS & Constant-Volume Sampling \\
\hline $\mathrm{CO}$ & Carbon Monoxide \\
\hline $\mathrm{CO}_{2}$ & Carbon Dioxide \\
\hline EERL & Engine and Emissions Research Laboratory \\
\hline EPA & Environmental Protection Agency \\
\hline $\mathrm{HC}(\mathrm{THC})$ & Total Hydrocarbons \\
\hline HFID & Heated Flame Ionization Detector \\
\hline IARC & International Agency for Research on Cancer \\
\hline NDIR & Non-Dispersive Infrared Detector \\
\hline MSHA & Mine Safety and Health Administration \\
\hline NIOSH & National Institute for Occupational Safety and Health \\
\hline NIST & National Institute for Standards and Technology \\
\hline NO & Nitric Oxide \\
\hline $\mathrm{NO}_{\mathrm{x}}$ & Oxides of Nitrogen \\
\hline $\mathrm{NO}_{2}$ & Nitrogen Dioxide \\
\hline PM/DPM & Diesel Particulate Matter \\
\hline SAE & Society of Automotive Engineers \\
\hline $\mathrm{SO}_{2}$ & Sulfur Dioxide \\
\hline WVU & West Virginia University \\
\hline
\end{tabular}




\section{CHAPTER 1 - INTRODUCTION}

\subsection{Introduction}

Historically, the vast majority of regulatory diesel emissions legislation has focused on pollution contributions associated with engines operating in the on-highway sector. However, trends suggest that future legislation will be ever more scrutinizing of the performance of diesel engines used in the off-road arena. Federal regulation agencies are working to improve awareness and the information database associated with the use of diesel engines operating in the confined environments of coal mines. More specifically, the Mine Safety and Health Administration (MSHA) is presently involved with the monumental task of assessing regulatory limits for the emissions levels that are produced by diesel-powered equipment operating in underground mines - with the paramount issue being the initiation of a federal restriction regarding diesel particulate matter production levels. To date, federal regulations have merely governed the amounts of gaseous emissions permissible in underground mines, with the responsibility of DPM regulation falling upon state bodies. However, due to the growing awareness of the probable carcinogenic nature of diesel particulate matter, measures are being taken to effect national standards.

In addition to face haulage, diesel equipment plays an equally important role in other vital functions, such as material haulage, personnel transportation, and support operations. Other underground coal mine equipment that may be powered by diesel engines include shuttle cars, compressors, hydraulic pumps, generators, scoops and roof bolters. The versatility, maneuverability, and mobility of diesel power equipment make it an efficient alternative to electrically powered equipment. In addition, the use of dieselpowered equipment eliminates some of the electrical safety hazards that are associated with their electrically-powered counterparts, such as electrical shock and electrical sparkgenerated mine fires (particularly a risk in the deep methane environments common to WV coal mines). 


\subsection{Objectives}

The global objective of this study was to evaluate mass emission rates of exhaust emissions from diesel engines typically involved with mining operations. The West Virginia Diesel Equipment Commission procured four test engines and various aftertreatment devices so that an experimental assessment of "available" exhaust curtailment technology could be performed. The experimental data generated by this study will be utilized by the WV Diesel Equipment Commission to promulgate initial rules, requirements, and standards governing the operation of diesel equipment in underground coal mines.

Since gaseous emissions are currently regulated and most of the current emphasis on the control of diesel emissions in underground mines focuses on particulate matter, the results of this study will focus on the findings associated with the particulate reduction performance of the aftertreatment devices tested. Nonetheless, complete emissions records of both gaseous phase and particulate matter are included in the appendices. This report presents the details on the test equipment, procedures, results, and conclusions and recommendations. A list of specific activities included in this study are:

1. MWM D916-6 engine using high sulfur diesel fuel $(0.36 \% \mathrm{~S})$.

2. MWM D916-6 engine using low sulfur diesel fuel $(0.05 \% \mathrm{~S})$.

3. Lister-Petter LPU-2 engine (baseline).

4. Lister-Petter LPU-2 engine with a catalyzed trap with a catalytic converter - trap failed.

5. Lister-Petter LPU-2 engine with a catalyzed trap with a catalytic converter - retested with new trap.

6. Lister-Petter LPU-2 engine with a catalytic converter.

7. Isuzu C240 engine with a catalyzed trap followed by a catalytic converter.

8. Isuzu C240 engine with a catalytic converter.

9. Isuzu C240 engine with a catalytic converter followed by a catalyzed trap.

10. Caterpillar 3306 engine (baseline).

11. Caterpillar 3306 engine with catalyzed trap.

12. Caterpillar 3306 engine with a dry scrubber system.

13. Caterpillar 3306 engine with dry scrubber system - retest with the repaired heat exchanger.

14. Preliminary development and testing of high temperature trap for use with catalytic converter/trap combination and for other engines. 


\section{CHAPTER 2 - REVIEW OF LITERATURE}

\subsection{Introduction}

The utilization of permissible diesel-powered equipment poses less potential for dust or methane ignitions than do comparable electrically-powered equipment. By replacing electrically-powered units with diesel-powered units, the risk of injury to coal miners, such as electrocution due to electric cables and open trolley wires, is reduced. Current trolley wire systems consistently expose miners to bare 300-volt DC conductors, while batteries and battery overcharging present several hazards to coal miners. Additionally, electric sparks are significant sources of ignition in dust- and methane-filled environments. An additional advantage of diesel-powered equipment is the potential for safe and rapid evacuation of personnel in the event of a power failure. Considering higher productivity, which can be obtained by using diesel equipment, on a per-ton basis, there is less human exposure to the known health and safety hazards associated with underground coal mining [31]. As the amount of exposure necessary to mine a given quantity of coal is reduced, subsequent frequency of accidents will also diminish. Thus, the use of diesel-powered equipment with appropriate exhaust emissions controls in mining operations may improve the overall safety.

Because of its relationship with health problems, the exhaust from diesel engines operated in the closed confines of underground mines has been a subject of concern. MSHA has recently proposed a rule that would establish new health standards for underground coal mines that use diesel engine powered equipment. Their proposal requires installation of high-efficiency filters on diesel-powered inby equipment (equipment that is used at the mine face). Within 30 months, heavy-duty outby equipment (equipment that is not used at the mine face) will also have to be equipped with such high-efficiency filters. Whole diesel exhaust is considered to be a probable human carcinogen and the National Institute for Occupational Safety and Health (NIOSH) considers it a potential occupational carcinogen [13,25]. Cohen and Higgins suggested a small to moderate excess relative risk of lung cancer in workers who were exposed to emissions from older, mechanically-injected diesel engines. This finding is 
particularly relevant to mining applications because the majority of engines in use are older designs with mechanical injection, similar to those discussed by Cohen and Higgins [7]. It is understood that, to date, no epidemiological study has presented quantitative evidence of the past exposures of the study subjects and, hence, the use of this data to estimate the magnitude of cancer risk is limited. Heavy-duty diesel vehicle exhaust particulate is of concern because long-term exposure to particulate matter has been associated with excess lung cancer rates in laboratory animals $[15,19,24]$. Several other toxicological and epidemiological studies have also investigated the relationship between diesel emissions and the development of cancer and other diseases [5,7,35]. These studies have shown that long-term exposures to very high concentrations of diesel emissions produce lung tumors in rats and that soot (carbonaceous core DPM), not the adsorbed chemicals, is the likely cause of tumors in this species. The intent of this discussion is not to debate the relevance of the current rat model for risk assessments. Rather, to show that these recent findings confirm WVU's earlier findings that diesel soot particles can express in vitro genotoxic activity without extraction, as simple dispersions in surrogate pulmonary surfactant $[40,41]$.

Diesel engines, in general, emit solid particulates in the range of $0.1 \mu \mathrm{m}(100 \mathrm{~nm})$ diameters at concentrations above $1 \times 10^{5}$ particles $/ \mathrm{cm}^{3}$ depending on the engine type and operation. While Cohen and Higgins focused on older engines, other reports indicate that fine diesel soot below one micron in size is produced in high number counts by modern engines running low sulfur fuel, high-pressure injection and late injection timing (strategies designed to reduce the regulated emission inventory) [7]. It should be noted that most of the engines studied were turbocharged. Details of those studies have been given in a paper by Pataky et al. and a Health Effects Institute report [2,28]. Associations between suspended particulate matter and lung function parameters, respiratory symptoms, and mortality have been reported by Monn et al., Braun et al., Pope and Dockery, and Dockery et al. $[4,8,25,30]$. The respiratory health effects have been found to be associated with particulate matter with diameters less than $10 \mu \mathrm{m}$. These particles constitute the respirable range, that is, particles that penetrate the alveolated regions of the lung. In addition to the particle size, the number of inhaled particles could be of great relevance. A change of the median particle diameter from $1 \mu \mathrm{m}$ to $0.1 \mu \mathrm{m}$ increases the 
number of particles by more than a factor of a thousand for a constant total particulate mass [25]. This causes problems in the macrophage clearing mechanism. Kreyling has suggested that macrophage clearing is more efficient for a smaller number of larger particles than for a very high number of fine particles [18]. Recent studies have suggested that the very smallest particles, smaller than $0.1 \mu \mathrm{m}$ in diameter, are toxic by virtue of their size and cause stress of lung cell lining, leading to irritation and inflammation in some areas [10]. Size related toxicity, rather than chemical composition alone, might be of greater concern because chemical composition has been shown to be highly variable [16]. Diesel particulate impact on human health has been highlighted in recent reports [7,27]. The International Agency for Research on Cancer (IARC) conducted an extensive evaluation that concluded that there is sufficient evidence for the carcinogenicity in experimental animals of whole diesel engine exhaust. IARC reported that there is inadequate evidence for the carcinogenicity in experimental animals of gas phase diesel engine exhaust (particulate-filtered), but there is sufficient evidence for the carcinogenicity in experimental animals of extracts of diesel engine exhaust particles. Moreover, IARC reported that there is limited evidence for the carcinogenicity in humans of diesel engine exhaust. IARC's conclusions were reached based heavily on the evidence provided by several human epidemiological studies of railroad workers, bus company workers, and "dockers" [43].

Data suggesting the health risks associated with the use of diesel-powered equipment has lead to increased investigation efforts. It is proposed that the reduction of the engine emissions produced by off-road engines can be accomplished by integrating three focus areas in order to develop an effective emission reduction strategy: engine design enhancement, exhaust aftertreatment devices, and advanced fuel formulation/additives. Due to economic and practical constraints, the mining community cannot directly implement all of these methods. However, a review of current research practices is included for completeness. 


\subsection{Engine Design Enhancement}

The majority of diesel engines that are currently being utilized in underground mining applications are of the mechanically injected variety. Due to low unit demands and economic concerns, electronic control strategies have, for the most part, not been implemented into the underground mining environment. As the average level of electronic control increases in the diesel engine industry, governed mostly by the cost effectiveness of offering such advanced operation strategies, adaptation of such units to the mining arena will logically follow.

Abdul-Khalek et al., Bagley et al., and several supporting references suggest that advanced diesel engines yield a high number count of ultra-fine particles and that these particles may pose a significant human health risk [1,2]. A recent joint European study evaluated the exhaust emissions from diesel engines employed in the large tunnel construction projects in Austria, Germany and Switzerland [37]. The exclusive motivation was to minimize the effect of nanometer particles on occupational health. The study evaluated several particulate trap systems, catalytic converters, and fuel types with the objective of reducing emissions of nanometer particles. The report indicates that only particulate traps can curtail the total solid particulate count, in the fine particulate range below $50 \mathrm{~nm}$, by more than two orders of magnitude. The VERT study neither addressed the regeneration of traps nor assessed the genotoxic potential of the DPM emitted from engines equipped with the after-treatment devices.

Current diesel engine designs typically emit $90 \%$ less particulate matter by mass than comparable designs of 15-20 years ago. Optimization of piston bowls, enhanced injection pressures, and spray patterns, as well as improved boosting practices, have significantly curtailed the production of large-scale agglomerates and overall opacity. However, Mayer reports that, although a 1996 US-certified engine produced half the oxides of nitrogen emissions and exhibited better fuel economy and improved power as compared to an earlier design from the same family, no improvement was made on the emissions of ultra-fine nano-particles. In fact, Mayer found that new low-emission engines emit more ultra-fine particles at all load points [21]. 


\subsection{Exhaust Aftertreatment Devices}

Various aftertreatment systems are currently being evaluated throughout the world. An important concern with any control device/system is whether the potential health hazard is reduced or whether more harmful contaminants are produced. One must be very careful not to overlook detrimental by-products while assessing the gleaming positive attributes.

Some commercial systems integrate various components, and the design specifics of all (chemical treatments, component materials, etc.) are quite proprietary in nature. However, the basic components of any system can typically be represented by catalytic (oxidation) converters and particulate traps. Therefore, this section will be divided to discuss these technologies separately.

\subsubsection{Particulate Traps}

The concern about diesel particulate matter (DPM) has resulted in the development and application of a number of new on-board control systems that limit the quantities of DPM produced by the engine, collect the DPM, or convert it to a potentially less harmful form. Both ceramic and paper filters have been designed for use in underground mines, with limitations inherent in each. Paper filters must be replaced often, which has a significant impact on its acceptability. Two entirely different temperature-related problems occur with ceramic filters. One is the result of the regulated limits on equipment surface temperatures $\left(302^{\circ} \mathrm{F}\right)$ that exist for U.S. underground coal mines. The other problem arises as PM builds up in a ceramic filter in the diesel's exhaust system. The engine backpressure increases to such a high level the level that the DPM must be removed (a process called regeneration) or else the engine may be damaged. Combusting these particles to less harmful gases during normal operations (on-board regeneration) is essential if the filter's use is to be continued for more than a few shifts without a special regeneration process.

Catalyzed traps have also been employed to not only trap the soot but also achieve regeneration at lower exhaust temperatures under normal engine operating conditions. These traps drastically reduce the DPM emissions, but the utilization of precious metal 
washcoats to achieve regeneration often results in excessively high mass emissions rates of sulfates.

Mayer presented data at the culmination of an 18-month study that concluded that "drastic curtailment of pulmonary intruding particulates is not feasible by further development of the engine combustion, nor by reformulation of fuels, nor by deployment of oxidation catalytic converters" [21]. However, the use of particulate traps did have a significant effect on the reduction of DPM levels - reducing the fine particulate range below $50 \mathrm{~nm}$ by more than two orders of magnitude. Mayer also indicates that current gravimetric analysis standards of particulate matter production deliver "no toxically relevant information," and that number count seems to be a much more significant criterion. Moreover, traps exhibited reductions in the polycyclic aromatic hydrocarbon (PAH) sum, which are at least partially carcinogenic, likely by adsorption onto the trap surface area and subsequent conversion reactions during regeneration periods [21].

Mayer et al., in a later study, investigated the particle size distribution of particulate sample measurements taken downstream of different particulate trap systems [22]. The study culminated by comparing the size distribution of the two extremes of common trap designs. Surface-impaction filters, exemplified by those of the ceramic monolith (Cordierite wall-flow type) design, produce similar gravimetric particulate trapping efficiencies as the deep-bed filters of the knitted fiber (high temperature glass) variety. However, evaluation on the basis of particle count indicates that the efficiency of the surface filter drops below 70\%, whereas those of the deep-bed filter increases. Spectral analysis of distinct solid particulates resulted in conclusions regarding the size-sensitive nature of the filtration efficiencies of the two types of traps. Deep-bed filters have a very uniform filtration rate down to primary particulates of $20 \mathrm{~nm}$. In contrast, surface filters are only acceptable for particulates greater than $100 \mathrm{~nm}$. The tests performed during this study were made exclusively on new traps, and the researchers held that observations might differ for filters that had aged and had subsequently been exposed to regeneration cycles [22].

In a study investigating the effect of a ceramic particulate trap on the DPM and vapor phase emissions of a Cummins LTA10 heavy-duty diesel engine, researchers reported that ceramic particulate traps significantly reduced the levels of total particulate 
matter, soluble organic fractions, and solid carbon matter (TPM- $\left.\left[\mathrm{SOF}+\mathrm{SO}_{4}{ }^{2-}\right]\right)$. This is particularly important because the polynuclear aromatic hydrocarbon and nitro-PAH components of diesel exhaust are known carcinogens. However, results did indicate an increase in particles in the $0.0075-0.056 \mu \mathrm{m}$ range $(+\sim 30 \%)$ while particles in the $0.056-$ $1.0 \mu \mathrm{m}$ range were significantly reduced (over 90\%) [11].

The use of a paper-like pleated media filter has some problems that need to be resolved before these filters can be accepted in mines. The exhaust temperature for these systems must be controlled to prevent the filter media from igniting. This has been accomplished by using a wet scrubber system. These wet scrubbers require significant maintenance, a foolproof system to insure proper water level, and a considerable space within the equipment. Wet scrubbers have been known to run out of water during operation. In the past, the wet scrubbers have added excess moisture to the exhaust, while lowering its temperature. In addition, wet exhaust can lead to unexpected and/or premature failure of the pleated paper filters.

A dry exhaust system that cools the exhaust to an acceptable level for the pleatedmedia would seem to resolve several of the shortcomings of the wet scrubber systems. West Virginia University (WVU) has investigated two designs of the dry scrubber systems for two different engines. The first system, the DST Management System for an MWM-D916-6 engine, was studied under a grant from the Generic Technology Center for Respirable Dust (U.S. Bureau of Mines). The test plan was drawn up in consultation with the industry, miners and MSHA. Both transient and steady-state testing with a high sulfur diesel no. $2(0.37 \% \mathrm{~S}$ - the specified fuel at the time of the study) yielded DPM emission reductions in excess of $95 \%$. The management system is an emissions control system that may or may not utilize an oxidation catalyst. It employs dry cooling of the exhaust gases and a disposable paper filter to reduce both gaseous and particulate emissions. Another dry scrubber system designed for the Caterpillar 3306 was evaluated under the current WV Diesel Study.

\subsubsection{Oxidation Catalysts}

Oxidation catalytic converters have been utilized with diesel engines far more regularly than any other form of exhaust aftertreatment device. Catalytic converters are 
known to reduce the soluble organic fraction by $20 \%$ to $45 \%$. However, the undesirable aspect of the catalytic converters is the promotion of reactions that lead to sulfate formation at temperatures above $350^{\circ} \mathrm{C}$. In addition, the VERT report indicates that catalytic converters may have an effect of converting up to $40 \%$ of the $\mathrm{NO}$ to $\mathrm{NO}_{2}$ and increase the $\mathrm{NO}_{\mathrm{x}}$ toxicity. The VERT report suggested that the negative effects of catalytic converters outweigh the potential advantages [37]. This is similarly supported by other researchers. Walsh reports that the tendency of the precious metal catalyst to convert $\mathrm{SO}_{2}$ to particulate sulfates requires the use of low sulfur fuel: otherwise, this increase in sulfate emissions would more than counterbalance the decrease in SOF [42]. Results from the present study support Walsh's report [42].

Oxidation catalysts were reported to have no effect on the reduction of combustion particulates (soot), and, moreover, produced additional DPM material by way of sulfate particulates. In addition, the unfavorable oxidation reactions associated with $\mathrm{NO}$ and $\mathrm{SO}_{2}$ produced diesel exhaust with higher levels of toxicity [21].

Researchers at Southwest Research Institute investigated the feasibility, developed, and assessed the performance of a catalytic converter on a 1994 heavy-duty diesel engine. Results indicated that careful formulation of the catalyst can lead to good VOG reduction without excessive sulfate emissions. Fuel sulfur levels were obviously directly related to overall sulfate production levels. Moreover, low temperature aging using high sulfur fuel ( $0.3 \%$ by mass) lead to catalyst deactivation (poisoning) and increased particulate levels. This deactivation appeared to be somewhat reversible by exposing the catalyst to an exhaust stream resulting from an engine operating on low sulfur $(0.04 \%)$ fuel. Conclusions were also established regarding the effect of washcoat materials. Catalytic systems with silica-based washcoats and palladium noble metals exhibited superior sulfate control, whereas those containing alumina based washcoats and platinum noble metals exhibited high VOF, HC, and $\mathrm{CO}$ reduction but only at the expense of high sulfate emissions [17]. 


\subsection{Advanced Fuel Formulations/Additives}

Diesel fuel specification is also of relevance in the development of methodologies for particulate matter control. Diesel no. 2, that meets the requirements of the Code of Federal Regulations (CFR) 30, Part 7, does have a lower sulfur content compared to the fuel from a few years ago, but it is still not low enough to prevent the high rates of sulfate emissions. If the fuel sulfur content could be lowered to a few ppm, the aromatic content of the fuel be reduced to below $10 \mathrm{ppm}$ and the cetane number increased well beyond 50, then the catalyzed traps or combinations of catalytic converters and traps could readily yield extremely high DPM reductions. These reductions would be realized even during high speed/high load conditions and also during regeneration modes that may or may not need an external energy source. In addition, the reduction of fuel sulfur directly reduces the production of sulfur dioxide during the combustion process, and, perhaps more importantly, limits the formation of sulfates in the atmosphere, which are known contributors to acid rain.

Fischer-Tropsch (F-T) diesel fuel is one of the two types of fuels that were discussed during this study. F-T liquid fuels produced from synthesis gas (a mixture of carbon monoxide and hydrogen) are straight chain aliphatic hydrocarbons containing virtually no aromatic compounds or sulfur species. F-T diesels are currently being processed from methane (coal bed methane could be a potential source) and/or coal. The cetane number could be higher than 70, thus making it an excellent compression ignition fuel. F-T liquid fuels offer such significantly different chemistry that, when compared to typical petroleum based diesel fuels, a new DPM versus $\mathrm{NO}_{\mathrm{x}}$ variable emerges. F-T diesel, with virtually zero sulfur content, would be an excellent candidate for engines equipped with exhaust treatment devices, such as catalyzed traps. Regeneration of the traps to temperatures beyond $350^{\circ} \mathrm{C}$ would not lead to high sulfate emission levels and by the virtue of the low aromatic content and the high cetane number; $\mathrm{NO}_{\mathrm{x}}$ emissions could be simultaneously reduced. It is understood that $\mathrm{NO}_{\mathrm{x}}$ remains the hardest of all regulated emissions to alter by fuel reformulation. Shell Oil operates a gas-based middle distillate synthesis plant that supplies F-T liquid fuel as a blending stock to California. The California Air Resources Board (CARB) has mandated a maximum fuel aromatics 
content of $10 \%$ (poly-aromatics $<1.4 \%$ ) and a minimum cetane number of 48 . Blends of diesel no. 2 and F-T diesel (synthesized from natural gas) meet the tough emissions standards imposed by CARB.

Mayer suggests that current data indicates that fuel reformulation and the subsequent diminished sulfur content, decreased aromatic components, and increased Cetane index can effect a total DPM reduction from $5-15 \%$. Results from the VERT study indicated that zero sulfur and bound nitrogen fuel produced a $10 \%$ reduction of DPM emissions but did not effect any improvement in diminishing nano-particulate emissions. The VERT study concluded that reformulated fuel could not singularly offer significant reductions in particulate matter emission levels. However, the addition of iron and cerium based fuel additives did enhance particulate trap technology [21]. The additives (other than copper-based additives) serve to curtail raw emissions and do not form secondary (ash) emissions or dioxins and furanes when used in conjunction with trap technology. The use of fuel additives has provided a relatively predictable means of catalyzing particulate trap regeneration processes. Regeneration of a bare ceramic trap requires temperatures in excess of $550^{\circ} \mathrm{C}$, while implementation of fuel additives reduces this temperature requirement to below $450^{\circ} \mathrm{C}$, without the associated sulfate production or poisoning problems inherent to catalyzed systems [9].

Baranescu reported that for an increase of $0.1 \%$ (wt.) in fuel sulfur, brake specific particulates increased by about $0.025 \mathrm{~g} / \mathrm{bhp}$-hr, due to the addition of soluble sulfates and bound water [3]. Moreover, combustion systems, engine type, cycle loading, and particulate makeup had only a weak contribution to the brake specific sulfate variation. Conversion rates of fuel sulfur to sulfates on particulates were in the range of one to three percent.

Van Beckhoven reported that IDI engine vehicles on average responded minimally (3\%) to a change in sulfur content of $0.30 \%$ to $0.05 \%$ by mass. On the other hand, IDI engines responded to such fuel sulfur variations by emitting $15 \%$ less particulates under the European 13-mode tests and 30\% less under the US transient test conditions [36]. 


\section{CHAPTER 3 - EXPERIMENTAL EQUIPMENT AND PROCEDURES}

\subsection{Equipment and Procedures}

This section discusses the experimental equipment and procedures that were used to evaluate the performance of the various engine-exhaust aftertreatment system combinations. All testing for this study was performed at the Engine and Emissions Research Laboratory (EERL) at WVU. This facility has been in full-time operation since 1993 and operates according to the procedures set forth by the CFR 40, Part 86, Subpart $\mathrm{N}$. The design of the facility also permits compliance with the standards set forth by CFR 30, Part 7, and ISO/CD 8178-1. During this study, the requirements prescribed by the CFR 40, Part 86, Subpart N, for the measurements of dilute diesel exhaust emissions, were followed as closely as possible, while the engine operations (test modes) were taken from ISO/DIS 8178-4 standards. All engines and exhaust aftertreatment devices tested under this study were provided by the private sector and were tested as received, with no confirmations made as to their mechanical status. For this reason no claims will be made regarding the representative nature of such devices to other units provided by the respective companies. A detailed description of the engines, aftertreatment devices, test cycles, test fuels, laboratory equipment, and methods of operation follows.

\subsection{Test Engines and Exhaust Aftertreatment Devices}

The West Virginia Diesel Equipment Commission provided four different engines that serve to representatively span the power density spectrum currently utilized for coal mining operations. The Commission likewise secured various aftertreatment devices that exemplify currently available exhaust emissions curtailment technology. Table 1 lists basic technical specifications of the engines, while Table 2 includes a summary of the exhaust aftertreatment systems tested, by engine make.

Due to space limitations and program scheduling at the EERL, the dynamometer test beds for each engine-exhaust aftertreatment device had to be designed in a modular fashion. Extensive modifications had to be made to the engine mounting assemblies and 
dynamometer skids. Details of the design and fabrication of the various assemblies are not included in this thesis.

\subsubsection{MWM D-916-6}

A naturally aspirated, pre-chamber, in-line six-cylinder MWM D-916 engine was used for the portion of the study that compared and contrasted the exhaust emissions produced by high $(0.25 \%)$ sulfur and low $(0.05 \%)$ sulfur fuel. Fuel analysis revealed that the actual sulfur content was $0.37 \%$ and $0.04 \%$ for the high and low-sulfur fuels, respectively. The experimental setup is shown in Figure 2.

\subsubsection{Lister Petter LPU-2}

A naturally aspirated, pre-chamber, in-line two-cylinder Lister Petter LPU-2 engine was tested with various combinations of a DCL/Rohmac exhaust aftertreatment system. Figure 3 illustrates the engine-aftertreatment system and the eddy-current test bed that was utilized for evaluation. The combinations of the oxidation catalyst, catalyzed soot filter, and high-temperature paper filter that were used during the experiments are outlined in Table 2.

\subsubsection{Isuzu C240}

An Isuzu C240, pre-chamber, in-line four-cylinder engine was also tested with various combinations of a DCL/Rohmac exhaust aftertreatment system. An illustration of the engine-aftertreatment system and the eddy-current dynamometer test bed is included as Figure 4. Table 2 outlines the specific aftertreatment device combinations tested during this study.

\subsubsection{Caterpillar 3306}

A Caterpillar 3306, in-line, direct-injection six-cylinder engine was tested with both a Dry Systems Technologies and a Clean-Air Systems aftertreatment device. The 3306DST system is illustrated in Figure 5, while the 3306-Clean Air System setup is presented in Figure 6. Since space constraints prevented the Clean Air trap from being mounted 
directly to the engine exhaust manifold, an elbow adapter pipe was fabricated, and then the entire assembly was double insulated. The resultant setup provided substantial clearance with negligible temperature differences between the exhaust manifold exit and trap entrance. Two 8-Mode tests had to be performed on the DST system due to manufacturing flaws, which necessitated repair by the supplier, Goodman Equipment Corporation. While details of all of the problems that were encountered with the CAT 3306-DST systems are spared, a brief documentation of the repair procedures and supporting illustrations are included in the Chapter 4. The engine specifications for the 3306 are given in Table 1, while the exhaust aftertreatment configuration is presented in Table 2 .

Table 1 Test Engine Specifications.

\begin{tabular}{|c|c|c|c|c|}
\hline Engine & $\begin{array}{c}\text { MWM } \\
\text { D-916-6 }\end{array}$ & $\begin{array}{c}\text { Lister Petter } \\
\text { LPU-2 }\end{array}$ & $\begin{array}{l}\text { Isuzu } \\
\text { C240 }\end{array}$ & $\begin{array}{c}\text { Caterpillar } \\
3306 \\
\end{array}$ \\
\hline Injection & Indirect & Indirect & Indirect & Direct \\
\hline Cylinders & 6 - inline & 2 -inline & 4 - inline & $6-$ inline \\
\hline $\begin{array}{l}\text { Bore } \times \text { Stroke } \\
\quad \text { (inches) }\end{array}$ & $4.13 \times 4.72$ & $3.38 \times 3.15$ & $3.39 \times 4.02$ & $4.75 \times 6.0$ \\
\hline Displacement & $\begin{array}{l}379 \text { CID } \\
(6.234 \mathrm{~L})\end{array}$ & $\begin{array}{c}56.5 \text { CID } \\
(0.93 \mathrm{~L}) \\
\end{array}$ & $\begin{array}{c}144 \mathrm{CID} \\
(2.369 \mathrm{~L})\end{array}$ & $\begin{array}{c}638 \text { CID } \\
(10.46 \mathrm{~L}) \\
\end{array}$ \\
\hline Compression Ratio & $22: 1$ & $22: 1$ & $20: 1$ & $21: 1$ \\
\hline Peak Torque (ft-lbs.) & $\begin{array}{c}211 \\
\text { @ } 1500 \mathrm{rpm} \\
\end{array}$ & $\begin{array}{c}33.5 \\
\text { @ } 2150 \mathrm{rpm} \\
\end{array}$ & $\begin{array}{c}98 \\
\text { @1960 rpm }\end{array}$ & $\begin{array}{c}375 \\
\text { @ } 1320 \text { rpm } \\
\end{array}$ \\
\hline Rated Power (Hp.) & $\begin{array}{c}82 \\
\text { @ } 2100 \mathrm{rpm}\end{array}$ & $\begin{array}{c}20.7 \\
\text { @ } 3100 \mathrm{rpm}\end{array}$ & $\begin{array}{c}47.4 \\
\text { (a) } 3000 \text { rpm }\end{array}$ & $\begin{array}{c}123 \\
\text { (a) } 2200 \mathrm{rpm}\end{array}$ \\
\hline
\end{tabular}


Table 2 Engines and Associated Exhaust Aftertreatment Devices.

\begin{tabular}{|c||c||}
\hline \multirow{2}{*}{ Engine Tested } & Exhaust Aftertreatment Device \\
\hline \hline \multirow{2}{*}{$\begin{array}{c}\text { Lister Petter } \\
\text { LPU-2 }\end{array}$} & Rohmac/DCL Catalyzed Trap Followed by Oxidation Catalyst \\
\cline { 2 - 3 } & $\begin{array}{r}\text { Rohmac/DCL Catalyzed Trap Followed by Oxidation Catalyst } \\
\text { and Pallflex High Temperature Glass Fiber Filter }\end{array}$ \\
\hline \hline \multirow{2}{*}{\begin{tabular}{c} 
Isuzu C240 \\
\cline { 2 - 2 }
\end{tabular}} & Rohmac/DCL Catalyzed Trap Followed by Oxidation Catalyst \\
\cline { 2 - 2 } & Rohmac/DCL Oxidation Catalyst \\
\hline \hline \multirow{2}{*}{ Caterpillar 3306 } & Clean Air Systems Catalyzed Trap \\
\cline { 2 - 2 } & Dry System Technology Dry Scrubber System \\
\hline
\end{tabular}

\subsection{Engine Instrumentation}

Due to the time constraints imposed by the WV Diesel Study, test bed instrumentation was designed in a modular fashion so as to reduce down- time during the changeover periods between various test engines. Exhaust pressure measurements were made using Validyne Model P305 pressure transducers. These transducers were calibrated before each emissions test. Exhaust temperature measurements were made using Omega K-type thermocouples, which were calibrated on a regular basis as per manufacturer specifications. These measurements were taken in order to assure compliance with all manufacturer specifications on exhaust backpressure limitations. Obviously, measured backpressures associated with DPM traps are largely dependent upon the amount of particulate loading at the time of testing. If, during a test, the backpressure figures increased to a level near the manufacturer's threshold, a regeneration procedure, outlined in the Chapter 4, was performed. Similarly, if the DST system reached manufacturer's limits, a clean-up procedure was performed, by injected water into the upstream manifold of the DST heat exchanger assembly.

\subsubsection{MWM D916-6}

The MWM D916-6 was fitted with a pressure tap at the exit of the exhaust manifold in order to obtain total exhaust pressure measurements. However, since no aftertreatment devices were tested with this engine, pressure and temperature data were not included. 


\subsubsection{Lister Petter LPU-2}

The Lister Petter LPU-2 engine was fitted with exhaust pressure and temperature taps at the entrance and exit of the Rohmac/DCL aftertreatment system. The pressure differential across the trap and/or oxidation catalyst was obtained by a comparison of the respective aftertreatment configuration data with the baseline backpressure measurements. It should be noted that, due to the over-design of the exhaust-transfer tube, bare-engine total exhaust backpressure was minimal. Lister Petter requires that the maximum exhaust backpressure for the LPU-2 be less than 35 inches of water. Only once did the backpressure exceed this value, and that was during the initial regeneration cycle (40 inches). After this test, a Rohmac representative inspected the system and performed a pressurized cleaning of the trap and the catalyst substrate.

\subsubsection{Isuzu C240}

As with the LPU-2, the Isuzu C240 engine was fitted with exhaust pressure and temperature taps on the entrance and exit of the Rohmac/DCL aftertreatment. Again, the pressure differential across the trap and/or oxidation catalyst can be obtained by comparison of the respective aftertreatment configuration data with the baseline backpressure measurements. Isuzu specified that the maximum engine exhaust backpressure could not exceed 40 inches of water. Values observed while testing never exceeded 30 inches of water.

\subsubsection{Caterpillar 3306}

The Caterpillar 3306 was fitted with exhaust pressure and temperature taps on an insulated elbow at the exit of the exhaust manifold. In addition, for the DST tests a thermocouple was also placed at the exit of the paper filter canister. Caterpillar recommends that exhaust system backpressure should be maintained below 34 inches of water, and this backpressure limit was never exceeded. 


\subsection{Operating Conditions}

All test engines were operated at eight different steady-state modes. The engine speed and load factors of the 8-Mode test cycle are shown in Table 3. The operating speeds and loads are taken from the ISO/DIS 8178-4 Section 6.3.1.1 standards, "Test Cycles Type C - Off-Road Vehicles and Industrial Equipment," and closely resemble the operating set-points prescribed by CFR 30, Part 7. When overall emission reduction or weighted-averages were reported, the associated weighting factors given in Table 3 were used.

Table 3 The ISO 8-Mode Test Cycle.

\begin{tabular}{|c||c|c||c||}
\hline Mode Number & Engine Speed & $\begin{array}{c}\text { Load Factor } \\
\text { (Percent Load) }\end{array}$ & $\begin{array}{c}\text { Weighting } \\
\text { Factor }\end{array}$ \\
\hline \hline 1 & Rated & 100 & 0.15 \\
2 & Rated & 75 & 0.15 \\
3 & Rated & 50 & 0.15 \\
4 & Rated & 10 & 0.10 \\
5 & Intermediate & 100 & 0.10 \\
6 & Intermediate & 75 & 0.10 \\
7 & Intermediate & 50 & 0.10 \\
8 & Idle & 0 & 0.15 \\
\hline
\end{tabular}

\subsection{Dynamometers}

In order to simulate real-world loading operations on an engine in a laboratory environment, a dynamometer, or power absorber, is used. Engine testing is generally performed with one of three basic types of dynamometers. In order to familiarize the reader with the basic principles of operation, the following discussion has been included.

\subsubsection{Water-brake Dynamometers}

Water-brake, or fluid, dynamometers are generally divided into two categories: viscous shearing types and agitator types. Viscous shearing fluid dynamometers absorb 
engine loads by shearing a fluid between a rotor and a stator (housing). The amount of load is controlled by varying the flow rate of water into the housing. An agitator fluid dynamometer loads an engine by changing the direction of water flow from rotor vanes to stator (housing) vanes, i.e. an inward flow to an outward flow. The associated change in momentum results in a reaction force on the stator housing. In addition, a viscous shearing force is superimposed as the rotor cuts through the fluid moving from rotor pockets to stator pockets. Load adjustment for the agitator-type fluid dynamometers is accomplished by varying the inlet water flow rate or the restriction of the casing outlet.

\subsubsection{Eddy-Current Dynamometers}

Air-cooled eddy current dynamometers operate by establishing a magnetic field by energizing a set of stationary coils with DC power. Iron rotors, which are attached to the output shaft of the test engine, rotate in the magnetic field and generate eddy currents in the rotors, which produce a counter force to the direction of rotational motion. The power absorbed by the dynamometer is then dependent upon the amount of DC power applied to the dynamometer and the speed at which it is rotating. The absorbed energy is converted into heat in the two externally located rotors, which are designed with curvilinear cooling fins for fast heat dissipation. The windage losses associated with this cooling are compensated for during data reduction.

\subsubsection{Electric Dynamometers}

Electric dynamometers operate much like electric motors. In fact, to start the test engine, the dynamometer is operated as an electric motor, while the fuel (for compression-ignition engines) or ignition (for spark-ignition engines) sources for the test engine are disabled. In such a motoring configuration, the parasitic, or frictional, losses of the engine can be measured and simulations of coast-down may be performed. Once the fuel or ignition source for the engine is activated, the dynamometer may be used to load the engine by operating in the same manner as a generator. Torque is developed due to the magnetic coupling between the armature and stator. The engine output is then

determined from a side-arm load cell that is attached between the stator housing and the 
dynamometer-mounting frame. The load applied to the engine is varied by strengthening the field voltage or reducing the load resistance.

\subsection{Test Dynamometers Specifications}

The testing performed for this study utilized both water-brake and eddy-current dynamometers. The WV Diesel Equipment Commission did not request coast-down test cycles. Therefore, no electric dynamometers were used during this study.

\subsubsection{Go-Power D-100 (Lister Petter, LPU-2)}

At the onset of this study, an operational test bed that could accurately test smaller engines, such as the Lister Petter LPU-2, was not available. Many studies have tested comparable engines with large eddy-current dynamometer test beds and reported the results. However, since most of these large eddy-current dynamometers had operating windage losses that were larger than the Lister Petter LPU-2 power set-points for the ISO 8-Mode test cycle, data accuracy could have been suspect. To reduce such inherent errors, a Go-Power D-100 water brake dynamometer head was acquired. After mounting the Go-Power D-100 and Lister Petter LPU-2 on a custom-built test bed, preliminary tests indicated that the existing manual dynamometer controls for speed and torque were inadequate. These controls were replaced with automated components from another water brake dynamometer setup, and, after system optimization, the engine/dynamometer combination was re-evaluated. Results indicated that the automated control system provided adequate control of test set-points. Details regarding the development of the Go-Power D-100 dynamometer test bed are not included in this thesis.

The Go-Power D-100 water-brake dynamometer has a continuous operating range of $14,000 \mathrm{rpm}$ and a maximum operation speed of $16,500 \mathrm{rpm}$. The dynamometer is capable of absorbing $100 \mathrm{hp}(75 \mathrm{~kW})$. It can handle full continuous loading (65 ft-lb; 90 $\mathrm{N}-\mathrm{m}$ ) at speeds ranging from $4000 \mathrm{rpm}$ through $8000 \mathrm{rpm}$.

\subsubsection{Mustang Dynamometers EC300 (MWM D916-6 and Isuzu C240)}

Mustang Dynamometers EC300 eddy current dynamometers were used to control the load applied to the MWM D916-6 and Isuzu C240 engines. The unit is rated for a 
maximum horsepower of $1100 \mathrm{hp}(825 \mathrm{~kW})$, under cold conditions, and has a continuous rating of $250 \mathrm{hp}(188 \mathrm{~kW})$. It can handle a continuous load of $390 \mathrm{ft}-\mathrm{lbs}(540 \mathrm{~N}-\mathrm{m})$ and a maximum load of $2170 \mathrm{ft}-\mathrm{lbs}$ (3005 N-m), under cold conditions.

For the MWM D916-6 engine tests, an existing test bed was used to produce results. The MWM engine test cell was outfitted with a Dyne Systems Co. DTC-1 throttle controller and a Dyne System Co. Dyn-Loc IV dynamometer controller. For the Isuzu test cell, a custom test bed was constructed and the cell was fitted with a manual fuel control linkage and a Dyn-Loc IV dynamometer controller.

\subsubsection{Mustang Dynamometers K-400 (Caterpillar 3306)}

The Caterpillar 3306 engine was mounted on a customized test bed equipped with a

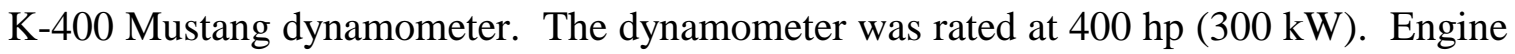
fueling rate was controlled pneumatically via the Caterpillar air actuator, and a Dyne-Loc IV dynamometer controller was used to control speed and load set points. Engine load measurements were made with an Interface SSM-500 load cell, mounted in a side-arm arrangement to the dynamometer housing. Engine speed was measured with an AccuCoder Model 220C PU rotary encoder.

\subsection{Dynamometer Controls}

\subsubsection{Water-Brake Controls}

For the water-brake test rig, a Mason Eilan Camflex II dynamometer controller was used to vary the load applied by the dynamometer. The system consists of a control unit and an electro-pneumatic water control valve. It is capable of using either torque or speed as the controlling parameter. In the "torque mode," a torque set point is compared to output from the load cell, which is mounted to the dynamometer case. In the "speed mode," an engine speed set point is compared to output from an angular speed encoder, which is mounted on the dynamometer shaft. In either mode of operation, the controller then varies the output voltage to the water control valve, in order to achieve the controlling parameter set point. 


\subsubsection{Eddy-Current Controls}

For the eddy-current test rigs, Dyne-Loc IV dynamometer controllers were used to vary the load applied by the dynamometer. The Dyne-Loc IV is capable of using either torque or speed as the controlling parameter. In the "torque mode," a torque set point is compared to output from a side-arm load cell, which is mounted to the dynamometer frame. In the "speed mode," an engine speed set point is compared to output from an angular speed encoder, which is mounted on the dynamometer shaft. In either mode of operation, the controller then varies the output current to the dynamometers in order to achieve the controlling parameter set point. The control unit is capable of maintaining speed and load set points to within $\pm 2 \mathrm{rpm}$ and $\pm 2 \mathrm{ft}-\mathrm{lbs} .( \pm 2.8 \mathrm{~N}-\mathrm{m})$, respectively.

For the portion of the testing where the MWM test rig was used, a Dyne Systems DTC-1 throttle controller was used to control the engine fueling-rate. The DTC-1 consists of a control unit, which is interfaced with the Dyn-Loc IV dynamometer controller, and a throttle actuator, which is mounted on the engine and attached to its fuel control linkage. By comparing an operator-defined set point with test rig output, the desired fueling rate, and hence engine speed, is obtained. The DTC-1 can be operated with either torque or speed as the controlling parameter.

\subsection{Test Fuels}

The testing performed for this study utilized both high- and low-sulfur diesel fuel number 2. The high sulfur fuel was purchased from Ashland Oil, and the low sulfur fuel was obtained from BP Oil. Analysts, Inc. tested representative samples of both fuel types. Test results, presented in Table 4 and Table 5, indicate that the actual sulfur mass content was $0.37 \%$ and $0.04 \%$ for the high- and low-sulfur fuels, respectively. According to federal regulations, high sulfur diesel can have a maximum of $0.5 \%$ sulfur content by weight, whereas low sulfur can have a maximum of $0.05 \%$. A comparative study between these two fuels was performed using the MWM D916-6 in order to determine the effects of sulfur content on baseline engine exhaust emissions. For the remainder of the study, the low sulfur fuel was used, in accordance with the requirements of CFR 30, Part 7. 
Table 4 Fuel Analysis Results for Low Sulfur Fuel.

\begin{tabular}{|c|c|c|c|}
\hline Properties & Measured & Minimum & Maximum \\
\hline $\begin{array}{c}\text { Distillation, }{ }^{\circ} \mathrm{F} \\
\text { Initial Boiling Point } \\
\text { Recovered }-5 \% \\
-10 \% \\
-20 \% \\
-30 \% \\
-40 \% \\
-50 \% \\
-60 \% \\
-70 \% \\
-80 \% \\
-90 \% \\
-95 \% \\
\text { End Point - FBP } \\
\text { Recovery, \% volume } \\
\text { Residue, \% volume } \\
\text { Loss, \% volume } \\
\end{array}$ & $\begin{array}{l}377 \\
414 \\
429 \\
449 \\
471 \\
490 \\
509 \\
528 \\
548 \\
571 \\
601 \\
632 \\
648 \\
97.6 \\
1.2 \\
1.2 \\
\end{array}$ & 540 & 640 \\
\hline Viscosity @ $40^{\circ} \mathrm{C}, \mathrm{cSt}$ & 2.6 & 1.9 & 4.1 \\
\hline Sulfur Content, \% Weight & 0.04 & & 0.05 \\
\hline $\begin{array}{l}\text { Hydrocarbon Types } \\
\text { Aromatics, \% volume } \\
\text { Olefins, \% volume } \\
\text { Saturates, \% volume }\end{array}$ & $\begin{array}{c}29.1 \\
2.1 \\
68.8 \\
\end{array}$ & & 35 \\
\hline API Gravity@60F & 35.6 & & \\
\hline Cetane Index (Calculated) & 47.9 & 40 & \\
\hline $\begin{array}{l}\text { Cetane Number } \\
\text { (Measured) }\end{array}$ & 47.0 & 40 & \\
\hline Flash Point, ${ }^{\circ} \mathbf{F}$ & 148 & 125 & \\
\hline \multicolumn{4}{|c|}{$\begin{array}{l}\text { Analysis Conducted by: } \\
\qquad \begin{array}{c}\text { Analysts Incorporated } \\
\text { P.O. Box 23200 Oakland, CA } 94623 \\
800-424-0099 \text { (Voice) } \\
510-536-5994 \text { (Facsimile) }\end{array}\end{array}$} \\
\hline
\end{tabular}


Table 5 Fuel Analysis Results for High Sulfur Fuel.

\begin{tabular}{|c|c|c|c|}
\hline \multicolumn{4}{|c|}{ Fuel Properties for High Sulfur Diesel Fuel No. 2} \\
\hline Properties & Measured & Minimum & Maximum \\
\hline $\begin{array}{c}\text { Distillation, }{ }^{\circ} \mathrm{F} \\
\text { Initial Boiling Point } \\
\text { Recovered -5\% } \\
-10 \% \\
-20 \% \\
-30 \% \\
-40 \% \\
-50 \% \\
-60 \% \\
-70 \% \\
-80 \% \\
-90 \% \\
-95 \% \\
\text { End Point - FBP } \\
\text { Recovery, \% volume } \\
\text { Residue, \% volume } \\
\text { Loss, \% volume } \\
\text { Viscosity @ 40 }{ }^{\circ} \text {, cSt } \\
\text { Sulfur Content, \% Weight } \\
\text { Hydrocarbon Types } \\
\text { Aromatics, \% volume } \\
\text { Olefins, \% volume } \\
\text { Saturates, \% volume } \\
\text { API Gravity @60F } \\
\text { Cetane Index (Calculated) } \\
\text { Cetane Number } \\
\text { (Measured) } \\
\text { Flash Point, }{ }^{\circ} \mathrm{F}\end{array}$ & $\begin{array}{c}374 \\
423 \\
444 \\
468 \\
484 \\
501 \\
517 \\
534 \\
553 \\
576 \\
609 \\
640 \\
655 \\
97.9 \\
1.0 \\
1.2 \\
2.7 \\
0.37 \\
\\
34.6 \\
3.1 \\
62.3 \\
32.2 \\
43.3 \\
46.0 \\
152\end{array}$ & $\begin{array}{r}40 \\
40 \\
\\
125\end{array}$ & $\begin{array}{l}4.1 \\
0.5 \\
35\end{array}$ \\
\hline $\begin{array}{r}\text { onducted by: } \\
\text { P. }\end{array}$ & $\begin{array}{l}\text { Analysts Incor } \\
\text { ox 23200 Oakl } \\
800-424-0099 \\
10-536-5994\end{array}$ & $\begin{array}{l}\text { ted } \\
\text { CA } 94623 \\
\text { e) } \\
\text { nile) }\end{array}$ & \\
\hline
\end{tabular}




\subsection{West Virginia University Engine and Emissions Research Laboratory}

This section discusses the experimental equipment and procedures that were used to evaluate the performance of the various engines exhaust aftertreatment systems. All engine testing was performed at the WVU-EERL in Morgantown, WV. The total exhaust dilution tunnel, gaseous and particulate matter sampling equipment, and testing and calibration procedures are presented herein.

\subsubsection{Full-Flow Exhaust Dilution Tunnel}

The obvious reason for performing exhaust emissions testing is to determine the effects of engine exhaust on the environment. In order to do this, it is necessary to simulate the dilution process of tailpipe emissions in a laboratory. Not only does this dilution process account for in-use exhaust-air interactions, but it also serves to quench post-cylinder combustion reactions and to lower the exhaust gas dew point in order to inhibit condensation. Exhaust line quenching is necessary in order to prevent inconsistent emissions measurements. The elimination of condensation is paramount, since water droplets can absorb certain gaseous components (for example, $\mathrm{NO}_{2}$ ). In addition, the presence of water in sampling lines would affect certain instruments, such as the non-dispersive infrared analyzers, and particulate matter measurements.

Two main dilution strategies are available for the researcher: full-flow dilution tunnels and mini-dilution tunnels. A full-flow tunnel collects the entire exhaust stream from the engine and mixes it with fresh ambient air, whereas a mini-, or partial, dilution tunnel samples a portion of an exhaust stream and dilutes this sample quantity. According to the CFR, only full-flow tunnels are recognized as a certifiable means of sampling engine exhaust emissions. The WVU-EERL utilizes a full flow dilution tunnel, designed and operated according to the specifications outlined in the CFR 40, Part 86, Subpart N.

The WVU full-flow system is based upon the critical flow venturi - constant volume sampler (CFV-CVS) concept in which a blower is used to draw diluted engine exhaust through critical flow venturis via a stainless steel 18 in. $(0.46 \mathrm{~m})$ diameter dilution tunnel that is approximately 40 feet in length. The laboratory uses a $75 \mathrm{Hp}(56.2 \mathrm{~kW})$ 
blower in tandem with a single $400 \mathrm{scfm}\left(11.32 \mathrm{~m}^{3} / \mathrm{min}\right.$.) and three $1000 \mathrm{scfm}$ (28.3

$\mathrm{m}^{3} / \mathrm{min}$.) venturis in order to provide total tunnel flow rates ranging from 400-2400 scfm (11.32-68 $\mathrm{m}^{3} / \mathrm{min}$.), $3400 \mathrm{scfm}\left(96.3 \mathrm{~m}^{3} / \mathrm{min}\right.$.) is unavailable due to blower limitations. schematic of the test facility is shown in Error! Reference source not found.. At the entrance to the tunnel, the entire engine exhaust was injected into an annulus of dilution air upstream of a mixing orifice plate. The orifice plate is eight inches in diameter and is located three feet from the beginning of the mixing region. The two streams are merged in the mixing region, and, at a distance of $15 \mathrm{ft}$. $(4.6 \mathrm{~m})$ downstream of the orifice plate, sample probes were placed to collect dilute gaseous exhaust samples. These probes are attached to the exhaust gas analyzer bench via electrically heated lines. At the end of the sampling region, diluted exhaust is drawn into a 4 in. $(0.10 \mathrm{~m})$ stainless steel secondary dilution tunnel by the particulate sampling system. Additional dilution air can be injected into this secondary tunnel in order to increase the dilution ratio (this can be used to ensure a soot collection filter face temperatures of less than $125^{\circ} \mathrm{F}\left(51.7^{\circ} \mathrm{C}\right)$. This sample system flow is then routed through the remainder of the particulate sampling system and exhausted into the analyzer bench exhaust manifold.

\subsubsection{Critical Flow Venturi}

In compliance with the CFR 40, Part 86, Subpart N, a constant volume sampler (CVS) was used to regulate the flow of diluted exhaust through the dilution tunnel. A constant mass flow rate is maintained in the dilution tunnel once the venturi section reaches sonic conditions (state of choked flow), as per the theory of critical flow nozzles [34].

Under choked conditions, the flow rate of a gas through a critical flow venturi is a function of the diameter of the venturi throat and the upstream temperature and pressure. A Viatran absolute pressure transducer, Model No. 1042 AC3AAA20, recorded upstream pressure and upstream temperature was logged via a Tayco 3-wire resistive temperature device, Model No. 68-3839. The mass flow rate was then calculated as follows: 


$$
Q=\frac{K_{v} P}{\sqrt{T}}
$$

Equation 1

where,

$\mathrm{Q}=\quad$ flow rate in standard cubic feet per minute at standard conditions of $20^{\circ} \mathrm{C}$, $101.3 \mathrm{KPa}\left(68^{\circ} \mathrm{F}, 29.92\right.$ in. $\left.\mathrm{Hg}\right)$.

$\mathrm{K}_{\mathrm{v}}=$ calibration coefficient.

$\mathrm{P} \quad=\quad$ absolute pressure at venturi inlet, in $\mathrm{KPa}$, (in. $\mathrm{Hg}$ ).

$\mathrm{T}=$ absolute temperature at venturi inlet, ${ }^{\circ} \mathrm{K},\left({ }^{\circ} \mathrm{R}\right)$.

The venturis were calibrated with the use of a subsonic flow venturi traceable to standards set forth by the National Institute of Standards and Technology (NIST). The CFV-CVS system utilizes a system of three critical venturis installed in-line with a $75 \mathrm{Hp}$ $(55.9 \mathrm{~kW})$ centrifugal blower [33]. Three of the venturis have a design flow rate of 1000 $\operatorname{scfm}\left(28.3 \mathrm{~m}^{3} / \mathrm{min}\right.$.), and the third has a design flow rate of $400 \mathrm{scfm}\left(11.32 \mathrm{~m}^{3} / \mathrm{min}\right.$.). A maximum tunnel flow rate of $2400 \mathrm{scfm}\left(67.92 \mathrm{~m}^{3} / \mathrm{min}\right.$.) can be achieved by using this system, due to blower operation limitations.

\subsubsection{Secondary Dilution Tunnel and Particulate Sampling System}

The WVU EERL uses a proportional sampling, double dilution method for particulate matter collection and analysis. In such a system, a diluted exhaust sample is drawn from the sampling region of the full-flow dilution tunnel into a secondary dilution tunnel. The flow rate into this secondary tunnel is varied throughout an emissions test in order to draw a proportional sample from both dilution tunnels. In the secondary dilution tunnel, additional dilution air may be added in order to obtain high dilution ratios and filter face temperatures below $125^{\circ} \mathrm{F}\left(51.7^{\circ} \mathrm{C}\right)$. The sample flow is then drawn across DPM collection filters, which enables the determination of the amount of DPM collected during a test cycle via gravimetric analysis. DPM consists of elemental carbon, soluble organic fractions, sulfates, and bound water. The DPM sample flow is then exhausted into a common sampling-stream exhaust manifold.

Specifically, the WVU sampling system draws a diluted exhaust sample through a 0.5 in. $(1.3 \mathrm{~cm})$ diameter transfer tube, 7 in. $(17.8 \mathrm{~cm})$ in length, located in the sampling 
zone of the primary dilution tunnel. The inlet faces upstream and is connected to the stainless steel secondary dilution tunnel, which is 3.0 in. $(7.62 \mathrm{~cm})$ in diameter and 30 in. $(76.2 \mathrm{~cm})$ long. The secondary tunnel provides sufficient residence time for the exhaust sample to be mixed with the dilution air, resulting in a sample with a temperature less than $125^{\circ} \mathrm{F}\left(51.7^{\circ} \mathrm{C}\right)$. The sample stream is drawn across a stainless steel filter holder, which attaches to the end of the secondary dilution tunnel. The filter holder houses two (a primary and a secondary) Pallflex $70 \mathrm{~mm}$ fluorocarbon-coated glass fiber filters, Model T60A20, upon which the DPM is collected. Two Sierra 740-L-1 mass flow controllers and two Gast 1023-101Q-583X rotary vane pumps control total secondary tunnel flow and secondary dilution airflow. An additional check on flow rates is provided by corrected measurements from a roots positive displacement flow meter. The total secondary flow ranges from 0-6 scfm $(0-170 \mathrm{lpm})$, while the secondary dilution airflow ranges from 0-3 scfm $(0-85 \mathrm{lpm})$. The mass flow controllers are routinely recalibrated by Sierra, and are additionally checked using a Meriam Instruments laminar flow element (LFE) Model No. 50MW20 rated at 0-23 scfm $\left(0-6.52 \mathrm{~m}^{3} / \mathrm{min}\right.$.). Further details of the WVU PM Sampling System are disclosed elsewhere [33].

\subsubsection{Gaseous Emission Sampling System}

The WVU EERL's gaseous emissions sampling system consists of heated sample probes, heated transfer lines, and a gas analysis bench. Three heated stainless steel sample probes were installed 10 diameters downstream of the mixing zone origin in the primary dilution tunnel in order to ensure fully developed turbulent duct flow. The probe tips were inserted six inches into the diluted exhaust flow stream and were directed toward the tunnel inlet (upstream). These probes are connected to the gaseous emissionsampling bench via electrically heated lines. The hydrocarbon probe and line were maintained at a wall temperature of $375^{\circ} \mathrm{F} \pm 10^{\circ} \mathrm{F}\left(191^{\circ} \mathrm{C} \pm 6^{\circ} \mathrm{C}\right)$ by Fuji Model No. 2231806 temperature controllers, in order to prevent the higher-molecular weight

hydrocarbons from condensing out in the sampling stream. The $\mathrm{NO}_{\mathrm{x}}$ and $\mathrm{CO} / \mathrm{CO}_{2}$ probes and lines were maintained at $235^{\circ} \mathrm{F} \pm 10^{\circ} \mathrm{F}\left(113^{\circ} \mathrm{C} \pm 6^{\circ} \mathrm{C}\right)$ by the temperature controllers in order to prevent water condensation and subsequent analyzer measurement errors. 


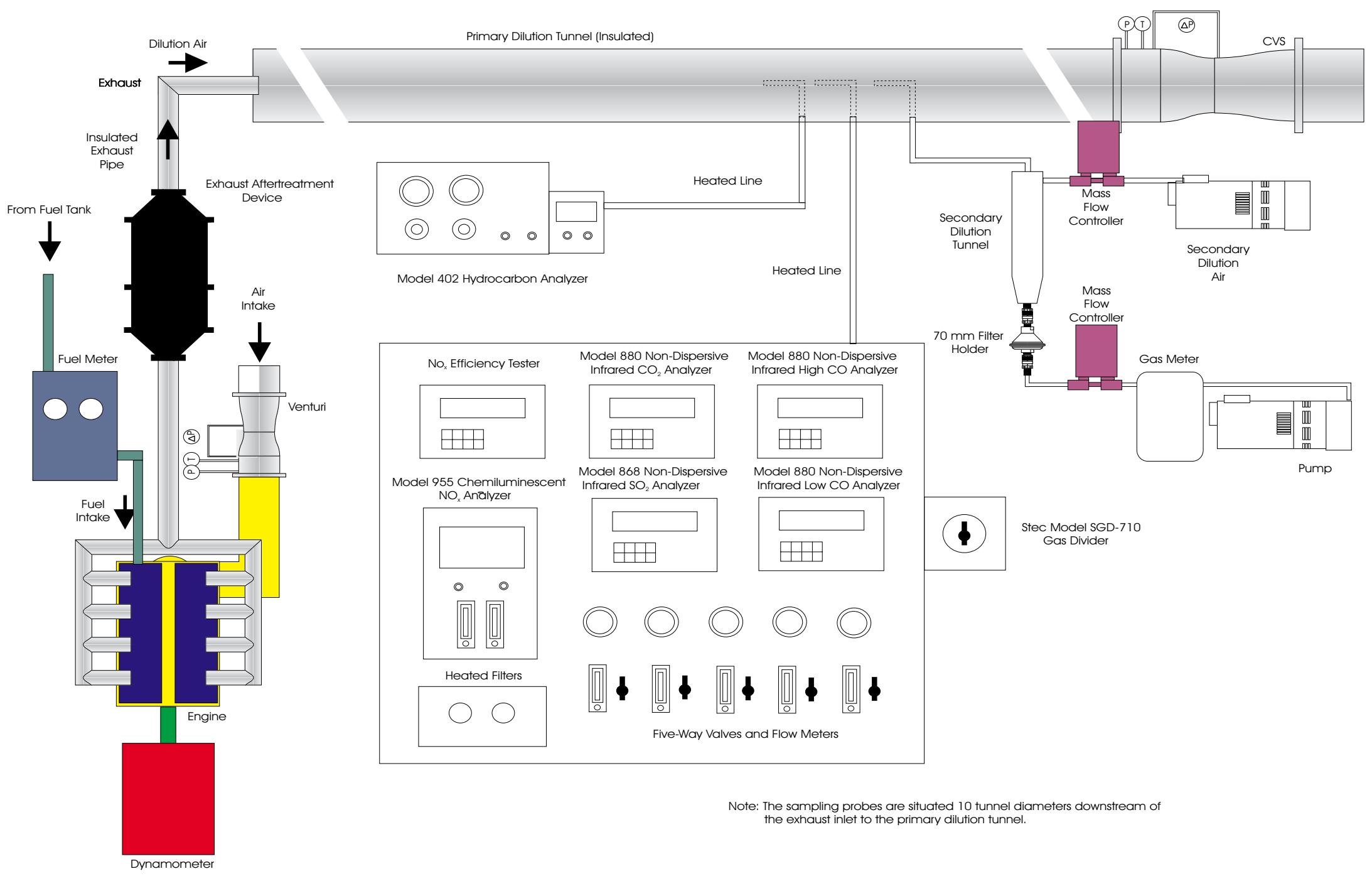

Figure 1 Schematic of the West Virginia University Engine and Emissions Research Laboratory Emissions Analysis System 
The gas analysis system consisted of four major components: $\mathrm{CO}_{2}$ analyzer, $\mathrm{CO}$ analyzer, $\mathrm{NO}_{\mathrm{x}}$ analyzer, and $\mathrm{HC}$ analyzer. The gas analysis bench housed Rosemount and Beckman analyzers and the sample flow conditioning system. Low $\mathrm{CO}$ and $\mathrm{CO}_{2}$ emissions were analyzed using Rosemount 868 and 880 Series Non-Dispersive Infrared (NDIR) analyzers. $\mathrm{NO}_{\mathrm{x}}$ measurements were performed by a Rosemount Model 955 heated chemiluminescent analyzer. A Beckman Model $958 \mathrm{NO}_{\mathrm{x}}$ efficiency tester was included in the bay in order to ensure that the Model 955 operated at above $90 \%$ converter efficiencies, as per CFR 40, Part 86, Subpart N. A stand-alone Rosemount Model 402 heated flame ionization detector (HFID) was used to measure exhaust hydrocarbons.

\subsubsection{Exhaust Gas Analyzers}

In order to make this document complete, a brief description of the analyzers and their theory of operation will be given in this section. A more thorough presentation of the analyzer theory is presented in the Rosemount operation manuals.

\subsubsection{Hydrocarbon (HC) Analyzer}

The hydrocarbon analyzer was a Rosemount Model 402 HFID. Exhaust hydrocarbon levels are measured by counting elemental carbon atoms. A regulated flow of sample gas flows through a flame that is produced by regulated flows of air and premixed hydrogen/helium fuel gas (FID fuel). The flame causes ions to be produced, which are in turn collected by polarized electrodes. The ion absorption produces a current flow through the associated electronic measuring circuitry that is proportional to the rate at which carbon atoms enter the burner [13,32]. The Model 402 is capable of measuring hydrocarbon concentrations up to 250,000 parts per million and produces a full-scale linear output.

\subsubsection{Carbon Monoxide (CO)/Carbon Dioxide $\left(\mathrm{CO}_{2}\right)$ Analyzers}

The $\mathrm{CO}$ and $\mathrm{CO}_{2}$ analyzers were Rosemount Model 868 and 880 Non-Dispersive Infrared (NDIR) analyzers. The NDIR operates upon the principle of selective absorption. Loosely stated, the infrared energy of a particular band of wavelengths, 
specific to a certain gas, will be absorbed by that gas, whereas infrared energy of other bands will be transmitted. The NDIR then determines gas concentration by the amount of transmitted (or absorbed) energy. The transmission (or absorption) is directly proportional to the concentration of the measured component gas. The NDIR's do not produce a linear output; therefore it was necessary to generate calibration curves for each of the analyzers. There are two $\mathrm{CO}$ analyzers on the gas analysis bench, a high $\mathrm{CO}$ analyzer and a low CO analyzer. The high CO analyzer has ranges of $0-2 \%$ and $0-10 \%$ while the low CO analyzer has ranges of 0-1000 ppm and 0-5000 ppm. The low CO analyzer was the only $\mathrm{CO}$ analyzer used in this research. The $\mathrm{CO}_{2}$ analyzer has ranges of $0-5 \%$ and $0-20 \%$.

\subsubsection{Oxides of Nitrogen $\left(\mathrm{NO}_{\mathrm{x}}\right)$ Analyzer}

The $\mathrm{NO} / \mathrm{NO}_{\mathrm{x}}$ analyzer used was a Rosemount Model 955 Chemiluminescent Analyzer. The analyzer can determine the concentration of either $\mathrm{NO}$ or $\mathrm{NO}+\mathrm{NO}_{2}$ which together is called $\mathrm{NO}_{\mathrm{x}}$. For the determination of $\mathrm{NO}$, the sample $\mathrm{NO}$ is quantitatively converted into $\mathrm{NO}_{2}$ by gas-phase oxidation with molecular ozone. When

this reaction takes place, approximately $10 \%$ of the $\mathrm{NO}_{2}$ molecules are elevated to an electronically excited state, followed by immediate reversion to the non-excited state. This conversion process produces a photon emission. A photon detector (multiplier tube) is then used to produce an instrument response that is proportional to the NO present in the original sample. The operation for $\mathrm{NO}_{\mathrm{x}}$ is identical to that of $\mathrm{NO}$ except that the gas sample stream is first passed through a converter, which converts the $\mathrm{NO}_{2}$ into NO. In this case, the instrument response is proportional to the NO present in the original sample plus the $\mathrm{NO}$ produced by the dissociation of $\mathrm{NO}_{2}$.

\subsubsection{Bag Sampling}

Diluted exhaust gas and background dilution air samples were collected in 80-liter Tedlar bags during each emissions test. After each test, the bags were analyzed and then evacuated, so as to be available for subsequent testing. The background dilution air bag was analyzed and the concentration levels were used to account for the dilution air contribution to emissions levels that were recorded during a given test. The dilute bag 
sample, when compared to the integrated sample, served as a quality control/quality assurance check.

\subsubsection{Instrumentation Control and Data Acquisition}

The software used in the study was previously developed and installed in the EERL data acquisition and dynamometer control system [6]. The program utilized an RTI-815F data acquisition board and rack-mounted signal conditioning boards, comprised of Analog Devices 3B series conditioning modules.

The data acquisition programs acquired the raw data (in the form of ADC codes) and a reduction program converted the raw data into proper engineering units [29].

\subsubsection{Fuel and Air Flow Metering}

Producing accurate dilution ratios for a full-flow dilution tunnel involves recording total tunnel volume flow rates and engine exhaust mass flow rates. Tunnel flow rates are measured using the CFV-CVS system. However, due to backpressure limitations, extreme temperatures, high particulate concentrations, and the general associated complexity, engine exhaust flow rates are not directly measured. Instead, an indirect approach is used to calculate engine exhaust flow rates, where a summation of engine fuel consumption rates and engine airflow rates are used.

A Max Flow Media 710 Series Fuel Measurement System performs the fuel flow rate measurements. During testing, a transfer pump directs fuel from the storage tank, through a filter, and into a vapor eliminator, which is maintained at $30 \mathrm{psi}(206.8 \mathrm{kPa})$. Before entering a Model 214 piston-displacement flow meter, excess fuel is routed via a pressure regulator through an internal heat exchanger and then back to the storage tank. This internal heat exchanger uses the by-pass supply fuel to cool the engine return fuel. The metered fuel supply then passes into a level-controlled tank. In this tank, it is mixed with unused engine return fuel, which has been cooled in the internal heat exchanger. The tank volume is maintained at a constant level, so the amount of metered fuel recorded during a given test period will necessarily be the quantity of fuel that is used by the engine. The exit to this mixing tank is connected to a secondary fuel pump. In most cases when the system is supplying a high-pressure injection system, this additional 
pump is used to further increase pressure, so as to minimize the requirements of the engine's original equipment fuel pump. Before the fuel exits the measurement system, it passes through a bubble detector, which controls a solenoid valve that connects the toengine and from-engine fuel lines. Removal of air and fuel vapors prevents poor engine performance and flow meter inaccuracies. After the purge solenoid, the fuel passes through an external heat exchanger, where the temperature is controlled via a Fuji Model No. 223-1806 temperature controller.

Meriam Laminar Flow Elements (LFE's) measure intake airflow rates. The LFE consists of a matrix of tiny capillaries that is used to produce a laminar flow stream from the normally turbulent flow found in the intake line. As the intake air flows through the triangular-shaped capillaries, friction creates a pressure drop. Meriam supplies a calibration equation and coefficients for each LFE. These are obtained through calibrations involving a flow meter that is traceable to NIST. Using the absolute pressure and temperature of the inlet flow, as well as the differential pressure across the LFE; the volume flow rate of air is obtained from Equation 2,

$$
\underset{\text { actual }}{\dot{V}}=\left\{B \times(\Delta P)+C \times(\Delta P)^{2}\right\} \times \frac{\mu_{\text {std }}}{\mu_{\text {flow }}}
$$

Equation 2

where $\mathrm{B}$ and $\mathrm{C}$ are the coefficients supplied by Meriam, and $\mu_{\text {stand }}$ and $\mu_{\text {flow }}$ are standard and actual flow kinematic viscosities. The viscosity variations are calculated using correction factors expressed in Equation 3 and Equation 4,

$$
\text { CorrectionFactor }=\left(\frac{529.67}{459.67+T\left(\text { in }^{\circ} \mathrm{F}\right)}\right) \times\left(\frac{181.87}{\mu g}\right)
$$


where,

$$
\mu g=\frac{14.58+\left(\frac{459.67+T\left(\text { in }^{\mathrm{o}} F\right)}{1.8}\right)^{1.5}}{110.4+\left(\frac{459.67+T\left(\text { in }^{\circ} F\right)}{1.8}\right)}
$$

Equation 4

Specifically, A Meriam Model 50MC2-6 LFE, 6 in. I.D.-1000 cfm (15.2 cm-28.3 m³min.), was used for the MWM D916-6 and Caterpillar 3306 tests, while a Model 50MC2-4 LFE, 4 in. I.D.-400 cfm (10.2 cm-11.32 m³/min.) was used for the Lister Petter LPU-2 and Isuzu C240 tests. Differential pressures across the LFE was measured using an MKS 223 B, while upstream absolute pressures are measured with a Setra Model C280E transducer. LFE inlet temperatures are recorded from Resistive Temperature Device (RTD) measurements. All pressure transducers were calibrated before each emissions test.

\subsection{Quality Control and Quality Assurance Procedures}

The WVU-EERL is committed to a Quality Control/Quality Assurance (QC/QA) program that assures data generation and measurement of the highest quality. The procedures adopted are discussed herein.

\subsubsection{Emissions Testing}

The laboratories are capable of measuring regulated and non-regulated vehicle emissions such as carbon monoxide $(\mathrm{CO})$, oxides of nitrogen $\left(\mathrm{NO}_{\mathrm{X}}\right)$, total hydrocarbons (THC), total particulate matter (TPM), and carbon dioxide $\left(\mathrm{CO}_{2}\right)$. Reliable sampling is assured through system design, periodic system inspection, and instrument calibration.

In order to obtain accurate and repeatable data the procedures presented by CFR 40, Parts 86 to 99, Subpart N were adopted and followed as closely as possible. 


\subsubsection{Sampling Lines and Probes}

The sampling streams use separate sampling probes and lines with their own pumps (heated in the case of $\mathrm{NO}_{\mathrm{X}}, \mathrm{THC}$, and also $\mathrm{CO} / \mathrm{CO}_{2}$ to avoid condensation of moisture in the lines). This design feature ensures reliable operation of the $\mathrm{THC}$ and $\mathrm{NO}_{\mathrm{X}}$ analyzers.

Verification of the operating condition of the emissions measurement equipment is performed before commencement of emissions testing. Prior to performing a test schedule, the condition of all dilution tunnel sample probes are verified. In addition, inspections are made to ensure the integrity of the sampling systems. Before testing, the sampling lines are leak checked (by pressurization) and back-flushed with instrumentgrade zero air in order to purge the lines of residual particulate matter. Heated sampling lines and their associated control systems (PID temperature controllers and associated thermocouples) are checked to ensure continuity between the controller, heater elements, and thermocouples. The temperature settings also are verified - THC sampling probes and lines are maintained at $375^{\circ} \mathrm{F}\left(190.6^{\circ} \mathrm{C}\right)$, while $\mathrm{NO}_{\mathrm{X}}$ lines and probes are maintained at $250^{\circ} \mathrm{F}\left(121.1^{\circ} \mathrm{C}\right)$. Periodically, sample line temperatures traces are recorded in order to verify that all components are functioning properly.

\subsubsection{Pumps and Blowers}

Periodically, the calibration and operation of the secondary dilution air and the secondary tunnel PM sample flow mass flow controllers are verified using a Roots-type positive displacement meter and a laminar flow element. The above-mentioned flows are also recorded during testing and are compared to corrected data collected from a Rootstype positive displacement meter.

\subsubsection{Exhaust Transfer Tube}

The exhaust transfer tube, which routes exhaust from the engine exhaust system to the inlet of the primary dilution tunnel, is checked for leaks after assembly. Joints in the tube are sealed using a high-temperature aluminum tape and periodically checked to ensure integrity. The exhaust transfer tube is insulated according to CFR 40, Part 86, Subpart N with no more than $12 \mathrm{ft}$. (3.66 m) of uninsulated tube and no more than $20 \%$ of 
the overall tube length consisting of flexible tubing. Such practices are afforded in an attempt to minimize errors in measurement due to thermophoretic effects.

\subsubsection{Exhaust Analyzer Calibration and Calibration Gases}

Calibration procedures utilized by the WVU EERL were in accordance with the requirements of CFR 40, Part 86, Subpart N and Part 8a. The gases used to calibrate the exhaust analyzers were certified by the supplier to have an accuracy of $1 \%$, traceable to NIST. No gas cylinder was used if the pressure drops below $200 \mathrm{psig}$, and the use of NO calibration gas cylinders was discontinued when the pressure reached 400 psig.

Zero reference states for the analyzers were provided by zero gas that did not exceed the following impurity concentrations: $1 \mathrm{ppm}$ equivalent carbon response, $1 \mathrm{ppm}$ carbon monoxide, $400 \mathrm{ppm}$ carbon dioxide, and $0.1 \mathrm{ppm}$ nitric oxide. Gases with concentrations that were approximately $20 \%$ to $30 \%$ higher than the measured exhaust constituent levels, when available, provided span reference. All exhaust gas analyzers were calibrated using ranges of operation that were in accordance with the engine being tested. These calibrations were performed before each series of tests and after any instrument maintenance was been performed. For the 10-point calibration curve, a Horiba SGD-710C gas divider was used. The divider accurately produced varying concentration of component gas in $10 \%$ increments by mixing the span gas with a balance zero reference gas. The instrument readings were allowed to stabilize at each measurement point and a computer averaged (100 points) reading of the instrument response was recorded. These data points and corresponding gas concentrations were fitted to a second-degree (third degree in the case of NDIRs) polynomial and constituted that particular analyzer's calibration data file. This calibration file superseded any previous calibration file for that analyzer in order to prevent the use of incorrect calibration files. The downloaded data disk for each test contained the calibration files for each analyzer.

\subsection{Hydrocarbon Analyzer}

The THC analyzer was subjected to the 'FID burner peaking process' to get the highest flame ionization detector (FID) response. This process involved measuring and 
recording the response of the instrument to $100 \%$ span gas and zero air with various settings of FID burner fuel and air. Upon completion of the FID burner peaking process, the fuel and air settings of the FID were placed at the setting that produced the highest instrument response, and the analyzer was calibrated.

An HC hang-up check was also performed on the heated FID. If the differences in the responses were more than two percent, the sampling probe was back flushed (direct injection of zero air into the analyzer and through the 'overflow' sampling probe) and steps were taken to rectify the problem.

\subsection{Oxides of Nitrogen $\left(N O_{x}\right)$ Analyzer}

Periodically, a $\mathrm{NO}_{\mathrm{X}}$ efficiency test was performed on the $\mathrm{NO}_{\mathrm{X}}$ analyzer. This test was performed to ensure that the analyzer converter (which converts $\mathrm{NO}_{2}$ to $\mathrm{NO}$ ) was performing satisfactorily. A conversion efficiency of less than $90 \%$ was considered a failure and maintenance was performed to rectify the situation. Filters in the $\mathrm{NO}_{\mathrm{X}}$ sampling were replaced after each day of testing.

\subsection{Carbon Monoxide (CO)/Carbon Dioxide $\left(\mathrm{CO}_{2}\right)$ Analyzers}

Since moisture can affect the operation of the NDIR analyzers used for carbon monoxide and carbon dioxide, a water interference check was performed. In addition, the sample flow was passed through a refrigerator dryer in order to condense sample stream water vaport before it reached the NDIR.

\subsubsection{Bag Sampling (Dilute Exhaust and Background)}

Two Tedlar bags $\left(2.82 \mathrm{ft}^{3}{ }^{3}-801\right)$ were used during each test to collect dilute exhaust and background samples for quantitative analysis. This bag analysis of dilute exhaust served as a check for the continuous gas measurements. The background sample was used to correct the dilute exhaust reading.

Prior to each test, the bags were evacuated and the pressures in the bags were noted.

Leaks in the bag sample system were indicated when the vacuum reading was less than 26 in. $(6 \mathrm{~cm})$ of $\mathrm{Hg}$. Replacement and zero air purge procedures were performed if bag readings appeared erroneous. 


\subsubsection{Particulate Sampling}

The mass flow controllers that were used to measure and adjust the flow rates of both secondary dilution air and dilute exhaust sample were calibrated using corrected readings from a Roots-type positive displacement meter as well as a laminar flow element. No conditioning was performed on the primary dilution air, but ambient particulate matter contributions are accounted.

PM collection filters were conditioned prior to, and following each test. An environmental chamber was used to condition the filters at 50\% relative humidity ( $\mathrm{RH})$ and $70^{\circ} \mathrm{F}\left(21.1^{\circ} \mathrm{C}\right)$ for at least one hour, but not more than 80 hours. Reference filters were conditioned along with test filters in order to account for the effects of humidity on the filter media. If the average weight of the reference filters changed between $\pm 5 \%$ or more of the nominal filter loading, then all sample filters in the process of stabilization (conditioning) were discarded and the emissions tests were repeated. If the average weight of the reference filters changed by more than $-1 \%$ but less than $-5 \%$ of the nominal filter loading, then the emissions test was repeated. If the difference in reference filter weights changed by more than $1 \%$ but less than $5 \%$ of the nominal filter loading, then the emissions test was repeated. If the weight of the reference filters changed by less than $\pm 1 \%$, then the measured sample weight was used. Dilution air contribution to collected PM mass was quantified by sampling across a filter through the secondary tunnel with the main dilution tunnel blowers operating. This method helped to account for entrained particles that might have been collected during an actual test and to account for the contribution of the dilution air to the test DPM filters (the WVU lab does not filter or condition primary dilution air). During the test, the filter face temperature was continuously monitored and recorded using a thermocouple. If the temperature rose above $125^{\circ} \mathrm{F}\left(51.7^{\circ} \mathrm{C}\right)$ at any time during a test, that test was voided. All particulate filters, reference, background, and sample, were stored in glass petri dishes (to minimize loss of particulate matter via static charge) while conditioning in the environmental chamber. These dishes were covered, but not sealed, to prevent dust from accumulating on the filters, while allowing humidity exchange. The total particulate matter (TPM) was determined via pre- and post-weighing, using a CAHN 32 microbalance, which had a 
sensitivity of $0.1 \mu \mathrm{g}$. The remote weighing unit of the balance was placed on a vibration isolator, and was calibrated using weights traceable to NIST.

As mentioned earlier, the CFR 30 considers diesel particulate matter to consist of elemental carbon, soluble organic fractions, sulfates, and bound water. Wall and Hoekman, suggested that at 50\% RH, 1.3 grams of water are present for every gram of sulfuric acid [39]. In addition, a linear relationship between bound water and sulfuric acid was reported to exist up to $60 \% \mathrm{RH}$. The amount of bound water increases rapidly beyond $60 \% \mathrm{RH}$. The CFR 30 recommends humidity control in the environmental chamber to ensure accurate gravimetric analysis of DPM. However, when the research objective is to determine the filtration efficiency of exhaust aftertreatment DPM control devices, sulfate formation can often skew findings and conclusions. WVU recognized the inherent inaccuracies in the DPM measurement guidelines set forth in CFR 40, but chose to report all test findings in accordance with these accepted government standards.

\subsubsection{Tunnel Injections}

Tunnel injections were used as an additional quality assurance procedure to check the operation of the whole emissions measurement system including the dilution tunnel, sample lines, and analyzers. These procedures involved the release of a known amount of gas into the dilution tunnel and a comparison of amount injected to amount recovered.

Propane injections were performed regularly in order to ensure that the CFV-CVS system was operating within federal guidelines. The procedure served primarily as a check on the total dilute exhaust flow rate through the primary dilution tunnel, but it also helped identify $\mathrm{HC}$ hang-up in the tunnel, as well as problems in the $\mathrm{HC}$ sampling system. Using a calibrated critical orifice and controlled pressure, a known quantity of 99.5\% propane was injected into the tunnel. The heated FID was used to measure the continuous concentration of propane in the diluted exhaust sample, as well as the dilute and background bag samples. Quantities reported by the continuous and integrated bag samples (minus background) were compared to the known amount of propane injected, in order to determine whether the THC sampling system and main dilution tunnel were operating correctly. A difference greater than $\pm 2 \%$ between the measured and actual injected mass of propane indicated an error in diluted-exhaust mass flow rate 
measurements. Testing was validated only when two successive propane injection tests reported less than a $\pm 2 \%$ difference.

\subsubsection{Experimental Uncertainty}

The determination of the uncertainty was approached by considering a quantity $\mathrm{N}$, where $\mathrm{N}$ is function of known variables:

$$
N=f\left(\mathrm{u}_{1}, \mathrm{u}_{2}, \mathrm{u}_{3}, \ldots, \mathrm{u}_{\mathrm{n}}\right)
$$

Equation 5

The absolute error is given by:

$$
\mathrm{E}_{\mathrm{a}}=\Delta \mathrm{N}=\left|\Delta \mathrm{u}_{1} \frac{\partial \mathrm{f}}{\partial \mathrm{u}_{1}}\right|+\left|\Delta \mathrm{u}_{2} \frac{\partial \mathrm{f}}{\partial \mathrm{u}_{2}}\right|+. .+\left|\Delta \mathrm{u}_{\mathrm{n}} \frac{\partial \mathrm{f}}{\partial \mathrm{u}_{\mathrm{n}}}\right|
$$

Equation 6

However, when the $\Delta \mathrm{u}$ 's are not considered as absolute limits, but instead as $\pm 3 \sigma$ limits; the method of computing the errors is according to the root-sum square formula.

$$
\mathrm{E}_{\mathrm{a}_{\mathrm{rss}}}=\Delta \mathrm{N}=\left[\left(\Delta \mathrm{u}_{1} \frac{\partial \mathrm{f}}{\partial \mathrm{u}_{1}}\right)^{2}+\left(\Delta \mathrm{u}_{2} \frac{\partial \mathrm{f}}{\partial \mathrm{u}_{2}}\right)^{2}+. .+\left(\Delta \mathrm{u}_{\mathrm{n}} \frac{\partial \mathrm{f}}{\partial \mathrm{u}_{\mathrm{n}}}\right)^{2}\right]^{1 / 2}
$$

Equation 7

A normal distribution is assumed for the random errors. The " $Z$ value" for the normal distribution for a $95 \%$ confidence level is 1.96 . Adding all the bias and random errors, the total error was obtained, $Z_{95 \%}=1.96$. 
The full dilution tunnel particulate mass equation is

$$
\left.\mathrm{P}_{\text {mass }}=\left(\mathrm{V}_{\text {mix }}+\mathrm{V}_{\text {sample }}\right)=\frac{\mathrm{P}_{\mathrm{e}}}{\mathrm{V}_{\text {sample }}}\left(\frac{\mathrm{P}_{\text {back }}}{\mathrm{V}_{\text {back }}} *\left[1-\frac{1}{\mathrm{DF}}\right]\right)\right]
$$

Equation 8

where

$\mathrm{P}_{\text {mass }}=\quad$ volume corrected particulate mass.

$\mathrm{V}_{\text {mix }}=$ total dilution exhaust volume.

$\mathrm{V}_{\text {sample }}=\quad$ volume of dilute exhaust flow across the primary/secondary filters.

$\mathrm{P}_{\mathrm{e}} \quad=\quad$ particulate mass from the gravimetric analysis.

$\mathrm{P}_{\text {back }}=$ particulate mass from the background filter.

$\mathrm{V}_{\text {back }}=$ volume of background flow across the background filter.

$\mathrm{DF}=$ dilution factor.

and the uncertainty, $\mathrm{DP}_{\text {mass }}$ is

$$
\Delta \mathrm{P}_{\text {mass }}=\left[\begin{array}{l}
\left.\left(\frac{\partial \mathrm{P}_{\text {mass }}}{\partial \mathrm{V}_{\text {mix }}} \Delta \mathrm{V}_{\text {mix }}\right)^{2}+\left(\frac{\partial \mathrm{P}_{\text {mass }}}{\partial \mathrm{V}_{\text {sample }}} \Delta \mathrm{V}_{\text {sample }}\right)^{2}+\left(\frac{\partial \mathrm{P}_{\text {mass }}}{\partial \mathrm{P}_{\mathrm{e}}} \Delta \mathrm{P}_{\mathrm{e}}\right)^{2}+\right]^{1 / 2} \\
\left(\frac{\partial \mathrm{P}_{\text {mass }}}{\partial \mathrm{P}_{\text {back }}} \Delta \mathrm{P}_{\text {back }}\right)^{2}+\left(\frac{\partial \mathrm{P}_{\text {mass }}}{\partial \mathrm{V}_{\text {back }}} \Delta \mathrm{V}_{\text {back }}\right)^{2}+\left(\frac{\partial \mathrm{P}_{\text {mass }}}{\partial \mathrm{DF}} \Delta \Delta \mathrm{F}\right)^{2}
\end{array}\right]^{2}
$$

Equation 9

The errors for $\mathrm{NO}_{\mathrm{x}}, \mathrm{CO}, \mathrm{CO}_{2}$, and THC are tabulated in Table 6 . 
Table 6 Errors Involved in Reporting of $\mathrm{NO}_{x}, \mathrm{CO}, \mathrm{CO}_{2}$, and $\mathrm{THC}$.

\begin{tabular}{|c||c|c||c||c||c||c|}
\hline Analyzer & $\%$ FS & Type & NOx & CO & CO2 & HC \\
\hline \hline Sample ppm & & & 547.415 & 250.68 & 11071 & 376.552 \\
Background ppm & & & 0.725 & 67.928 & 36.597 & 280.406 \\
Range ppm & & & 251 & 250 & 50400 & 10.2 \\
Calibration Gas & $\pm 1 \%$ & Bias & 10 & 10 & 591 & 3 \\
Gas Divider Accuracy & $\pm 0.5 \%$ & Bias & 5 & 5 & 295.5 & 1.5 \\
Gas Divider Reproducibility & $\pm 0.2 \%$ & Random & 2 & 2 & 118.2 & 0.6 \\
Analyzer Repeatability & $\pm 1 \%$ & Random & 5 & 10 & 591 & 3 \\
DAS 16 bit & $\pm 0.02 \%$ & Random & 0.2 & 0.2 & 11.82 & 0.06 \\
Total error ppm & & & 7.82 & 7.79 & 1571.08 & 0.31 \\
\hline
\end{tabular}

Once the uncertainty analysis was completed, the error for particulate matter was found to be $\pm 1.95 \%$.

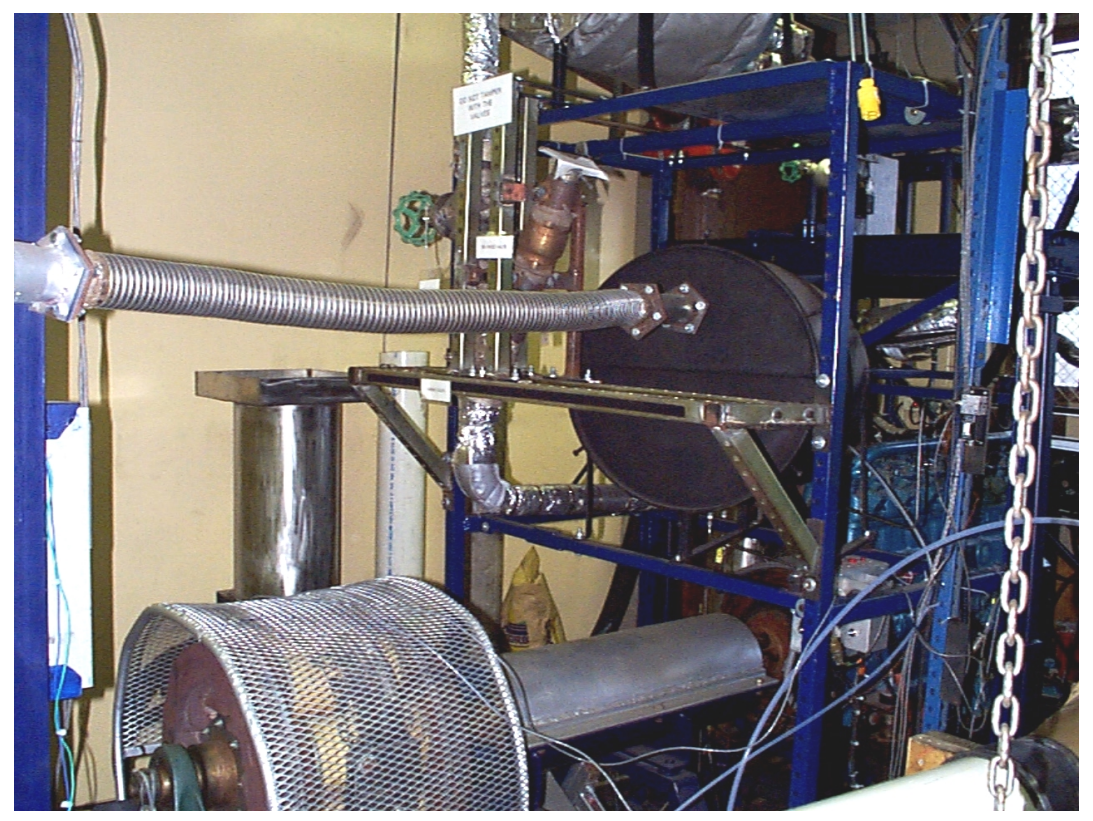

Figure 2 MWM D916-6 Installed on an Eddy Current Dynamometer Test Bed. 


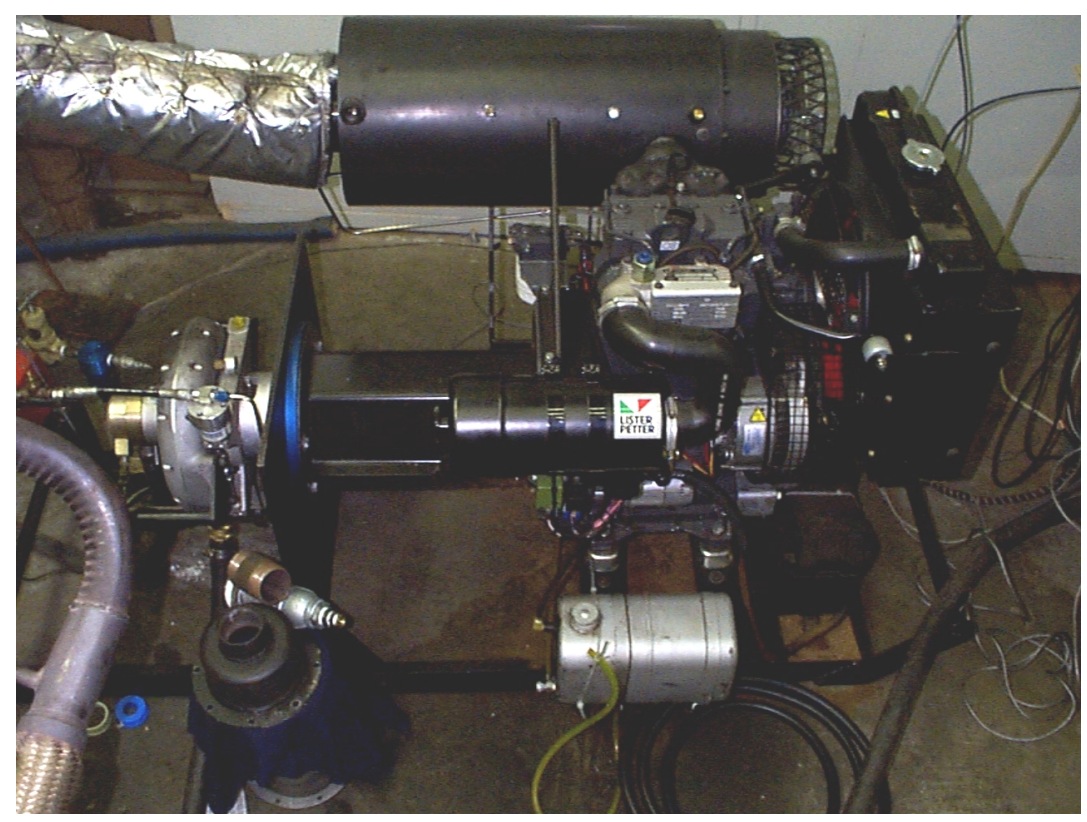

Figure 3 Lister Petter LPU-2 with Rohmac/DCL DPM Control System mounted on a Water-Brake Dynamometer Test Bed.

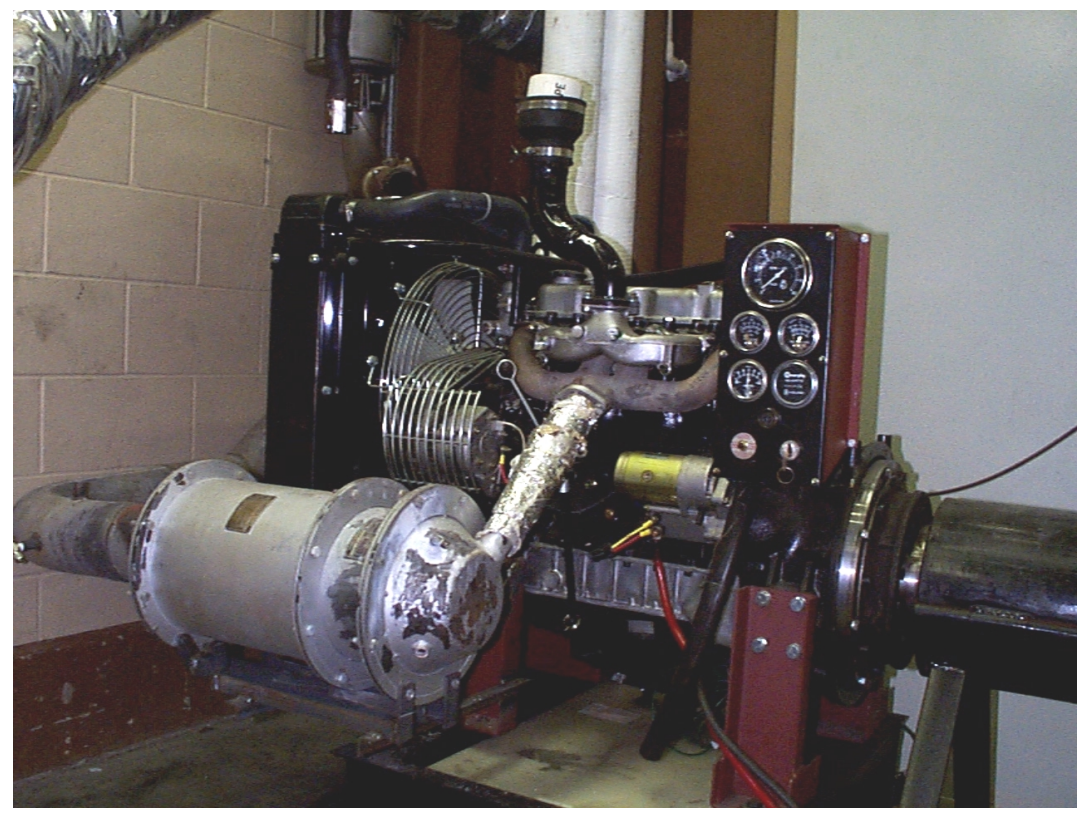

Figure 4 Isuzu C240 Rohmac/DCL DPM Control System Installed on an Eddy-Current Dynamometer Test Bed. 


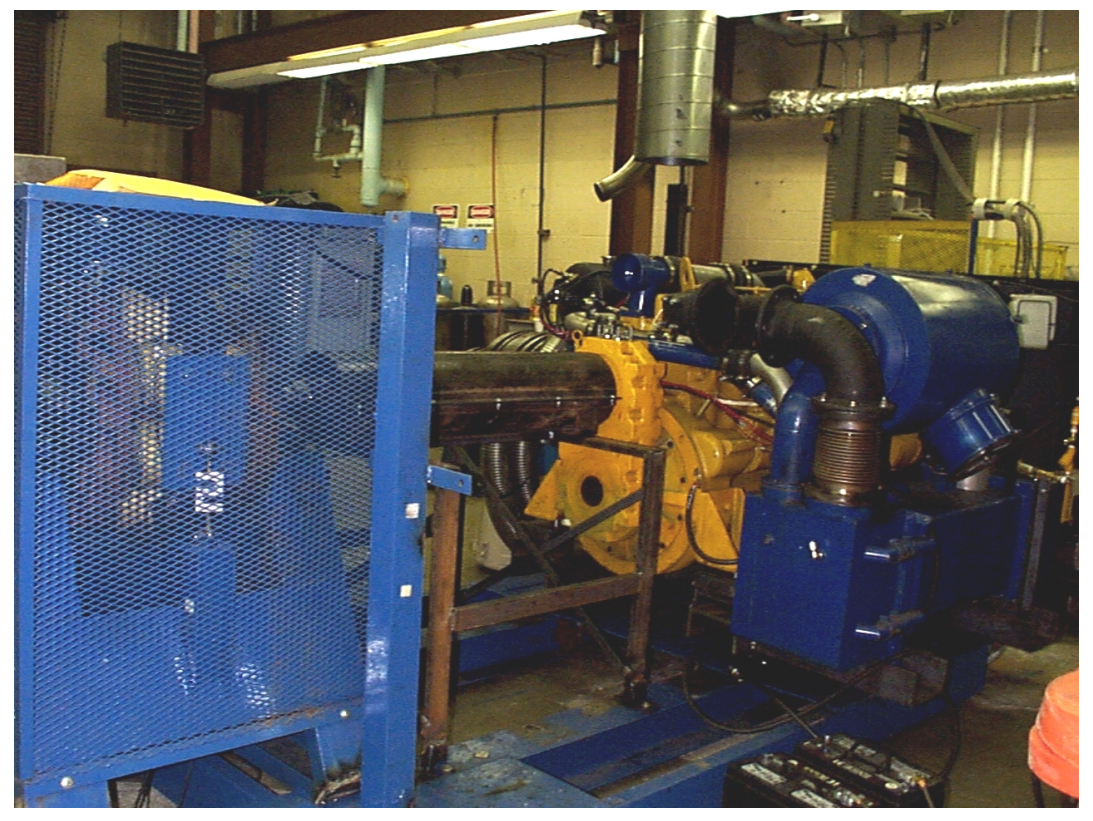

Figure 5 Caterpillar 3306 with DST Dry Scrubber System Installed on an Eddy-Current Dynamometer Test Bed.

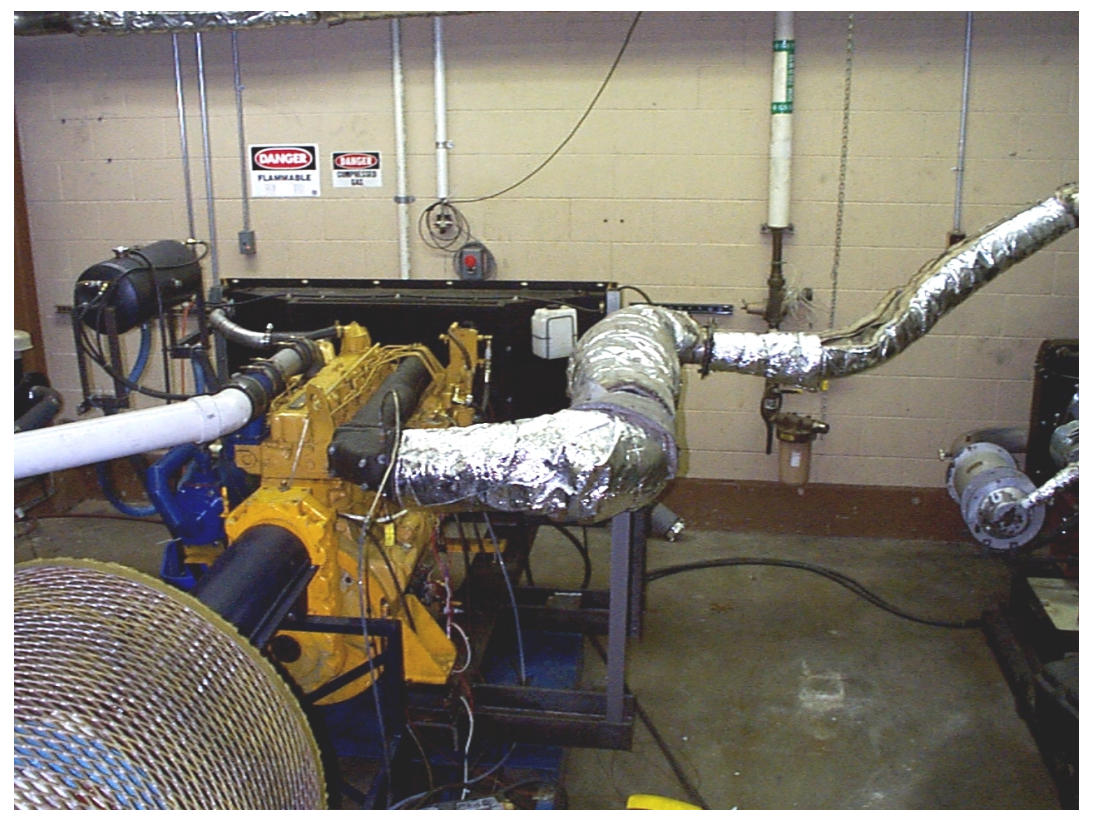

Figure 6 Caterpillar 3306 with Clean Air Systems Catalyzed DPM Trap Installed on an EddyCurrent Dynamometer Test Bed. 


\section{CHAPTER 4 - RESULTS AND DISCUSSION}

\subsection{Introduction}

The objectives of this study were two-fold: first, to evaluate the mass emissions rates of the exhaust from diesel powered equipment, and second, to collect pertinent performance data from current technology that is directed toward curtailing exhaust emissions from diesel engines earmarked for underground coal mine operations. The engines and the aftertreatment devices were tested in their as-received condition. Modification of engines or exhaust aftertreatment devices were performed by the manufacturers or with their expressed consent. The experimental data generated by this study will be utilized to assist the WV Diesel Equipment Commission in its promulgation of initial rules, requirements and standards governing the operation of diesel equipment in underground coal mines.

At the onset of the investigation it became clear that diesel particulate matter was of primary concern, and for that reason particulate matter reductions will be used to form any conclusions concerning the performance of the various devices. In order to present the results in an orderly fashion, this chapter has been subdivided according to test engines. All DPM mass emissions test results may be found in tabular form at the conclusion of each engine section. In addition, the recorded mass emission data for the entire study, gaseous and DPM, is presented in a tabular fashion in Appendix A (g/bhphr) and Appendix B (g/hr). For the remainder of this chapter, all discussion will focus the results presented on a $\mathrm{g} / \mathrm{hr}$ basis. Although brake-specific units are included in the appendix, DPM reduction efficiencies will be calculated from a $\mathrm{g} / \mathrm{hr}$ standpoint. The brake-specific units that typically accompany on-highway test results are not as pertinent to applications involving diesels in underground mines. The inevitable determining factor of system performance is the associated contribution to overall PM in the mining environment. The addition of aftertreatment devices alters an engines performance figures (generally a decrease in power, due to associated backpressures). However, since

most equipment manufacturers oversize their power source, this performance penalty is 
inherently compensated. Thus a brake-specific reporting method is not as meaningful as in other areas of diesel engine implementation.

\subsection{Considerations Involving the Measurement of Diesel Particulate Matter}

According to CFR 30, Part 7, Subpart E, diesel particulate matter is considered to be any of the following constituents found in a diesel exhaust stream: elemental carbon, soluble organic fractions, engine wear metals, sulfates, and bound water. Therefore, the mass measurements of collected DPM could consist of all of these contributors. Of particular interest is the contribution of sulfates and bound water. Wall and Hoekman suggested that, at $50 \% \mathrm{RH}, 1.3$ grams of water is present for every gram of sulfuric acid [39]. In addition, a linear relationship between bound water and sulfuric acid was reported to exist up to $60 \% \mathrm{RH}$, with a rapid increase at levels above $60 \% \mathrm{RH}$. Such bound water would tend to skew reported conclusions, particularly since water is not the DPM component that is associated with any known health hazards or targeted for reduction. Increased sulfate production, which results in increased amounts of bound water on sample filters, often results from the use of high contents of noble metal catalysts, such as platinum, in aftertreatment devices. Although most manufacturers are reluctant to divulge information on their catalyst coatings, it is believed that the high sulfate production levels encountered during this study were a direct result of such large quantities. Moreover, the sulfuric acid aerosols formed from such reactions may act as a nucleation site for DPM - once again contributing to higher DPM mass emissions figures. Nonetheless, in accordance with the requirements of the CFR 30, Part 7, CFR40, Part 86, Subpart N, and CFR 40, Part 89, WVU equilibrates the particulate matter filters at 50\% $\mathrm{RH}$ and $70^{\circ} \mathrm{F}$ in an environmental chamber. Hindsight, however, might suggest that a lower humidity-conditioning environment be used and mandatory sulfate analysis for collected DPM filters. Such methods could eliminate some of the bound water effects that tend to make data interpretations more difficult and results more misleading. 


\subsection{MWM D916-6 Results}

An MWM D916-6 was used to compare emissions levels produced by an engine operating on diesel fuels of different sulfur content. Specifically, the study measured the combustion products generated during engine operation with high sulfur $(0.37 \%$ by mass) fuel and low sulfur (0.04 \% by mass) fuel. Analysts, Inc. tested samples of both fuels, and the analysis results are included in the Chapter 3 of this thesis. Table 7 and Figure 7 indicate a slight reduction in measured particulate matter, while data included in Appendices $\mathrm{A}$ and $\mathrm{B}$ indicate that gaseous emissions, as expected, were basically unaffected by the fuel sulfur content. The complete test results, averaged over three tests per operating mode, are presented in Appendix A (g/bhp-hr) and Appendix B (g/hr). In conclusion, the lower sulfur content produced a weighted 8-mode DPM reduction of approximately $22 \%$.

Comparison of Particulate Mass Emission Rates from an MWM D916-6

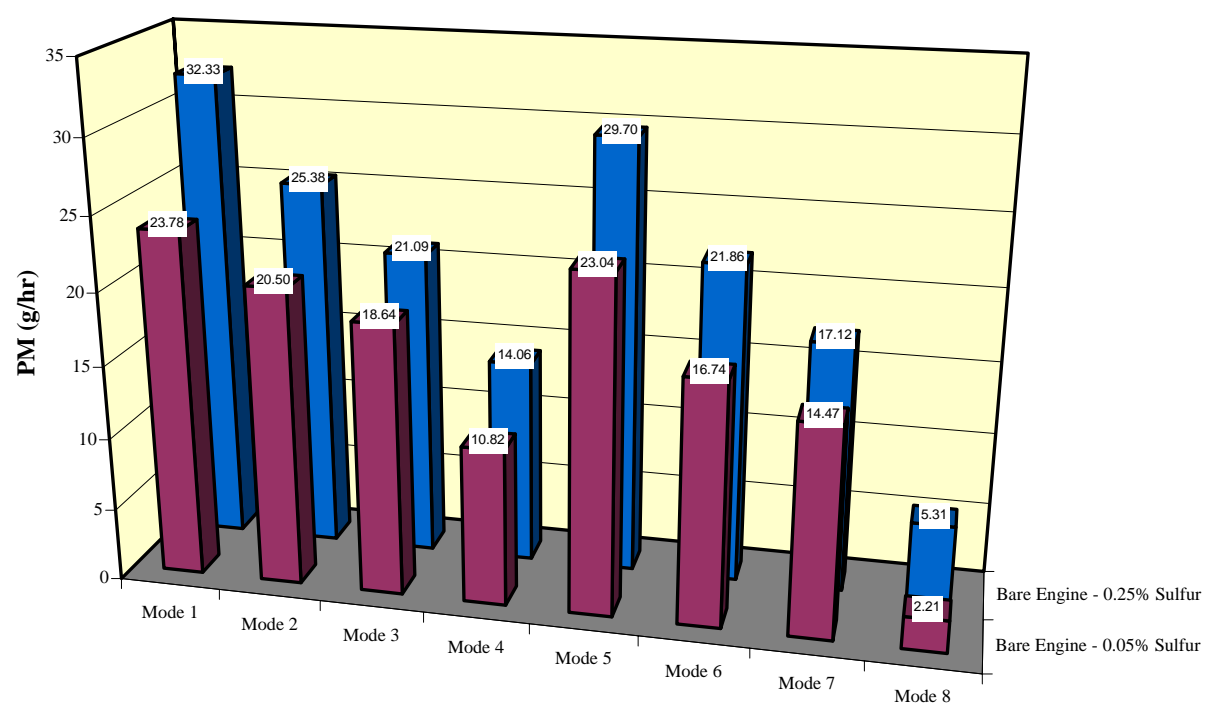

Figure 7 Comparison of Particulate Mass Emissions Rates Associated With the Low- Versus HighSulfur Tests Performed on an MWM D916-6. 
Table 7 Overall DPM Reductions for the MWM D916-6 (g/hr).

\begin{tabular}{|c|c|c|c|}
\hline & High-Sulfur (g/hr) & Low-Sulfur (g/hr) & DPM Reduction (\%) \\
\hline Mode 1 & 32.33 & 23.77 & 26.46 \\
\hline Mode 2 & 25.39 & 20.5 & 19.26 \\
\hline Mode 3 & 21.11 & 18.65 & 11.66 \\
\hline Mode 4 & 14.09 & 10.83 & 23.14 \\
\hline Mode 5 & 29.70 & 23.03 & 22.48 \\
\hline Mode 6 & 21.87 & 16.73 & 23.51 \\
\hline Mode 7 & 17.12 & 14.46 & 15.51 \\
\hline Mode 8 & 5.09 & 2.18 & 57.18 \\
\hline \multicolumn{4}{|c|}{ Weighted-Averages } \\
\hline Eff. Total & 20.87 & 16.27 & 22.02 \\
\hline
\end{tabular}

\subsection{Lister Petter LPU-2 Results}

A Lister Petter LPU-2 was used to test the emissions reduction performance of a Rohmac/DCL exhaust aftertreatment system (see Figure 9) as well as provide preliminary feasibility results for a Pallflex high-temperature glass-fiber paper filter. Emission data is presented in tabular form in Table 8 and graphically in Figure 8, while the reduced data for all tests is compiled in Appendix A (g/bhp-hr) and Appendix B (g/hr).

After results were compiled from the first ISO 8-mode test, it was concluded that a failure had occurred in the catalyzed particulate filter, due to the characteristically low DPM reduction values (see Rohmac/DCL-1 configuration data in Table 8 and Figure 8). This failure could have occurred during the limited amount of operation that had transpired prior to the tests performed for this study or during regeneration processes that were performed prior to the ISO 8-mode test. After recommendations were made, Rohmac returned the PM filter to DCL, where backpressures were compared to other comparable models. DCL concluded that the trap had indeed failed and provided a replacement. Once the new particulate trap was installed, preliminary tests indicated that the trap was not correctly sized for the engine exhaust emissions rates. Unusually high PM loading was encountered, and passive trap regeneration could not be accomplished. While attempting to perform another 8-mode test, engine exhaust backpressures exceeded 
limitations imposed by Lister Petter. After consulting Rohmac and DCL, only a limited amount of testing was performed with the new trap. The results of these tests did not provide significantly higher PM reductions (see Rohmac/DCL-2 configuration data in Table 9 and Figure 8). A limited number of tests (3 modes) were performed using the Rohmac/DCL catalytic converter (oxidation catalyst) as the sole aftertreatment device. These results are presented as DCL Catalyst Only configuration data in Table 8 and Figure 8. Finally, in order to produce preliminary results for the Pallflex high-temperature glass-fiber paper filter, a single Mode 7 test was performed. The results for this test are included as the Rohmac/DCL-2 + Pallflex Paper Filter configuration data in Table 9 and Figure 8.

As the data indicates, the particulate reduction for the initial (failed) trap ranged from $15 \%-87 \%$, with a weighted 8 -mode average of $64.4 \%$. The replacement trapcatalyst system provided an average reduction of $80 \%$ over Modes 6 and 7. The single Mode 7 test performed with the trap-catalyst and paper filter yielded a 95\% reduction, while the catalyst only modes reduced particulate by an average of $43 \%$. Total hydrocarbon reductions are tabulated in Appendices A and B, with a weighted 8-mode average reduction of $97 \%$ for the initial trap-catalyst system (Rohmac/DCL-1). Similar results for $\mathrm{HC}$ were obtained by the other aftertreatment system configurations. The Rohmac/DCL system provided significant reductions of carbon monoxide (CO), with a weighted 8-mode average reduction of $90 \%$. Similar reductions were obtained for the replacement trap tests, as well as the catalyst-only tests. Gaseous data also suggests that, although the system made no provisions for reduction, oxides of nitrogen $\left(\mathrm{NO}_{\mathrm{x}}\right)$ were reduced by $28 \%$ by the original Rohmac/DCL system (Rohmac/DCL-1), with as much as $50 \%$ reductions being produced by the catalyst only tests. Such attenuation is attributed largely to high fueling rates and, in part, to increased exhaust backpressures. High fueling rates can cause a reducing atmosphere in the exhaust, a reaction that is qualitatively given by

$$
(2+\mathrm{n} / 2) \mathrm{NO}\left(\text { or } \mathrm{NO}_{2}\right)+\mathrm{C}_{\mathrm{y}} \mathrm{H}_{\mathrm{n}} \rightarrow(1+1 / 4) \mathrm{N}_{2}+\mathrm{yCO}_{2}+\mathrm{n} / 2 \mathrm{H}_{2} \mathrm{O}
$$


High exhaust backpressures result in internal exhaust gas recirculation, which inhibits the in-cylinder formation of $\mathrm{NO}_{\mathrm{x}}$ by displacing oxygen in the induced intake-air charge.

Regeneration studies were performed on both aftertreatment systems (Rohmac/DCL-1 and Rohmac/DCL-2). The regeneration process consisted of operating the engine at rated power for approximately five minutes, followed by a five minute period of operation at high idle (no load at rated speed). This two-step process first elevated the exhaust temperature, in order to achieve trap light-off, and then supplied the system with excess oxygen, in order to assist the regenerative combustion process. Two cycles were performed on the original (failed) trap, while only one test could be run on the replacement trap, due to manufacturer-imposed backpressure limitations. The regeneration tests for the initial trap seemed to exhibit trends that are characteristic of normal trap regeneration. During the first regeneration test on the original trap, hydrocarbon ( $\mathrm{HC})$, carbon monoxide $(\mathrm{CO})$, and carbon monoxide $\left(\mathrm{CO}_{2}\right)$ traces all peaked during particulate combustion and then decreased as the trap regeneration ceased. Similar trends were mimicked by exhaust backpressure measurements. The second regeneration study with the failed trap did not exhibit such characteristic trends. Since the engine did not experience very much operation between the first and second regenerative tests, it was hypothesized that low particulate loading levels were the reason for the differing results. It should be noted that the engine was operated at low load conditions for at least three hours prior to the first regeneration study. The low exhaust temperatures associated with such operation is not at all conducive to trap light-off, so, even in its failed state, the trap would have had a considerable amount of particulate loading. A successful regeneration process could not be accomplished using the secondgeneration aftertreatment system (Rohmac/DCL-2). Unlike the two previous regeneration tests, increased PM loading and associated backpressures could not be reduced via the regeneration procedure outlined above. The Rohmac/DCL-2 system was obviously undersized for the exhaust emissions levels produced by the Lister Petter LPU2. Unlike the regeneration studies performed on the first generation path, a failure path, which served as a pressure relief mechanism, was not present. Therefore the trap had a much higher loading rate - high enough that the particulate reductions afforded by regeneration could not keep up with the rate of particulate deposition associated with 
continuous operation. For this reason only a limited number of modes could be run before exhaust backpressure levels exceeded Lister Petter's imposed limitations. Included in Figure 10 and Figure 11 are photographs illustrating the inlet face (upstream) of the PM trap before and after a regeneration process (Rohmac/DCL-1).

As a direct result of the testing performed during this study, Rohmac and ListerPetter derated the LPU-2 engine within the limits imposed by the MSHA certification requirements. Such a maneuver should decrease baseline engine emissions and provide a better scenario for implementation of future exhaust aftertreatment systems. Further tests with the LPU-2 were not performed under this study, but tests have been scheduled as part of future research activities.

Comparison of Particulate Mass Emission Rates from a Lister Petter LPU-2

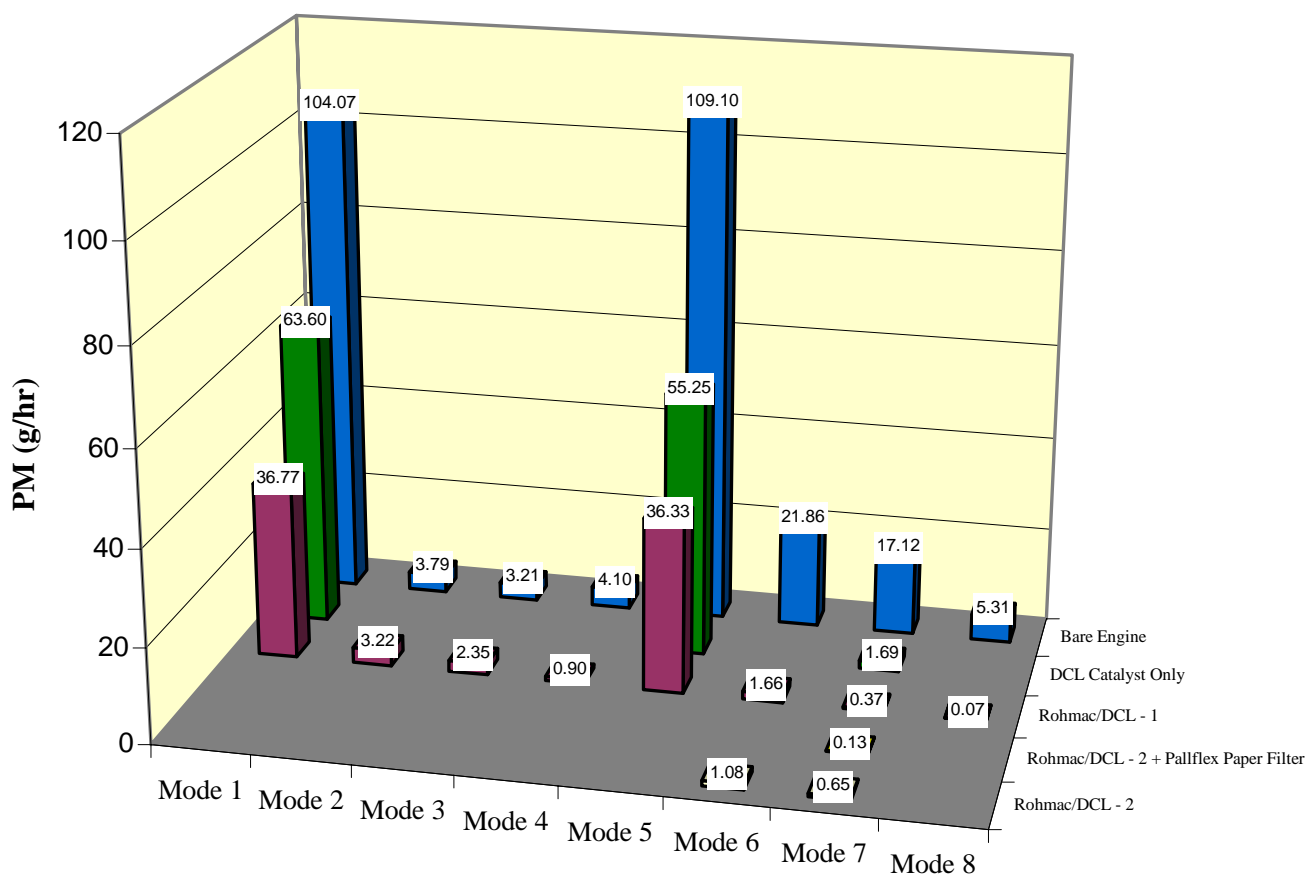

Figure 8 Comparison of Particulate Mass Emissions Rates Associated With the Various Aftertreatment Devices Evaluated on a Lister Petter LPU-2. 
Table 8 Overall DPM Reductions for the Lister Petter LPU-2 (g/hr).

\begin{tabular}{|c|c|c|c|c|c|}
\hline & $\begin{array}{l}\text { Bare } \\
\text { (g/hr) }\end{array}$ & $\begin{array}{c}\text { Rohmac/DCL-1 } \\
\text { (g/hr) }\end{array}$ & $\begin{array}{c}\text { DPM } \\
\text { Reduction } \\
(\%)\end{array}$ & $\begin{array}{c}\text { DCL } \\
\text { Catalyst } \\
\text { Only } \\
\text { (g/hr) }\end{array}$ & $\begin{array}{c}\text { DPM } \\
\text { Reduction } \\
(\%)\end{array}$ \\
\hline Mode 1 & $\begin{array}{l}104.07 \\
\end{array}$ & 36.77 & 64.70 & 63.60 & 38.90 \\
\hline Mode 2 & 3.79 & 3.22 & 15.00 & & \\
\hline Mode 3 & 3.21 & 2.35 & 26.80 & & \\
\hline Mode 4 & 4.10 & 0.90 & 78.00 & & \\
\hline Mode 5 & 109.10 & 36.33 & 66.70 & 55.25 & 49.40 \\
\hline Mode 6 & 5.84 & 1.66 & 71.60 & & \\
\hline Mode 7 & 2.88 & 0.37 & 87.20 & 1.69 & 41.30 \\
\hline Mode 8 & 0.15 & 0.07 & 53.30 & & \\
\hline \multicolumn{6}{|c|}{ Weighted Averages: } \\
\hline Eff. Total & 28.87 & 10.28 & 64.4 & & \\
\hline
\end{tabular}

Table 9 Overall DPM Reductions for the Lister Petter LPU-2 (g/hr).

\begin{tabular}{|c|c|c|c|c|c|}
\hline & $\begin{array}{c}\text { Bare } \\
(\mathrm{g} / \mathrm{hr})\end{array}$ & \begin{tabular}{|c} 
Rohmac/DCL-2 \\
+ Pallflex Paper \\
Filter \\
$(\mathrm{g} / \mathrm{hr})$
\end{tabular} & $\begin{array}{c}\text { DPM } \\
\text { Reduction } \\
(\%)\end{array}$ & $\begin{array}{c}\text { Rohmac/DCL-2 } \\
\text { (g/hr) }\end{array}$ & $\begin{array}{c}\text { DPM } \\
\text { Reduction } \\
(\%)\end{array}$ \\
\hline Mode 1 & 104.07 & & & & \\
\hline Mode 2 & 3.79 & & & & \\
\hline Mode 3 & 3.21 & & & & \\
\hline Mode 4 & 4.10 & & & & \\
\hline Mode 5 & 109.10 & & & & \\
\hline Mode 6 & 5.84 & & & 1.08 & 81.50 \\
\hline Mode 7 & 2.88 & 0.13 & 95.50 & 0.65 & 77.40 \\
\hline Mode 8 & 0.15 & & & & \\
\hline \multicolumn{6}{|c|}{ Weighted Averages: } \\
\hline Eff. Total & & & & & \\
\hline
\end{tabular}




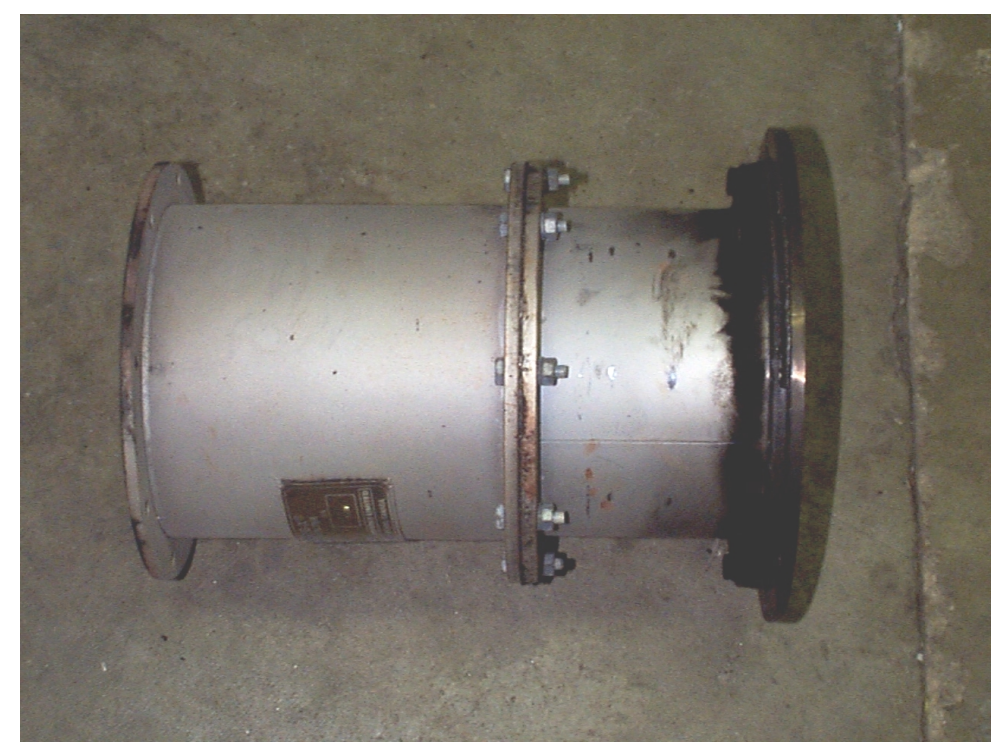

Figure 9 Side View of the Rohmac/DCL DPM Control System.

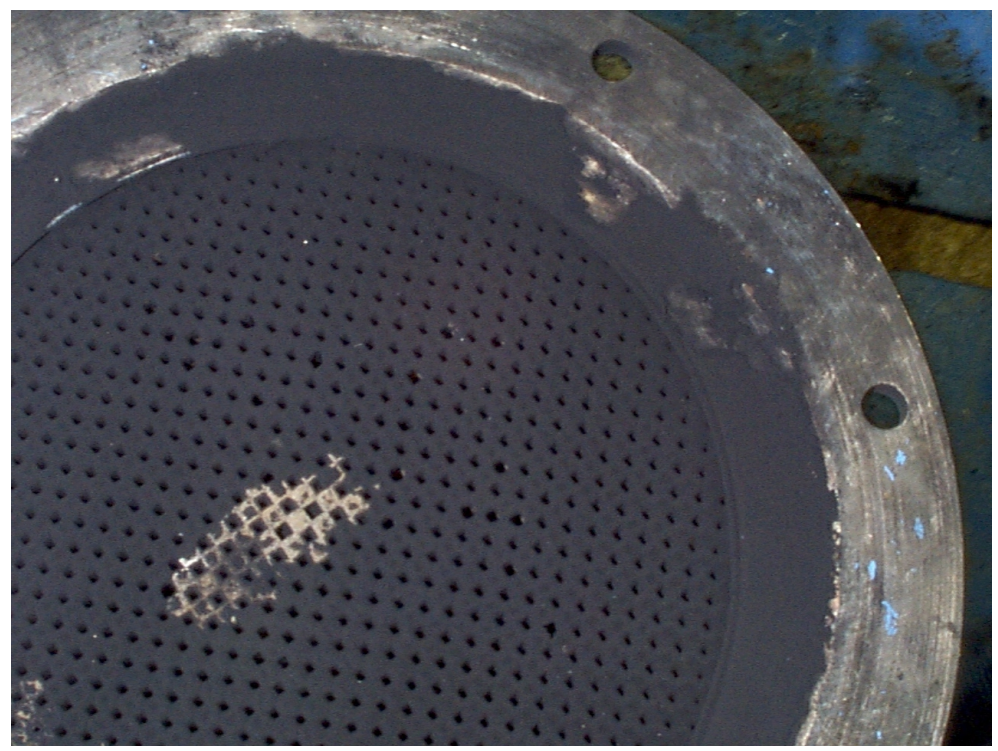

Figure 10 Upstream Face of the Rohmac/DCL DPM Control System DPM Trap Prior to Regeneration. 


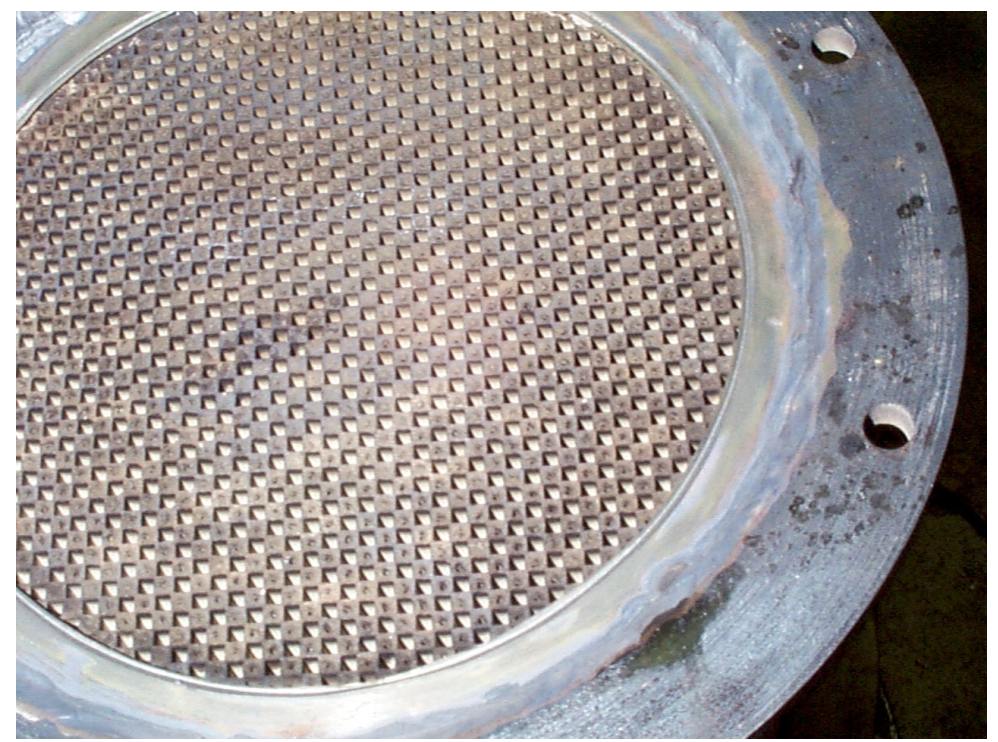

Figure 11 Upstream Face of the Rohmac/DCL DPM Control System DPM Trap Immediately Following Regeneration.

\subsection{Isuzu C240 Results}

An Isuzu C240 was used to evaluate the emission reduction capabilities of a second Rohmac/DCL exhaust aftertreatment system. Similar to the LPU-2 system, the C240 system consisted of a catalyzed particulate filter in series with an oxidation catalyst. With the experience afforded by the Lister Petter tests, Rohmac was advised to size the catalyst and particulate filters for the Isuzu C240 system after baseline emissions values were established. For the C240 tests, system efficiency was optimized by altering the order of the oxidation catalyst and catalyzed particulate filter. A full 8-mode test was performed with the catalyst positioned downstream of the particulate trap, while 4 modes $(1,3,5$, and 7) were tested with the catalyst positioned upstream. In addition, the engine was operated for 4 modes $(1,3,5$, and 7$)$ with only an oxidation catalyst. While performing the 8-mode test, the trap-catalyst system did not need to be regenerated. The final test performed on the Isuzu C240 involved the downstream placement of a Pallflex paper filter downstream of the Rohmac/DCL-2 system. A full 8-mode test was performed with this configuration. At the conclusion of the reported emissions tests, informal regeneration procedures were performed. Although time constraints did not permit data recording, typical regeneration patterns were observed. Test results for DPM mass 
reductions associated with the Isuzu C240 are presented in Table 10, Table 11, and Figure 12, while tabulated emissions data for DPM and gaseous constituents are included in Appendix A (g/bhp-hr) and Appendix B (g/hr).

The weighted 8-mode average DPM reduction for the system consisting of the particulate trap with a downstream oxidation catalyst was $67.7 \%$ (see Table 10). Considering, however, that the testing performed for this study was the first of its kind for the Rohmac/DCL system, it should be evident that further development work could produce enhanced particulate reduction values. Rohmac independently had the particulate sample filters analyzed for sulfate content and verbally disclosed that sulfates contributed approximately $50 \%$ of the total measured DPM mass. As the data indicates, the DPM reduction for the catalyst-trap (reverse order) tests ranged from 40-99\%, with an average of $78 \%$. This configuration was tested in an attempt to gain some insight concerning the effects of downstream PM trap placement on the problem of sulfate formation associated with oxidation catalysts (catalytic converters). As hypothesized, the contribution to measured PM quantities produced by the formation of sulfates tends to exhibit itself at lower temperatures, after condensation of the vapor-phase species. Trap placement has little affect on this contribution, since PM traps are unable to filter vapor phase sulfate contributors. Similar results were obtained for the tests involving downstream placement of the Pallflex paper filter (see the Rohmac/DCL + Pallflex paper filter configuration data in Table 11 and Figure 12). The overall weighted 8-mode average DPM reduction for this test was $43.4 \%$. Once again, it is suspected the hightemperature glass-fiber filter was ineffective at containing vapor phase constituents. Moreover, in the instances where a DPM increase was measured, it is hypothesized that filter fragments were collected on the sampling media as a result of damage that was sustained during fabrication. No PM filter analysis was performed to confirm this suspicion. It is assumed that the Pallflex design was incapable of trapping substantial amounts of DPM that was able to pass through the catalyzed trap of the Rohmac/DCL system. However, the attributes of this prototype may be best realized from stand-alone operation. Regeneration of the prototype was not attempted. The final test result that needs to be highlighted involves the catalyst only test configuration that yielded an average 66\% higher DPM measurement. This data is in accordance with findings from 
other researchers, such as Mayer [21]. Obviously such an increase in DPM production indicates a substantial amount of collected sulfates.

The trap-catalyst system reduced $\mathrm{HC}$ by $79 \%$ (weighted 8 -mode average), but Mode 5 produced minimal $(27 \%)$ reductions. Increased regeneration activity during Mode 5 is likely responsible for such sub-par reductions. The system produced a weighted 8-mode reduction of $\mathrm{CO}$ of $95 \%$. As expected, $\mathrm{NO}_{\mathrm{x}}$ emissions were relatively unaffected by the addition of the system (weighted 8-mode average increase of $6 \%$ over baseline). HC reductions for the Rohmac/DCL catalyst-trap (reverse-order) system averaged $87 \%$, while $\mathrm{CO}$ was reduced by $94 \%$. $\mathrm{NO}_{\mathrm{x}}$ emissions were basically unaffected by the addition of the reverse-configuration system $(6 \%)$ reduction. The catalyst-only tests reduced $\mathrm{HC}$ by an average of $72 \%$ and $\mathrm{CO}$ by $93 \%$, while $\mathrm{CO}_{2}$ and $\mathrm{NO}_{\mathrm{x}}$ emissions were relatively unaffected.

Comparison of Particulate Mass Emission Rates from Isuzu C240

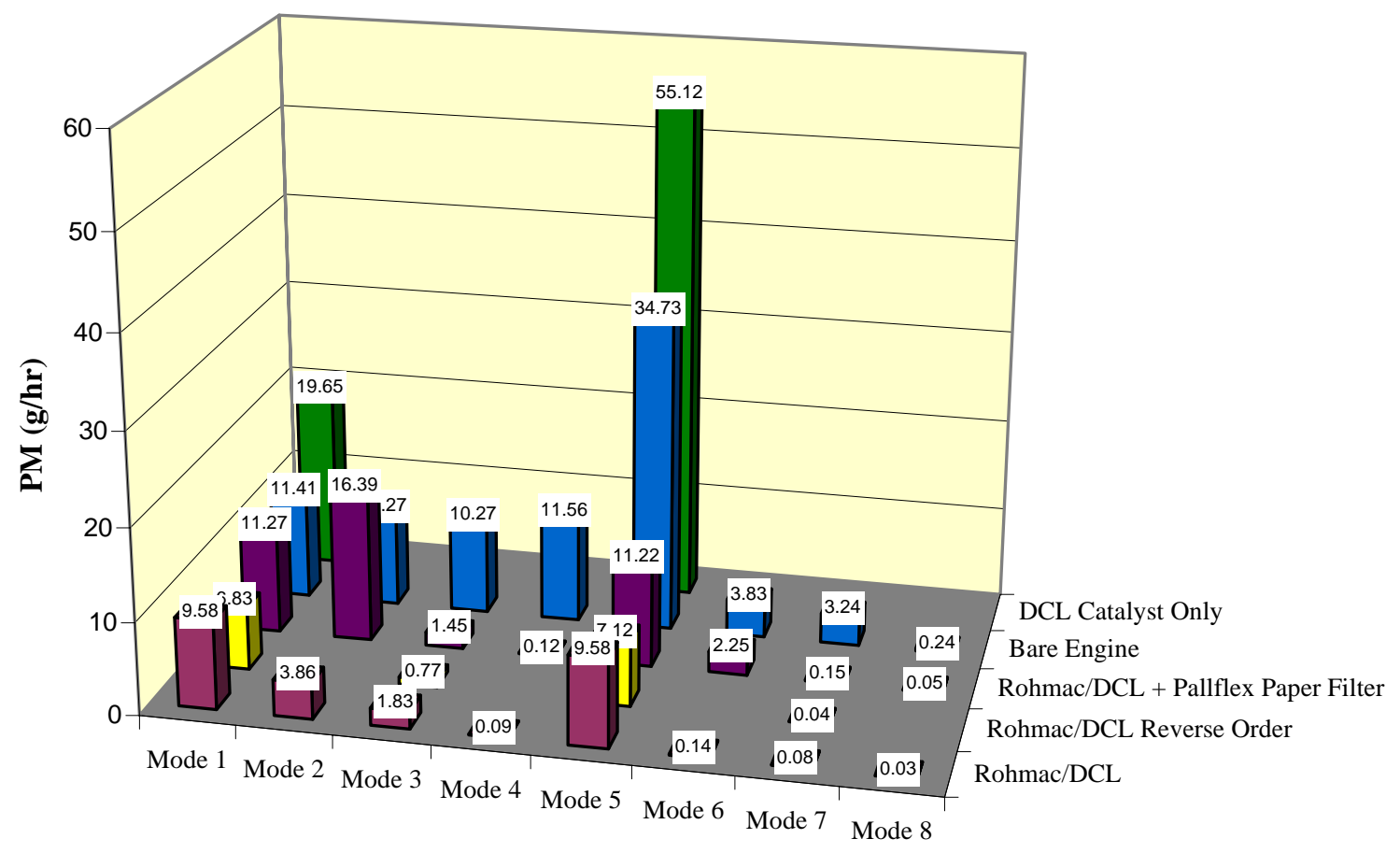

Figure 12 Comparison of Particulate Mass Emissions Rates Associated With the Various Aftertreatment Devices Evaluated on an Isuzu C240. 
Table 10 Overall DPM Reductions for the Isuzu C240 (g/hr).

\begin{tabular}{|c|c|c|c|c|c|c|c|}
\hline & $\begin{array}{l}\text { Bare } \\
\text { (g/hr) }\end{array}$ & $\begin{array}{c}\text { Rohmac/ } \\
\text { DCL } \\
\text { (g/hr) }\end{array}$ & $\begin{array}{c}\text { DPM } \\
\text { Reduction } \\
(\%)\end{array}$ & $\begin{array}{c}\text { Rohmac/ } \\
\text { DCL } \\
\text { (Reverse } \\
\text { Order) } \\
\text { (g/hr) }\end{array}$ & $\begin{array}{c}\text { DPM } \\
\text { Reduction } \\
(\%)\end{array}$ & $\begin{array}{c}\text { Catalyst } \\
\text { Only } \\
(\mathrm{g} / \mathrm{hr})\end{array}$ & $\begin{array}{c}\text { DPM } \\
\text { Reduction } \\
(\%)\end{array}$ \\
\hline Mode 1 & 11.41 & 9.58 & 16.0 & 6.83 & 40.1 & 19.65 & -72.2 \\
\hline Mode 2 & 10.27 & 3.86 & 62.4 & & & & \\
\hline Mode 3 & 10.27 & 1.83 & 82.2 & 0.77 & 92.5 & 5.92 & 42.3 \\
\hline Mode 4 & 11.56 & 0.09 & 99.2 & & & & \\
\hline Mode 5 & 34.73 & 9.58 & 72.4 & 7.12 & 79.4 & 55.12 & -58.7 \\
\hline Mode 6 & 3.83 & 0.14 & 96.3 & & & & \\
\hline Mode 7 & 3.24 & 0.08 & 97.5 & 0.04 & 98.7 & 1.78 & 45.0 \\
\hline Mode 8 & 0.24 & 0.03 & 87.5 & & & & \\
\hline \multicolumn{8}{|c|}{ Weighted Average } \\
\hline Eff. Total & 10.16 & 3.28 & 67.7 & & & & \\
\hline
\end{tabular}

Table 11 Overall DPM Reductions for the Isuzu C240 (g/hr).

\begin{tabular}{|c|c|c|c|}
\hline & $\begin{array}{l}\text { Bare } \\
(\mathrm{g} / \mathrm{hr})\end{array}$ & $\begin{array}{l}\text { Rohmac/DCL+Pallflex Paper Filter } \\
\text { (g/hr) }\end{array}$ & $\begin{array}{l}\text { DPM Reduction } \\
(\%)\end{array}$ \\
\hline Mode 1 & 11.41 & 11.27 & 1.2 \\
\hline Mode 2 & 10.27 & 16.39 & -59.6 \\
\hline Mode 3 & 10.27 & 1.45 & 85.9 \\
\hline Mode 4 & 11.56 & 0.12 & 99.0 \\
\hline Mode 5 & 34.73 & 11.22 & 67.7 \\
\hline Mode 6 & 3.83 & 2.25 & 41.3 \\
\hline Mode 7 & 3.24 & 0.15 & 95.4 \\
\hline Mode 8 & 0.24 & 0.05 & 79.2 \\
\hline \multicolumn{4}{|c|}{ Weighted Average } \\
\hline Eff. Total & 10.16 & 5.75 & $\overline{43.4}$ \\
\hline
\end{tabular}




\subsection{Caterpillar 3306 Results}

Two aftertreatment devices were tested on a Caterpillar 3306. A Dry Systems Technology (DST) dry scrubber system and a Clean Air Systems catalyzed particulate trap were evaluated for their exhaust emissions reduction capabilities. Test results for DPM mass reductions associated with the Caterpillar 3306 are presented in Table 12, Table 13, and Table 14, while tabulated emissions data for DPM and gaseous constituents is included in Appendix A (g/bhp-hr) and Appendix B (g/hr). Graphical representation of DPM reductions are included in Figure 13 and Figure 14.

Goodman Equipment Corporation supplied for evaluation, a Caterpillar 3306 that had been retrofitted with a DST dry scrubber system. Based upon previous experience afforded by an MWM D916-6-DST system and DPM sample filters that were collected during the first 8-mode test (DST I), it was hypothesized that a problem existed with the system. Since the aforementioned MWMD916-6 DST system did not contain the same oxidation catalyst as this CAT 3306 system, the catalyst was omitted in an attempt to isolate the source of the problem. Results from a 2-Mode test indicated that the catalyst was not the cause of high particulate emissions. Consequently, the system was disassembled and inspected for coolant leaks inside of the heat exchanger. A coolant leak, caused by manufacturing flaws, was indeed detected in the heat exchanger of the DST system (see Figure 16 , Figure 17, and Figure 18). In addition, exhaust passage leaks were also found in the manifold end of the heat exchanger and the filter canister (see Figure 19). Goodman representatives and Mr. Norbert Paas (inventor of the DST system) performed subsequent repairs and inspections. At the onset of the second test, visual inspection of the sample filters for Mode 1 and Mode 2 resulted in the elimination of four modes for the remainder of the test (only Modes 1, 2,5, and 7 were tested). The results of this 4-mode test are presented in Table 12 and Figure 13 as DST II. Immediately following this four-mode test, Goodman and Mr. Paas were contacted, resulting in a scheduled engine checkup by a local Caterpillar maintenance technician and various system inspections and clean-up procedures. The Caterpillar 3306-DST combination was tested for a third time, but, once again, the reductions from this system 
were rather low under high speed/high load (Mode 1, in particular) conditions, as presented in Table 13 and Figure 14 (DST III configuration).

The original DST 8-Mode test indicated a weighted 8-mode average DPM reduction of $41.2 \%$. After the leak was repaired, only 4 Modes were tested, with an average DPM reduction of $70 \%$. However, similar to the results found during the first 8-Mode test, Modes 1 and 2 had much lower reductions than Modes 5 and 7. During the second full 8Mode test (DST III) the weighted 8-mode average DPM reduction was 82\%, but Mode 1 only posted an $8 \%$ reduction.

From the DST I results, Mode 8 produced large increases in $\mathrm{HC}$ and $\mathrm{CO}$ over the bare engine values. Omitting this mode resulted in average reductions of $56 \%$ for $\mathrm{HC}$ and $89 \%$ for $\mathrm{CO} . \mathrm{CO}_{2}$ and $\mathrm{NOx}$ emissions were not substantially affected by the addition of the DST system. The gaseous emissions from the limited 4-mode DST II tests indicated reductions of $\mathrm{HC}$ and $\mathrm{CO}$ emissions of $67 \%$ and $92 \%$, respectively. As with the DST I tests, $\mathrm{CO}_{2}$ and NOx emissions were unaffected. The second complete 8-mode test (DST III) produced weighted 8-mode average $\mathrm{HC}$ reductions of $70 \%$ and $\mathrm{CO}$ reductions of $85 \%$. For these tests, $\mathrm{CO}_{2}$ emissions were reduced by $1 \%$ and $\mathrm{NO}_{\mathrm{x}}$ levels were decreased $25 \%$.

As a final note to be appended to the DST testing, Table 15 and Figure 15 provide documentation of the exhaust temperature at the exit of the DST paper filter canister (immediately following the flame arrestor). Data presented in Table 15 was taken from the second 8-Mode test (DST III), since there were coolant leaks associated with the first set of tests. The high heat-exchanger outlet temperatures in Modes 1 and 2 could explain the low DPM reductions. At these elevated temperature, filter binding agents could deteriorate, thus reducing overall filtration efficiency. In addition, vapor-phase exhaust constituents could pass through the filter media at such temperatures. Finally, in comparison to earlier tests performed on an MWM D916-6 with a DST system, this system's performance figures could be limited by the substitution of water-jacketed exhaust manifold with high-performance insulation-wrapped counterparts. Although the similar results were obtained for exhaust manifold surface temperature, the insulated manifold could have provided increased temperatures necessary for oxidation catalyst sulfate production. Tests of filter efficiency, as a function of stream temperature and flow 
rates, were not conducted during this study, and time limitations prevented further investigation of the temperature effects associated with Modes 1 and 2.

Clean Air Systems provided for evaluation, a catalyzed particulate filter that had been designed for the Caterpillar 3306. The overall weighted 8-mode average DPM reduction of the system was $72 \%$. The average reductions in $\mathrm{HC}, \mathrm{CO}$, and $\mathrm{CO}_{2}$ were found to be $88 \%, 83 \%$, and $21 \%$, respectively. Oxides of Nitrogen $\left(\mathrm{NO}_{\mathrm{x}}\right)$ were not substantially reduced by the Clean Air System. It should be noted that Mode 8 presented a significant problem with $\mathrm{HC}$ and $\mathrm{CO}$ emissions. As per regulations, Mode 8 testing followed Mode 7 after a period of stabilization (generally 10 minutes). While following this standard procedure, $\mathrm{HC}$ and $\mathrm{CO}$ emissions would increase until both analyzers were out of range. In order to continue testing, the engine had to be shutdown so that the $\mathrm{HC}$ and $\mathrm{CO}$ analyzers could be purged. After startup, $\mathrm{HC}$ and $\mathrm{CO}$ emissions were still much greater than those obtained from other test modes, but they were measurable. This problem is attributed to a regeneration process that would be quenched during the shutdown period. Considering that this study serves as the first and only set of emissions tests for this particular system model, there is likely room for improvement. In addition, the particulate sample filters were not analyzed, but based on previous experience, it is anticipated that a considerable amount of sulfates were contained on the filters. Thus, further development could minimize sulfate production and, hence, improve overall particulate reduction efficiency. 
Comparison of Particulate Mass Emission Rates from Caterpillar 3306

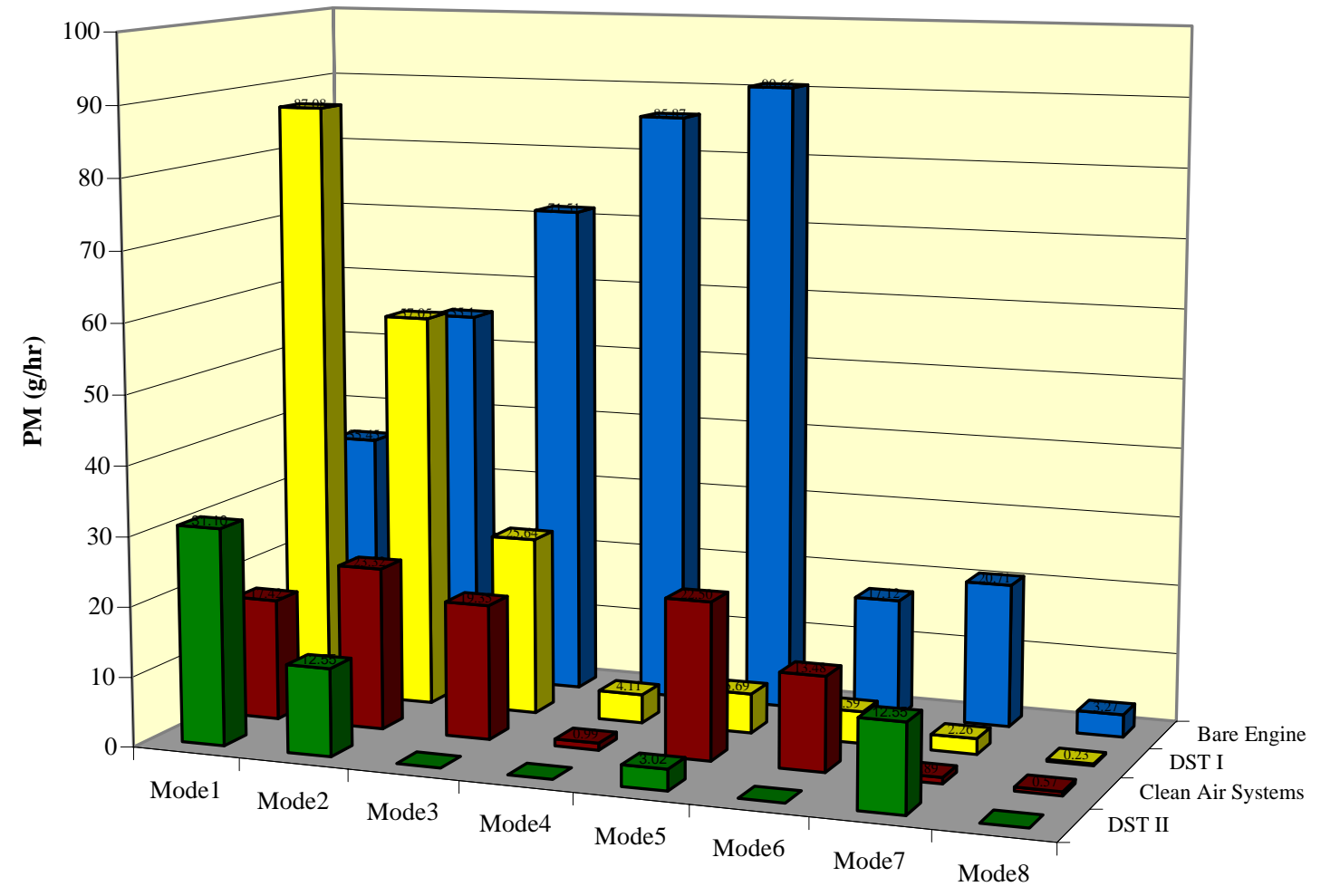

Figure 13 Comparison of Particulate Mass Emissions Rates Associated With the Various Aftertreatment Devices Evaluated on an MWM D916-6. 
Comparison of Particulate Mass Emission Rates from a Caterpillar 3306

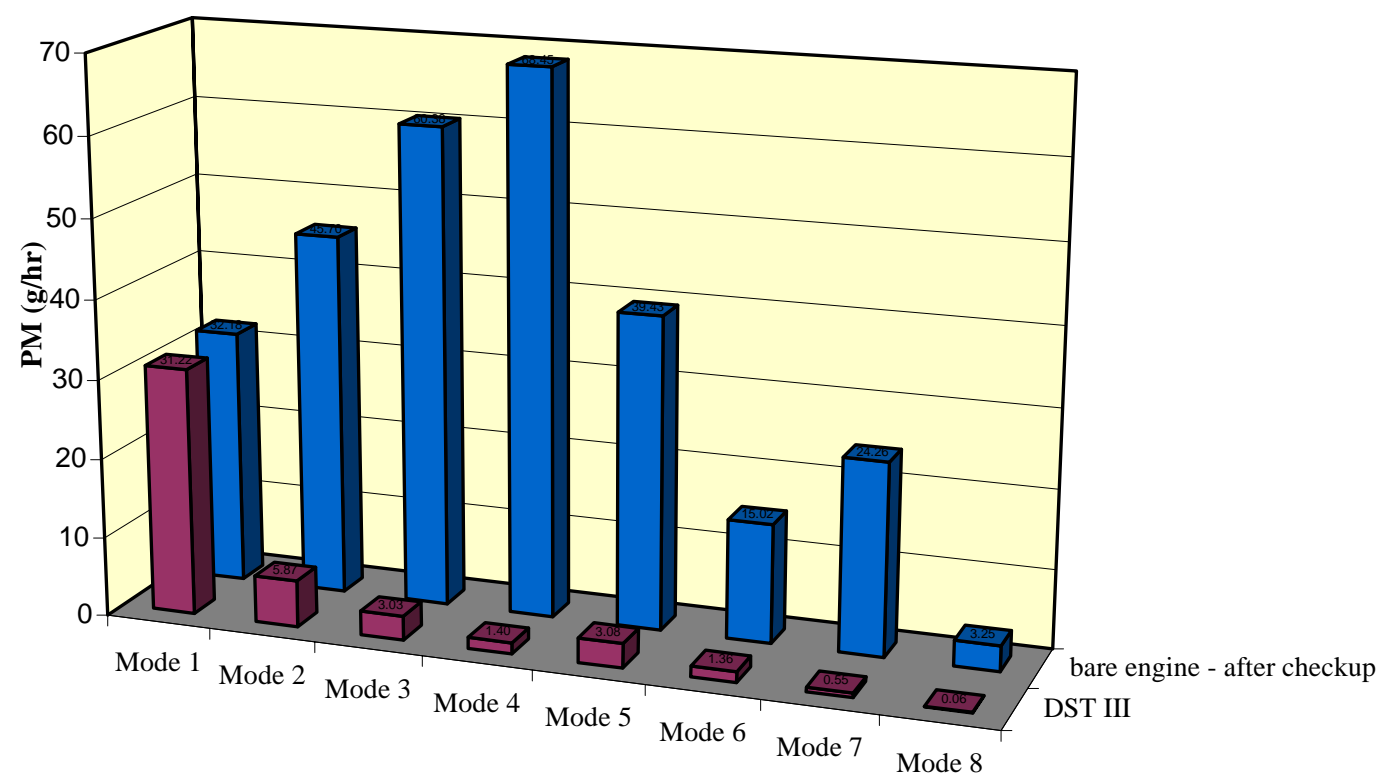

Figure 14 Comparison of Particulate Mass Emissions Rates Associated With the Final DST Configuration Evaluated on a Caterpillar 3306.

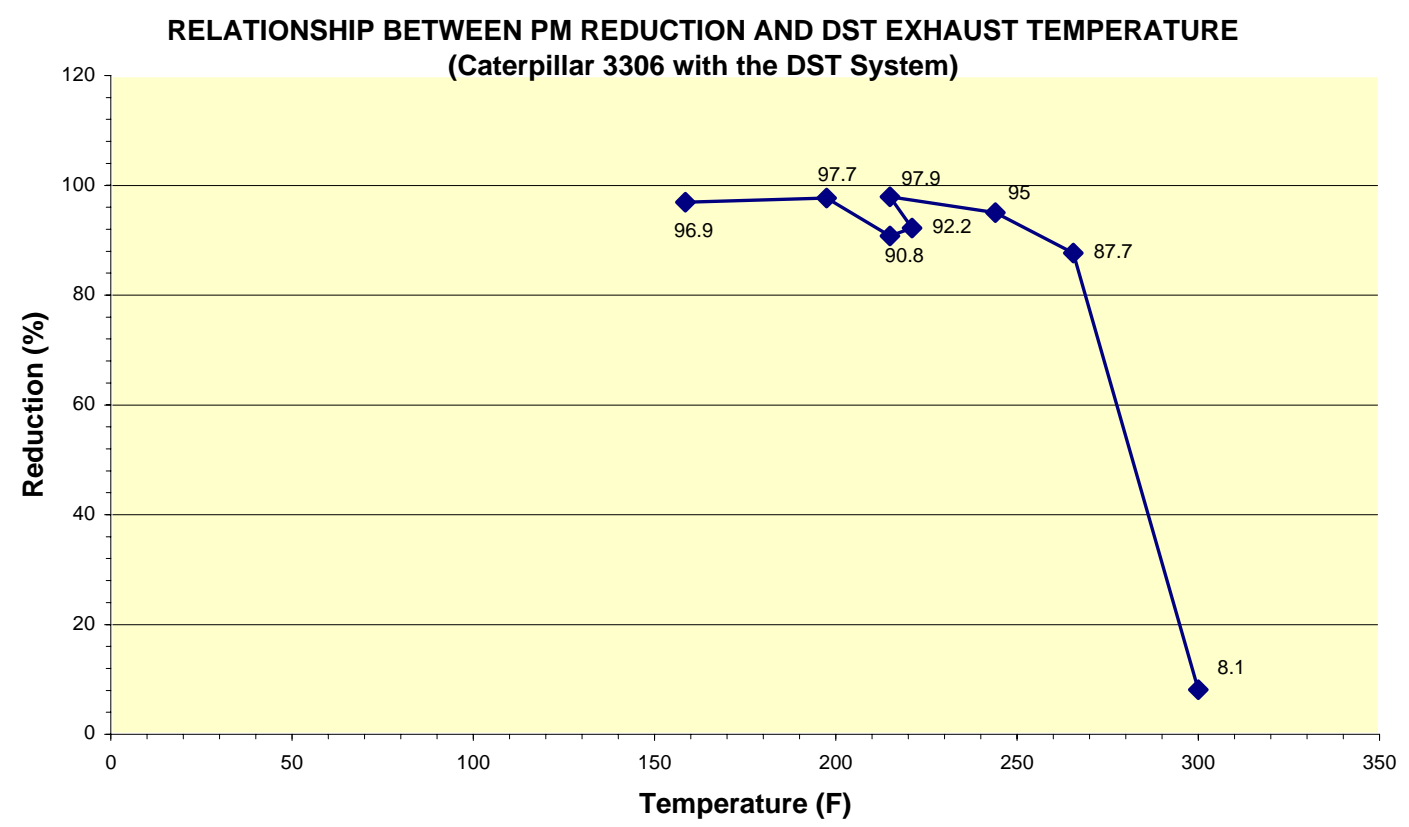

Figure 15 Exhaust Temperatures Measured at the Entrance to the Filter Canister of the DST System During the Final DST Evaluation Test on a Caterpillar 3306. 
Table 12 Overall DPM Reductions for the Caterpillar 3306 - DST I and DST II (g/hr).

\begin{tabular}{|c|c||c|c||c|c|}
\hline & $\begin{array}{c}\text { Bare } \\
(\mathrm{g} / \mathrm{hr})\end{array}$ & $\begin{array}{c}\text { DST I } \\
(\mathrm{g} / \mathrm{hr})\end{array}$ & $\begin{array}{c}\text { DPM } \\
\text { Reduction } \\
(\%)\end{array}$ & DST II (g/hr) & $\begin{array}{c}\text { DPM } \\
\text { Reduction } \\
(\%)\end{array}$ \\
\hline \hline Mode 1 & 35.45 & 87.08 & -145.6 & 31.10 & 12.3 \\
\hline Mode 2 & 55.1 & 57.05 & -3.5 & 12.55 & 77.2 \\
\hline Mode 3 & 71.51 & 25.64 & 64.1 & & \\
\hline Mode 4 & 85.87 & 4.11 & 95.2 & & \\
\hline Mode 5 & 90.66 & 5.69 & 93.7 & 3.02 & 96.7 \\
\hline Mode 6 & 17.12 & 4.59 & 73.2 & & \\
\hline Mode 7 & 20.71 & 2.26 & 89.1 & 0.97 & 95.3 \\
\hline Mode 8 & 3.27 & 0.23 & 93.0 & & \\
\hline \hline \multicolumn{7}{|l|}{} & Weighted-Averages \\
\hline \hline Eff. Total & 46.23 & 27.16 & 41.2 & & \\
\hline
\end{tabular}

Table 13 Overall DPM Reductions for the Caterpillar 3306 - DST III (g/hr).

\begin{tabular}{|c|c|c|c|}
\hline & $\begin{array}{c}\text { Bare } \\
\text { (After } \\
\text { Engine/DST } \\
\text { Inspection \& } \\
\text { Repair } \\
\text { (g/hr) }\end{array}$ & $\begin{array}{c}\text { DST III } \\
\text { (After Inspection } \\
\text { \& Repair) } \\
\text { (g/hr) }\end{array}$ & $\begin{array}{c}\text { DPM } \\
\text { Reduction } \\
(\%)\end{array}$ \\
\hline \hline Mode 1 & 33.38 & 30.68 & 8.1 \\
\hline Mode 2 & 47.64 & 5.88 & 87.7 \\
\hline Mode 3 & 60.29 & 3.03 & 95.0 \\
\hline Mode 4 & 68.22 & 1.41 & 97.9 \\
\hline Mode 5 & 39.38 & 3.06 & 92.2 \\
\hline Mode 6 & 15.05 & 1.38 & 90.8 \\
\hline Mode 7 & 24.26 & 0.56 & 97.7 \\
\hline Mode 8 & 1.93 & 0.06 & 96.9 \\
\hline \hline \multicolumn{4}{|c|}{ Weighted-Averages } \\
\hline \hline Eff. Total & 6.589 & 6.59 & 81.8 \\
\hline
\end{tabular}


Table 14 Overall DPM Reductions for the Caterpillar 3306 - Clean Air System (g/hr).

\begin{tabular}{||c|c||c|c||}
\hline & $\begin{array}{c}\text { Bare } \\
(\mathrm{g} / \mathrm{hr})\end{array}$ & $\begin{array}{c}\text { Clean Air Cat- } \\
\text { Trap } \\
(\mathrm{g} / \mathrm{hr})\end{array}$ & $\begin{array}{c}\text { DPM } \\
\text { Reduction } \\
(\%)\end{array}$ \\
\hline \hline Mode 1 & 35.45 & 17.42 & 50.9 \\
\hline Mode 2 & 55.1 & 23.32 & 57.7 \\
\hline Mode 3 & 71.51 & 19.35 & 72.9 \\
\hline Mode 4 & $\mathbf{8 5 . 8 7}$ & $\mathbf{0 . 9 9}$ & $\mathbf{9 8 . 8}$ \\
\hline Mode 5 & $\mathbf{9 0 . 6 6}$ & 22.5 & 75.2 \\
\hline Mode 6 & $\mathbf{1 7 . 1 2}$ & $\mathbf{1 3 . 4 8}$ & 21.3 \\
\hline Mode 7 & $\mathbf{2 0 . 7 1}$ & $\mathbf{0 . 8 9}$ & $\mathbf{9 5 . 7}$ \\
\hline Mode 8 & 3.27 & $\mathbf{0 . 5 7}$ & $\mathbf{8 2 . 6}$ \\
\hline \hline \multicolumn{5}{|c|}{ Weighted-Averages } \\
\hline \hline Eff. Total & 46.23 & 12.88 & 72.1 \\
\hline
\end{tabular}

Table 15 Observed Exhaust Temperatures $\left({ }^{\circ} \mathrm{F}\right)$ After the DST Flame Arrestor During the Final 8-Mode Test - DST III.

\begin{tabular}{|c|c|c|c|c|c|c|c|c|}
\hline & \multicolumn{8}{|c|}{ Observed Exhaust Temperatures after DST Flame Arrestor $\left({ }^{\circ} \mathrm{F}\right)$} \\
\hline & $\begin{array}{c}\text { Mode } \\
1\end{array}$ & $\begin{array}{c}\text { Mode } \\
2\end{array}$ & $\begin{array}{c}\text { Mode } \\
3\end{array}$ & $\begin{array}{c}\text { Mode } \\
4\end{array}$ & $\begin{array}{c}\text { Mode } \\
5\end{array}$ & $\begin{array}{c}\text { Mode } \\
6\end{array}$ & $\begin{array}{c}\text { Mode } \\
7\end{array}$ & $\begin{array}{c}\text { Mode } \\
8\end{array}$ \\
\hline \begin{tabular}{|l} 
Downstream \\
Temperature
\end{tabular} & 300 & $\overline{265.5}$ & $\overline{244}$ & $\overline{215}$ & 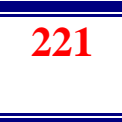 & $\overline{215}$ & 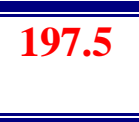 & 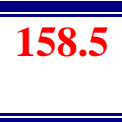 \\
\hline
\end{tabular}




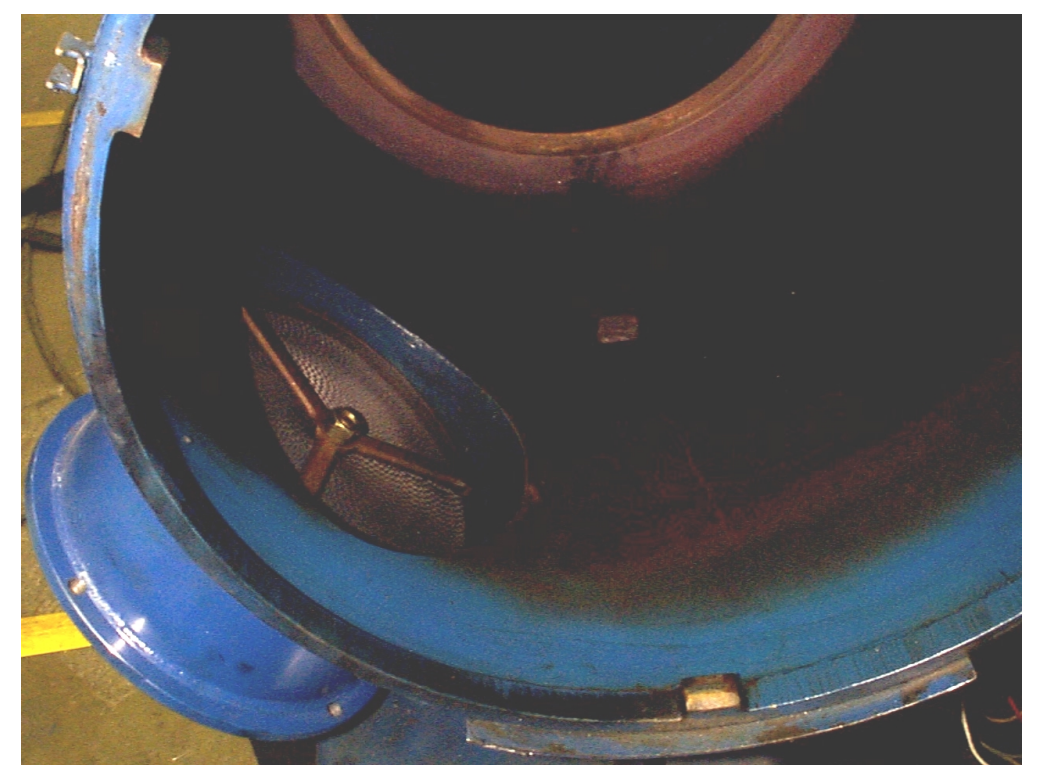

Figure 16 DST Filter Canister with Signs of Coolant Leakage.

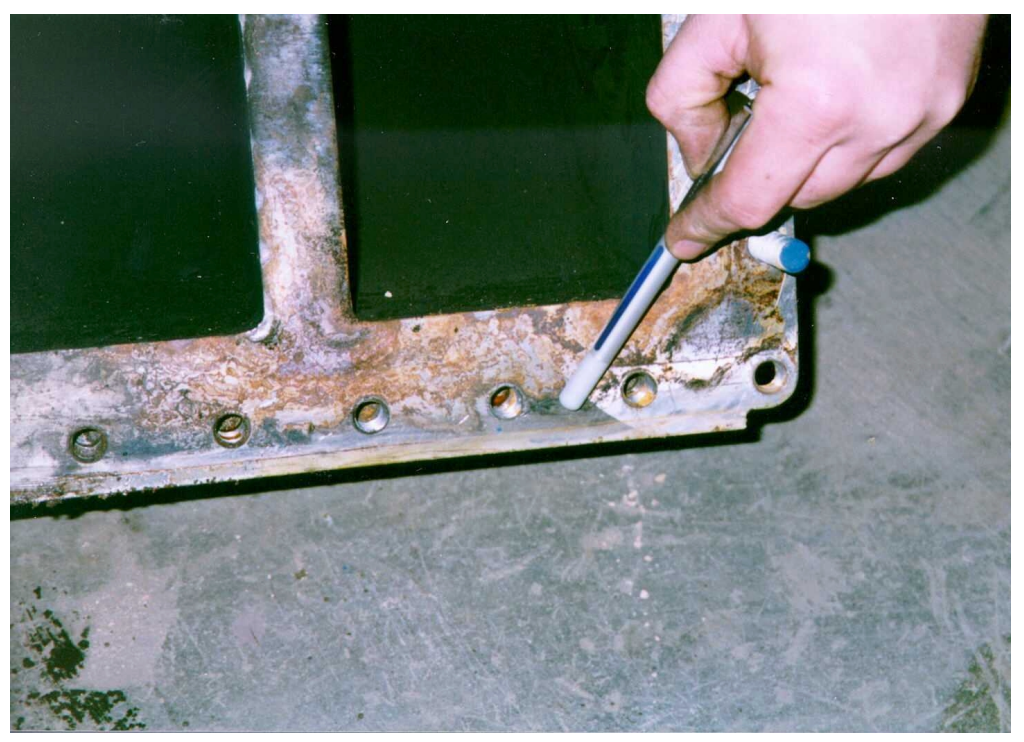

Figure 17 Evidence of Leak at Manifold Section of the DST Heat Exchanger. 


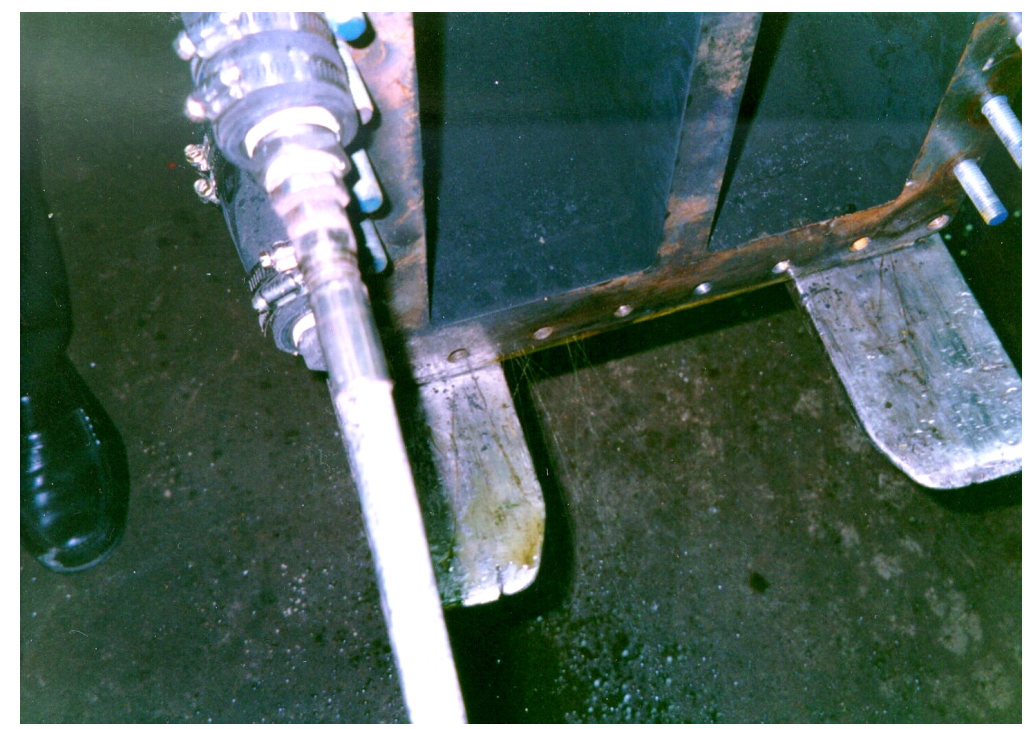

Figure 18 Manifold Section of the DST Heat Exchanger System Prior to Repair.

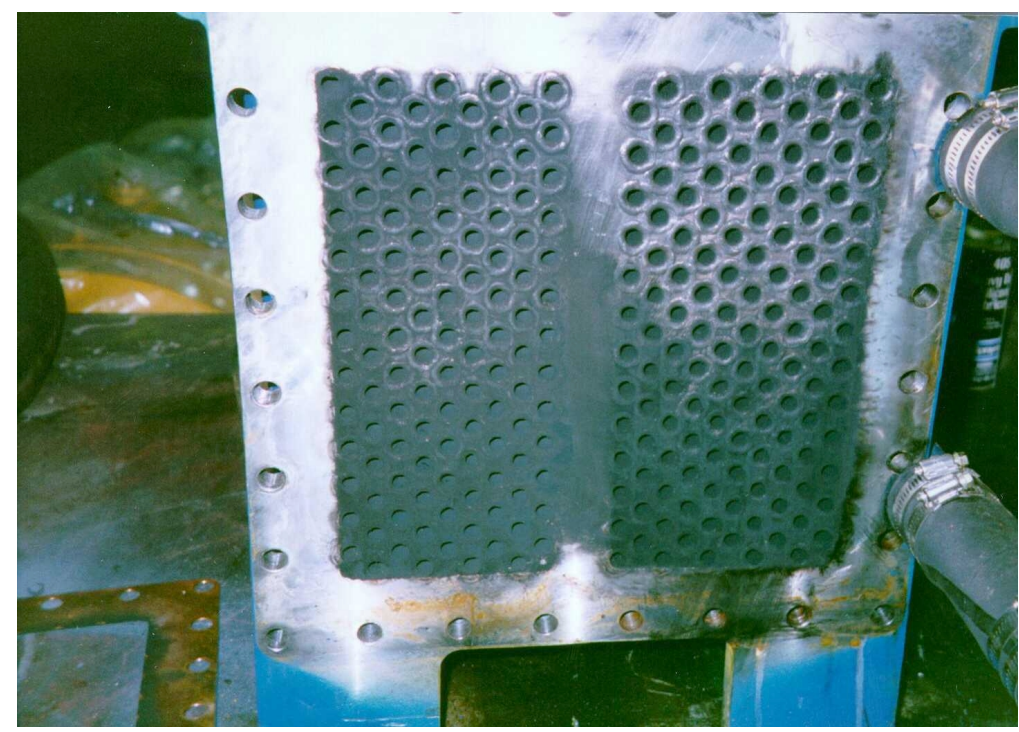

Figure 19 Evidence of DPM Leakage at the Manifold Section of the DST Heat Exchanger System Prior to Repair. 


\section{CHAPTER 5 - CONCLUSIONS AND RECOMMENDATIONS}

\subsection{Overview}

The curtailment of diesel exhaust emissions is a relatively complex procedure. Diesel control technology in underground coal mines is an even more difficult task due to the need for maintaining permissible conditions, which are mandated by safety regulations. Although there are systems currently operating in underground mines, in general, there has been very little activity in this specialized field of engine emissions. Primary on-highway control technologies such as ceramic filters may not be as readily applicable in coal mines. The temperatures necessary for on-line regeneration do not coincide well with the imposed regulations regarding surface temperatures. Off-line regeneration techniques or advanced regeneration concepts (e.g. microwave regeneration) could be employed, but these development issues were not included in the scope of this project. Pleated-media filters are being scrutinized very closely as a possible DPM control technology for coal mine face applications.

The results of this study were intended to be specific evaluations of the engineexhaust aftertreatment sytems that were tested. No generalizations should be made regarding the performance of similar devices or engines. Moreover, it should be noted that all performance figures were derived in a laboratory setting, and that in-field performance may vary substantially. In addition, due to the limited time constraints imposed by this study, no long-term testing was performed in order to provide a basis for establishing performance degradation characteristics for any of the devices. As a final note, this study does not intend to endorse or undermine any of the commercial products that were used throughout the course of the investigation.

\subsection{Conclusions}

The emissions tests performed under this study have provided a solid starting point for the development and evaluation of diesel engine aftertreatment devices used in

mining applications. The data produced by this study will be utilized by the WV Diesel 
Equipment Commission to promulgate initial rules, requirements, and standards governing the operation of diesel equipment in underground coal mines.

With the exception of the DST system, the emissions tests performed on the exhaust aftertreatment devices associated with this study were the first of their kind. It would be very misleading to form lasting conclusions concerning the performance of any aftertreatment device based solely on initial results. The "first-round" performance of systems was very promising, and the participating manufacturers of this study deserve a great deal of commendation. However, further testing and refinement is obviously necessary in order to maximize each system's potential.

The experimental data generated by this study suggests that particulate traps can reduce the mass emission rates of particulate matter by nearly $90 \%$. This data is in agreement with that derived from previous studies, such as those presented by Mayer in the VERT study [21]. These results, however, should be qualified as being trap-coating dependent. If a high content of noble metals are contained in the washcoat, regenerations will be promoted, but likely at the cost of increased sulfate production. Therefore, refinement of washcoat practices, and long-term regeneration studies are definitely warranted if a reliable design is to be achieved.

Results from this study also indicate that fuel sulfur reductions from $0.3 \%$ to $0.04 \%$, result in DPM mass emission reductions of $22 \%$. This is in good agreement with Van Beckhoven's findings of $15-30 \%$ curtailment of DPM emissions resulting from fuel sulfur mass content being reduced from $0.3 \%$ to $0.05 \%$ [36]. In addition, Baranescu reported that for an increase of $0.1 \%$ (by mass) in fuel sulfur, brake specific particulate emissions increased by about $0.025 \mathrm{~g} / \mathrm{bhp}-\mathrm{hr}$ [3]. MWM D916-6 results indicate that for the $0.33 \%$ by mass increase in fuel sulfur resulted in a $0.799 \mathrm{~g} / \mathrm{bhp}-\mathrm{hr}$ increase, or 0.24 $\mathrm{g} / \mathrm{bhp}-\mathrm{hr}$ increase per every $0.1 \%$ increase in fuel sulfur mass levels. The inconsistencies could be attributed to a mechanical problem, although Baranescu reported that combustion system, engine type, and emission levels were not significant factors affecting the emissions of sulfates [3]. However, Baranescu also indicated that load factor increases sulfate contributions to total mass DPM, so higher cycle load factors could be involved. 
This study further concludes that, although oxidation catalysts work well to reduce the production levels of carbon monoxide and hydrocarbons, their singular usage is not recommended in the confined spaces of a mining environment. Whereas for spark ignition engines, there is very little to gain from the use of oxidation catalysts with diesel engines - the levels of $\mathrm{CO}$ and $\mathrm{HC}$ are so small, even from non-aftertreatment fitted engines. There are, however, negative effects encountered from the use of catalytic converters, e.g. the oxidation of $\mathrm{NO}$ and $\mathrm{SO}_{2} . \mathrm{NO}_{2}$ is more toxic than $\mathrm{NO}$, and $\mathrm{SO}_{3}$ contributes to the formation of sulfate particulates and to aerosols of sulfuric acid. The use of washcoat catalysts similar to those found on both the converters and selfregenerating particulate traps that were evaluated during this study tend to enhance particulate matter sulfate production and can, furthermore, increase the toxicity of the diesel exhaust emissions. This problem is only magnified in the confined spaces of a coal mine.

The preliminary investigation of a novel high-temperature filter media that was provided under this study indicates that this technology is worthy of future research and development. A DPM trap, using the high temperature filter, was designed, fabricated, and tested on both the Lister Petter LPU-2 and Isuzu C240. The filter material employed by these devices can withstand temperatures as high as $2400^{\circ} \mathrm{F}$, well beyond the required temperatures that are necessary for passive regeneration of catalyzed PM traps. This prototype-design trap was located downstream of a Rohmac/DCL aftertreatment systems, and resulted in a 96\% reduction in DPM for a single Mode 7 test on a Lister Petter LPU-2 engine. Performance figures associated with the Isuzu C240 test provided similar results, but little or no enhancement over standard Rohmac/DCL system results. It is assumed that the filter media was incapable of trapping substantial amounts of DPM that was able to pass through the catalyzed trap of the Rohmac/DCL system. However, standalone performance may best exhibit the attributes of such a novel design. These tests, unfortunately, were not completed under this investigation. In addition, no regeneration studies were considered involving the prototype Pallflex filter. 


\subsection{Recommendations}

Looking forward, continued testing and development of emission-reduction strategies specifically aimed at mining applications is highly recommended. It is anticipated that an integration of key industry factions (industry, labor, and regulatory agencies) will not only result in improved system designs, but an evolutionary pattern in the development of both state and federal emissions standards. Additional research will generate interest, improve the demand for high-efficiency aftertreatment systems, and provide significant contributions to the existing database for mining-engine emissions. In addition future efforts can provide assistance in the development and improvement of test protocols and procedures. The future efforts suggested by this study have been divided into two categories: the first will be related to the scope of future work and the latter will involve refinement of test procedures.

\subsubsection{Future Research}

Further improvement in emissions reductions can be accomplished through increased research efforts. Advancements in catalyst formulation, improvements in trap selection and sizing, and reduction of base engine emissions should all be explored in order to optimize aftertreatment system performance. To date, the majority of the aftertreatment industry has not responded to the need for systems that accommodate the unique needs of mining-engines. Due to special design constraints and the limited demand in the current market, there are very few commercially available systems. Extensive testing is also required to both perfect current designs and provide additional insight for future systems. Development of oxidation catalysts and PM traps that tailor to the needs of mining-engine applications will obviously improve performance. It was apparent that the manufacturers of the catalyzed trap systems, employed in this study, had not carried out any development work on these systems. Hence, there is room for considerable improvement in catalyst formulation, trap selection and sizing and in the optimization of the complete packages.

In addition to aftertreatment component enhancements, efforts must be made to improve the quality of engines used in underground mines. Until recently, manufacturers 
of in-mine engines did not have to comply with any well-defined emissions standards. This study has highlighted this critical area, and has raised points of interest that need to be addressed. Derating the LPU-2 engine, which was a direct result of this study, is a good example of what manufacturers can do to improve in-mine environments. Combined efforts by MSHA and engine manufacturers to improve current designs, while developing new ones, would provide the mining industry with a larger variety of certified, high-quality, low-emission engines.

In addition to these industry-specific contributions, limited deregulation could also improve the level of system performance. Relaxation of the $300^{\circ} \mathrm{F}$ surface-temperature requirement would increase the available options for trap regeneration. In doing so, the current trends involving use of noble metal-rich catalyst formulations, which lead to high sulfate formation at elevated temperatures, could be avoided. Alternative regeneration techniques could lower system costs, improve reliability, and eliminate sources of additional health concerns.

During this investigation it became painfully evident that there is a dire need for extensive test cycle optimization. The ISO 8-Mode test cycle is not at all representative of current in-use duty cycles. Most engines operating in the off-highway sector, particularly the smaller-displacement units used by the mining community, rarely operate at more than two or three different set points. It is recommended that in-use (in-mine) diesel equipment be instrumented to collect data such as exhaust temperatures, speed (engine and vehicle), load, and the overall duty cycle. These parameters are crucial to the development of duty cycles and test procedures that are used in laboratory testing [2, 4, 5]. Such data is also paramount to the overall system optimization process, that can result in increased levels of emissions reductions.

An investigation focusing on the refinement of lubricating oil and the subsequent control of the lubricant contribution to combustion products should be investigated for off-road engines operating in mining environments. Engine oil contributes from 50 to 280 times as much material to the particulate emissions as does an equal amount of consumed fuel. Obviously fuel consumption quantities far outweigh those of the lubricating oil, nonetheless Mayer, et al. concluded that lubricating oil can still have a significant effect on particulate emissions [23]. 
Increased information regarding the design and washcoat material of aftertreatment components should accompany any future testing. Without such information, conclusions are difficult to establish. Moreover, such information is paramount to the overall system optimization.

\subsubsection{Refinement of Test Procedures}

Mayer reported that when gravimetric analysis indicated that DPM traps exhibited reductions of $80-85 \%$, particulate count methods would yield results in excess of $90 \%$ [21]. These findings should not be considered surprising when one considers that gravimetric methods will be influenced by bound water and subsequent deposition of constituents that passed through the substrate media in gaseous states. More specialized particulate filter conditioning practices need to be developed, particularly when testing involving aftertreatment devices is performed. Perhaps alteration of humidity to lower levels or accurate measurement of conditioning environment (vapor pressures, convective air disturbances, etc.) is in order. It is also suggested that procedures for gravimetric analysis, currently required by the various regulatory bodies, be altered to accommodate exhaust aftertreatment-equipped engines.

Further investigation should be directed toward characterizing the effects of various fuel properties on mass emissions levels. This study has addressed a primary concern of fuel sulfur mass levels, but the effects of other fuel properties were not explored. Van Beckhoven reported that cetane number and volatility can exhibit effects on emissions of the same order as those attributed to fuel sulfur content. For DI engines operating on European 13-mode cycles a 15 to $20 \%$ increase in particulate and hydrocarbon emissions could be caused by a $30^{\circ} \mathrm{C}$ increase in boiling range. For IDI engines, a decrease of cetane number or cetane index of six points exhibited an increase in emissions by $45 \%$ [36].

Increased emphasis should be given to DPM measurement techniques. Tighter controls should be imposed on the particulate collection filter face temperature. Instead of merely complying with the federal regulation of less than $125^{\circ} \mathrm{F}$, maintaining the filter at a predetermined temperature could be a substituted practice. Waldenmaier, et al. 
indicates that maintaining a constant filter face temperature improved the precision of mass collection from a dilution tunnel [38]. Longer sampling times should also be utilized - a practice that would be easily afforded through the reduction of the number of required engine operation test modes. Due to the low particulate emission qualities of the test engines outfitted with aftertreatment devices, higher flow rates were required to increase filter loading to substantially measurable levels. For quite some time, the possibility of stripping volatile organic compounds at high filter face velocities was questioned by some researchers. Guerrieri et al. reported findings from a rather extensive study that such high face velocities do not affect the collection of particulate matter [12]. However, high velocities could result in filter material deterioration. No visible signs of such deterioration were evident during this study, but such issues do tend to warrant the re-evaluation of current particulate measurement standards. In fact, the low level of current engine production, coupled with the use of advanced fuels and aftertreatment devices should promote at least secondary particulate comparison criteria, such as number count or size distribution.

During the investigation, neither the intake charge air nor the dilution air was accurately conditioned. Intake charge air has a substantial effect on $\mathrm{NO}_{\mathrm{x}}$ emissions, but this constituent was assigned a lower priority. Dilution air conditioning could provide more accurate and more repeatable particulate information. Perhaps such conditioning would not exhibit itself in gross measurements of the gravimetric nature, but speciation and size distribution information could benefit from such practices.

Although not requested for this study, hydrocarbon speciation could be implemented in order to help characterize and qualify the effects of exhaust aftertreatment components. This information, in conjunction with improved details regarding washcoat materials, could provide insight and data necessary for overall system refinement.

Although the bag sampling procedures that were practiced for this study are in agreement with the procedures outlined in CFR 40, Part 86, Subpart N, the bag sample results from the test are invariably lower than those of the continuous analyzer integrated results. Cold sampling of the dilute exhaust stream will obviously never produce similar measurements to the hot/wet analysis of the laboratory analyzers. A better practice 
would be to heat the sample streams and collect the contents in a heated stainless cylinder throughout the test. This procedure should provide closer agreement between dilute bag measurements and the integrated analyzer responses. For background bag collection, the heated sample stream would not be as necessary, but since the primary dilution air is not conditioned, a larger sample quantity should be used in order to minimize contaminant plume bias. 


\section{LITERATURE CITED}

1. Abdul-Khalek, I.S., Kittelson, D.B., Graskow, B.R., and Wei, Q. "Diesel Exhaust Particle Size: Measurement Issues and Trends.” SAE 980525, 1998.

2. Bagley, S. T., Baumgard, K. J., Gratz, L. D., Johnson, J. H. and Leddy, D. G. "Characterization of Fuel and Aftertreatment Device Effects on Diesel Emissions." Health Effects Institute Research Report, Number 76, 1996.

3. Baranescu, Rodica A. "Influence of Fuel Sulfur on Diesel Particulate Emissions." SAE 881174, 1988.

4. Braun, CH., Ackermann, U., Schwartz, J., Gnehm, H.P., Rutishauser, M., and Wanner, H.U. "Air Pollution and Respiratory Symptoms in Pre-School Children." Am. Rev., Respir., Vol. 145, 1992, pp. 42-47.

5. California Environmental Protection Agency "Health Risk Assessment for Diesel Exhaust. Public and Scientific Review Panel Review Draft." Office of Environmental Health Hazard Assessment, Sacramento, CA, 1998.

6. Chasey, T.D. "Design and Development of Data Acquisition and Control System Hardware and Software for Transportable Emissions Testing Laboratory." M.S. Thesis, Department of Mechanical and Aerospace Engineering, West Virginia University, Morgantown, WV, 1992.

7. Cohen, A.J. and Higgins, M.W.P. "Health Effects of Diesel Exhaust: Epidemiology. In: Diesel Exhaust: A Critical Analysis of Emissions, Exposure, and Health Effects (A Special Report of the Institute's Diesel Working Group)." Health Effects Institute, Cambridge, MA, 1995, pp. 125-137.

8. Dockery, D.W., Pope, W.A., Xu, Z., Spengler, J.D., Ware, J.H., Fay, M.E., Ferris, B.G., and Speizer, F.E. "An Association between Air Pollution and Morality in six U.S. Cities.” New Engl. J. Med., Vol. 329, 1993, pp 1753-1759.

9. DOE Workshop Proceedings "Emissions Control Strategies for Internal Combustion Engines." Westin La Paloma, Tucson, AZ, January 21, 1999.

10. Donaldson, K. "The Effect of Ultra fine Titanium Dioxide on Epithelial Cells." Meeting of Aerosol Soc., Birmingham, 1994.

11. Gratz, L.D., Bagley, S.T., King, K.S., Baumgard, K.J., Leddy, D.G., and Johnson, J.H. "The Effect of a Ceramic Particulate Trap on the Particulate and Vapor Phase Emissions of Heavy-Duty Diesel Engine." SAE91069, 1991. 
12. Guerrieri, D.A., Rao, V. and Caffrey, P.J. "An Investigation of the Effect of Differing Filter Face Velocities of Particulate Mass Weight from Heavy-Duty Diesel Engines." SAE 960253, 1996.

13. Heinein, N.A. and Patterson, D.J. "Emissions and Combustion Engines." Ann Arbor Science Publishers, Inc., 1972.

14. International Agency for Research on Cancer "Diesel and Gasoline Engine Exhaust and some Nitroarenes." IARC Monographs on the Evaluation of Carcinogenic Risks to Humans, Vol. 46, Lyon, France, 1989.

15. Iwal, K., Udagawa, T., Yamagishi, M. and Yamada, H. "Long-Term Inhalation Studies of Diesel Exhaust on F344 SPF Rats." Proc. Int'l Satellite Symp. On Toxicological Effects of Emissions from Diesel Engines, Elsevier Sci. Pub., New York, N.Y., 1986, pp. 349-360.

16. Kao, K. S. and Friedlander, S. K. "Frequency Distribution of $\mathrm{PM}_{10}$ Chemical Components and their Sources." Enviro. Sci. Technol., Vol. 29, 1995, pp. 198-199.

17. Khair, M.K., Bykowski, B.B. "Design and Development of Catalytic Converters for Diesels.” SAE 921677, 1992.

18. Kreyling, W.G. "Is The Mass Concentration of Particulate Air Pollution The Appropriate Parameter for Respiratory Health Effects?” Zbl. Hyg., Vol. 159, 1994 pp. 198-199.

19. Mauderly, J.L., Jones, R.K., McClellan, R.O., Henderson, R.F. and Griffith, W.C. "Carcinogenicity of Diesel Exhaust Inhaled Chronically by Rats." Proceedings of the Int'l Satellite Symp. On Toxicological Effects of Emissions from Diesel Engine, Elsevier Sci Publ., New York, N. Y., 1986, pp. 397-409.

20. Mauderly, J.H., Griffith, G.C., Henderson, R.F., Jones, R.K., McClellan, R.O. "Evidence from Animal Studies for the Carcinogenicity of Inhaled Diesel Exhaust." In: Nitro-Arenes (ed. PC Howard et al.), Plenum Press, New York, 1991, pp. 1-13.

21. Mayer, A. "VERT: Curtailing Emissions of Diesel Engines in Tunnel Sites." VERT Report W11/1297. TTM, Switzerland, 1998.

22. Mayer, A., Egli, H., Burtscher, H., Czerwinski, J., and Gehrig, D. "Particle Size Distribution Downstream Traps of Different Design.” SAE 950373, 1995.

23. Mayer, W.J., Lechman, D.C., and Hilden, D.L. "The Contribution of Engine Oil to Diesel Exhaust Particulate Emissions." SAE 800256, 1980.

24. McClellan, R.O. "Health Effects of Diesel Exhaust: A Case Study in Risk Assessment." Am. Ind. Hyg. Assoc. J., Vol. 3, 1986, pp. 332. 
25. Monn, C. H., Braendli, O., Schaeppi, G., Schindler, C., Ackermann-Liebrich, U., Leuenberger, P. and Spaldia T. "Particulate Matter $<10 \mu \mathrm{m}\left(\mathrm{PM}_{10}\right)$ and Total Suspended Particulates (TSP) in Urban, Rural and Alpine Air in Switzerland." Atmospheric Environment, Vol. 29, No. 19, 1995, pp. 2565-2573.

26. National Institute for Occupational Safety and Health "Carcinogenic Effects of the Exposure to Diesel Exhaust." Current Intelligence Bulletin 50, Department of Human Health and Services, NIOSH Publication No. 88-116, 1988.

27. NESCAUM "Heavy Duty Engine Emissions in the Northeast States for Coordinated Air Use Management." Boston, MA, 1997.

28. Pataky, G.M., Baumgard, K.J., Gratz, L.D., Bagley, S.T., Leddy, D.G., Johnson, J.H. "Effects of an Oxidation Catalytic Converter on Regulated and Unregulated Diesel Emissions." SAE Paper 940243, 1994.

29. Pei, Yao "Development of Software for the Heavy-Duty Engine Testing at Engine Research Center, West Virginia University." M.S. Thesis, Department of Mechanical and Aerospace Engineering, West Virginia University, Morgantown, WV, 1993.

30. Pope, C.A., and Dockery, D.W. "Acute Health Effects of PM Pollution on Symptomatic and Asymptomatic Children." Am. Rev. Respir. Dis., Vol. 145, 1992, pp. 1123-1128.

31. Power Systems Research "Biodiesel Fuels for Underground Mines." Eagan, MN, August 31, 1995, pp. 22-26.

32. Reschke, G.D. "Optimization of a Flame Ionization Detector for Determination of Hydrocarbon in Diluted Automotive Exhausts." SAE 770141, 1977.

33. Smith II, R.C. "Comparison of Heavy-Duty Diesel Engine Transient Emissions Measurements Using a Mini- and a Full-flow Dilution Tunnel." M.S. Thesis, Department of Mechanical and Aerospace Engineering, West Virginia University, Morgantown, WV, 1993.

34. Smith, R.E. Jr., and Matz, R.J. "A Theoretical Method of Determining Discharge Coefficients for Venturis Operating at Critical Flow Conditions." Journal of Basic Science, 1962, pp. 434-446.

35. U.S. Environmental Protection Agency "Health Assessment Document for Diesel Emission.” SAB Review Draft, EPA/600/8-90/057C, Off. Of Res. \& Dev., Wash., DC, 1998.

36. van Beckhoven, L.C. " Effects of Fuel Properties on Diesel Engine Emissions - A Review of Information Available to the EEC-MVEG Group.” SAE 910608, 1991. 
37. VERT Project "VERT: Curtailing Emissions of Diesel Engines in Tunnel Sites." Mayer A., VERT Report W11/1297, TTM, Switzerland, 1998.

38. Waldenmaier, D.A., Gratz, L.D., Bagley, S.T., Johnson, J.H., Leddy, D.G. "The Influence of Sampling Conditions on the Repeatability of Diesel Particulate and Vapor Phase Hydrocarbon and PAH Measurements.” SAE 900642, 1990.

39. Wall, J.C. and Hoekman, S.K. "Fuel Composition Effects of Heavy-duty Diesel Particulate Emissions." SAE Paper 841364, 1984.

40. Wallace W.E., Keane M., Xing S., Harrison J., Gautam M., Ong T. "Mutagenicity of Diesel Exhaust Soot Dispersed in Phospholipid Surfactants." Environmental Hygiene II, Eds.NH Seemayer and W Hadnagy, Springer Verlag, Berlin, ISBN 0-387-52735-4, 1990, pp. 7-10.

41. Wallace W.E., Keane M.J., Vallyathan V., Ong T.M., Castranova V., "Pulmonary Surfactant Interaction with Respirable Dust." Proceedings: 1984 Coal Mine Dust Conference, , NTIS Report \#PB86 169380/AS, 1986, pp. 180-186.

42. Walsh, M. "Global Trends in Diesel Particulate Control - A 1995 Update." SAE 950149, 1995.

43. Walsh, M.P. and Bradow, R. "Diesel Particulate Control Around the World." SAE 910130, 1991. 
APPENDIX A - EXHAUST MASS EMISSIONS DATA (G/BHP-HR) 


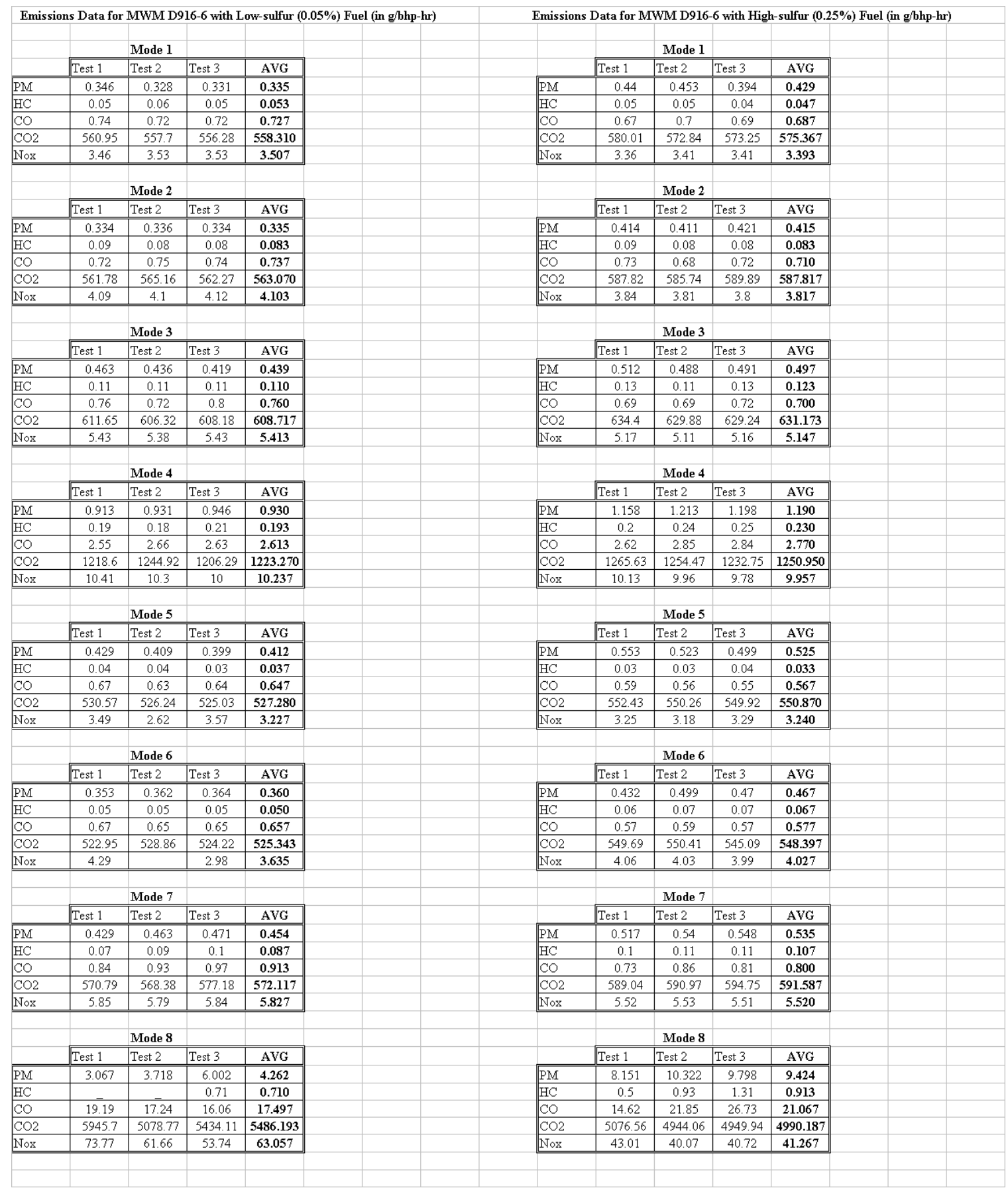




\begin{tabular}{|c|c|c|c|c|c|c|c|c|c|c|c|}
\hline Emissions & Data for $L$ & Lister Petter & r LPU-2 ba & re engine (i & (in g/bhp-hr & & Emissions Data $\mathrm{f}$ & or Lister $\mathrm{P}$ & etter LPU-2 & 2 with failed & trap (in g/bhp-hr) \\
\hline & & Mode 1 & & & & & & & Mode 1 & & \\
\hline & Test 1 & Test 2 & Test 3 & AVG & & & & Test 1 & Test 2 & AVG & \\
\hline PM & 6.122 & 5.778 & 5.676 & 5.859 & & & PM & 4.481 & 3.923 & 4.202 & \\
\hline $\mathrm{HC}$ & 0.27 & 0.12 & 0.09 & 0.160 & & & $\mathrm{HC}$ & 0.02 & 0.01 & 0.015 & \\
\hline $\mathrm{CO}$ & 44.71 & 36.82 & 34.79 & 38.773 & & & $\mathrm{CO}$ & 0.27 & 0.33 & 0.300 & \\
\hline \begin{tabular}{|l|}
$\mathrm{CO} 2$ \\
\end{tabular} & 921.7 & 933.69 & 927.82 & 927.737 & & & $\mathrm{CO} 2$ & 997.02 & 973.37 & 985.195 & \\
\hline Nox & 1.76 & 1.8 & 1.81 & 1.790 & & & Nox & 1.89 & 1.87 & 1.880 & \\
\hline Exh Temp & 1457 & 1775 & 1792 & 1674.667 & & & Exh Temp & 1452 & 1459 & 1455.500 & \\
\hline & & & & & & & & & & & \\
\hline & & Mode 2 & & & & & & & Mode 2 & & \\
\hline & Test 1 & Test 2 & Test 3 & AVG & & & & Test 1 & Test 2 & AVG & \\
\hline PM & 0.319 & 0.286 & 0.264 & 0.290 & & & PM & 0.332 & 0.345 & 0.339 & \\
\hline $\mathrm{HC}$ & 0.53 & 0.55 & 0.49 & 0.523 & & & $\mathrm{HC}$ & 0.01 & 0.01 & 0.010 & \\
\hline $\mathrm{CO}$ & 1.43 & 1.37 & 1.33 & 1.377 & & & $\mathrm{CO}$ & 0.05 & 0.12 & 0.085 & \\
\hline $\mathrm{CO} 2$ & 839.36 & 824.45 & 837.9 & 833.903 & & & $\mathrm{CO} 2$ & 950.12 & 934.63 & 942.375 & \\
\hline Nox & 3.9 & 3.93 & 4.01 & 3.947 & & & Nox & 3.9 & 3.95 & 3.925 & \\
\hline Exh Temp & 915 & 903 & 898 & 905.333 & & & Exh Temp & 940 & 937 & 938.500 & \\
\hline & & & & & & & & & & & \\
\hline & & Mode 3 & & & & & & & Mode 3 & & \\
\hline & Test 1 & Test 2 & Test 3 & AVG & & & & Test 1 & Test 2 & AVG & \\
\hline PM & 0.326 & 0.342 & 0.319 & 0.329 & & & PM & 0.223 & $\begin{array}{l}0.259 \\
\end{array}$ & 0.241 & \\
\hline $\mathrm{HC}$ & 1.31 & 1.45 & 1.27 & 1.343 & & & $\mathrm{HC}$ & 0 & 0 & 0.000 & \\
\hline $\mathrm{CO}$ & 1.62 & 1.85 & 1.58 & 1.683 & & & $\mathrm{CO}$ & 0.15 & 0.14 & 0.145 & \\
\hline \begin{tabular}{|l}
$\mathrm{CO} 2$ \\
\end{tabular} & 930.87 & 925.05 & 943.22 & 933.047 & & & $\mathrm{CO} 2$ & 1010.78 & 1018.72 & 1014.750 & \\
\hline Nox & 5.24 & 5.2 & 5.32 & 5.253 & & & Nox & 4.97 & 5.06 & 5.015 & \\
\hline Exh Temp & 748 & 747 & 748 & $\begin{array}{l}47.667 \\
\end{array}$ & & & Exh Temp & 931 & 763 & 847.000 & \\
\hline & & & & & & & & & & & \\
\hline & & Mode 4 & & & & & & & Mode 4 & & \\
\hline & Test 1 & Test 2 & AVG & & & & & Test 1 & Test 2 & AVG & \\
\hline PM & 0.881 & 0.727 & 0.804 & & & & $\mathrm{PM}$ & 0.164 & 0.196 & 0.180 & \\
\hline $\mathrm{HC}$ & 1.34 & 0.97 & 1.155 & & & & $\mathrm{HC}$ & 0.05 & 0 & 0.025 & \\
\hline $\mathrm{CO}$ & 3.39 & 2.71 & 3.050 & & & & $\mathrm{CO}$ & 0.41 & 0.12 & 0.265 & \\
\hline \begin{tabular}{|l|}
$\mathrm{CO} 2$ \\
\end{tabular} & 1359.75 & 1392.39 & 1376.070 & & & & $\mathrm{CO} 2$ & 1543.86 & 1535.71 & \begin{tabular}{|l||}
1539.785 \\
\end{tabular} & \\
\hline Nox & 7.84 & 8.05 & 7.945 & & & & Nox & 7.57 & 7.57 & \begin{tabular}{|l||}
7.570 \\
\end{tabular} & \\
\hline Exh Temp & 583 & 580 & 581.500 & & & & Exh Temp & 596 & 593 & 594.500 & \\
\hline & & & & & & & & & & & \\
\hline & & Mode 5 & & & & & & & Mode 5 & & \\
\hline & Test 1 & Test 2 & Test 3 & AVG & & & & Test 1 & Test 2 & AVG & \\
\hline $\mathrm{PM}$ & 7.833 & 7.889 & 7.996 & 7.906 & & & $\mathrm{PM}$ & 5.067 & 5.512 & 5.290 & \\
\hline $\mathrm{HC}$ & 1.26 & 1.22 & 1.25 & 1.243 & & & $\mathrm{HC}$ & 0.01 & 0.01 & 0.010 & \\
\hline $\mathrm{CO}$ & 33.98 & 32.8 & 33.38 & 33.387 & & & $\mathrm{CO}$ & 0.09 & 0.11 & 0.100 & \\
\hline \begin{tabular}{|l|}
$\mathrm{CO} 2$ \\
\end{tabular} & 831.94 & 825.37 & 823.84 & 827.050 & & & $\mathrm{CO} 2$ & 858.09 & 862.9 & 860.495 & \\
\hline Nox & 1.67 & 1.63 & 1.59 & 1.630 & & & Nox & 1.81 & 1.79 & 1.800 & \\
\hline Exh Temp & 1138 & 1162 & 1233 & 1177.667 & & & Exh Temp & 1208 & 1217 & 1212.500 & \\
\hline & & & & & & & & & & & \\
\hline & & Mode 6 & & & & & & & Mode 6 & & \\
\hline & Test 1 & Test 2 & Test 3 & Test 4 & Test 5 & AVG & & Test 1 & Test 2 & AVG & \\
\hline $\mathrm{PM}$ & 0.505 & 0.635 & 0.518 & 0.568 & 0.516 & 0.548 & $\mathrm{PM}$ & 0.317 & 0.308 & 0.313 & \\
\hline $\mathrm{HC}$ & 1 & 0.99 & 0.8 & 0.43 & 0.4 & 0.724 & $\mathrm{HC}$ & 0.09 & 0.05 & 0.070 & \\
\hline $\mathrm{CO}$ & 3.4 & 3.38 & 3.28 & 2.62 & 2.59 & 3.054 & $\mathrm{CO}$ & 0.04 & 0.17 & 0.105 & \\
\hline \begin{tabular}{|l}
$\mathrm{CO} 2$ \\
\end{tabular} & 758.93 & 750.02 & 737.97 & 707.17 & 703.16 & 731.450 & $\mathrm{CO} 2$ & 816.53 & 799.79 & 808.160 & \\
\hline Nox & 5.49 & 4.7 & 4.5 & 3.85 & 3.83 & 4.474 & Nox & 3.73 & 3.8 & 3.765 & \\
\hline Exh Temp & & & & 763 & 780 & 771.500 & Exh Temp & 827 & 824 & 825.500 & \\
\hline & & & & & & & & & & & \\
\hline & & Mode 7 & & & & & & & Mode 7 & & \\
\hline & Test 1 & Test 2 & Test 3 & AVG & & & & Test 1 & Test 2 & AVG & \\
\hline PM & 0.367 & 0.435 & 0.458 & 0.420 & & & PM & 0.116 & 0.102 & 0.109 & \\
\hline $\mathrm{HC}$ & 3.64 & 3.43 & 3.48 & 3.517 & & & $\mathrm{HC}$ & 0.3 & 0.29 & 0.295 & \\
\hline $\mathrm{CO}$ & 6.78 & 6.52 & 6.69 & 6.663 & & & $\mathrm{CO}$ & 0.2 & 0 & 0.100 & \\
\hline $\mathrm{CO} 2$ & 882.15 & 875.7 & 862.71 & 873.520 & & & $\mathrm{CO} 2$ & 959.55 & 956.54 & 958.045 & \\
\hline Nox & 8.26 & 7.87 & 7.9 & 8.010 & & & Nox & 7.66 & 7.72 & 7.690 & \\
\hline Exh Temp & 567 & 567 & 569 & 567.667 & & & Exh Temp & 602 & 592 & 597.000 & \\
\hline & & & & & & & & & & & \\
\hline & & Mode 8 & & & & & & & Mode 8 & & \\
\hline & Test 1 & Test 2 & Test 3 & AVG & & & & Test 1 & Test 2 & AVG & \\
\hline $\mathrm{PM}$ & 0.283 & 0.276 & 0.255 & 0.271 & & & $\mathrm{PM}$ & 0.146 & 0.202 & 0.174 & \\
\hline $\mathrm{HC}$ & 0 & 0 & 0 & 0.000 & & & $\mathrm{HC}$ & 0 & 0 & 0.000 & \\
\hline $\mathrm{CO}$ & 2.39 & 2.74 & 2.04 & 2.390 & & & $\mathrm{CO}$ & 0 & 1.71 & 0.855 & \\
\hline $\mathrm{CO} 2$ & 2162.11 & 2347.07 & 2318.72 & 2275.967 & & & $\mathrm{CO} 2$ & 3585.66 & 3221.89 & 3403.775 & \\
\hline Nox & 52.64 & 60.15 & 61.57 & 58.120 & & & Nox & 76.42 & 67.81 & 72.115 & \\
\hline Exh Temp & 269 & 231 & 227 & 242.333 & & & Exh Temp & 281 & 248 & 264.500 & \\
\hline & & & & & & & & & & & \\
\hline
\end{tabular}




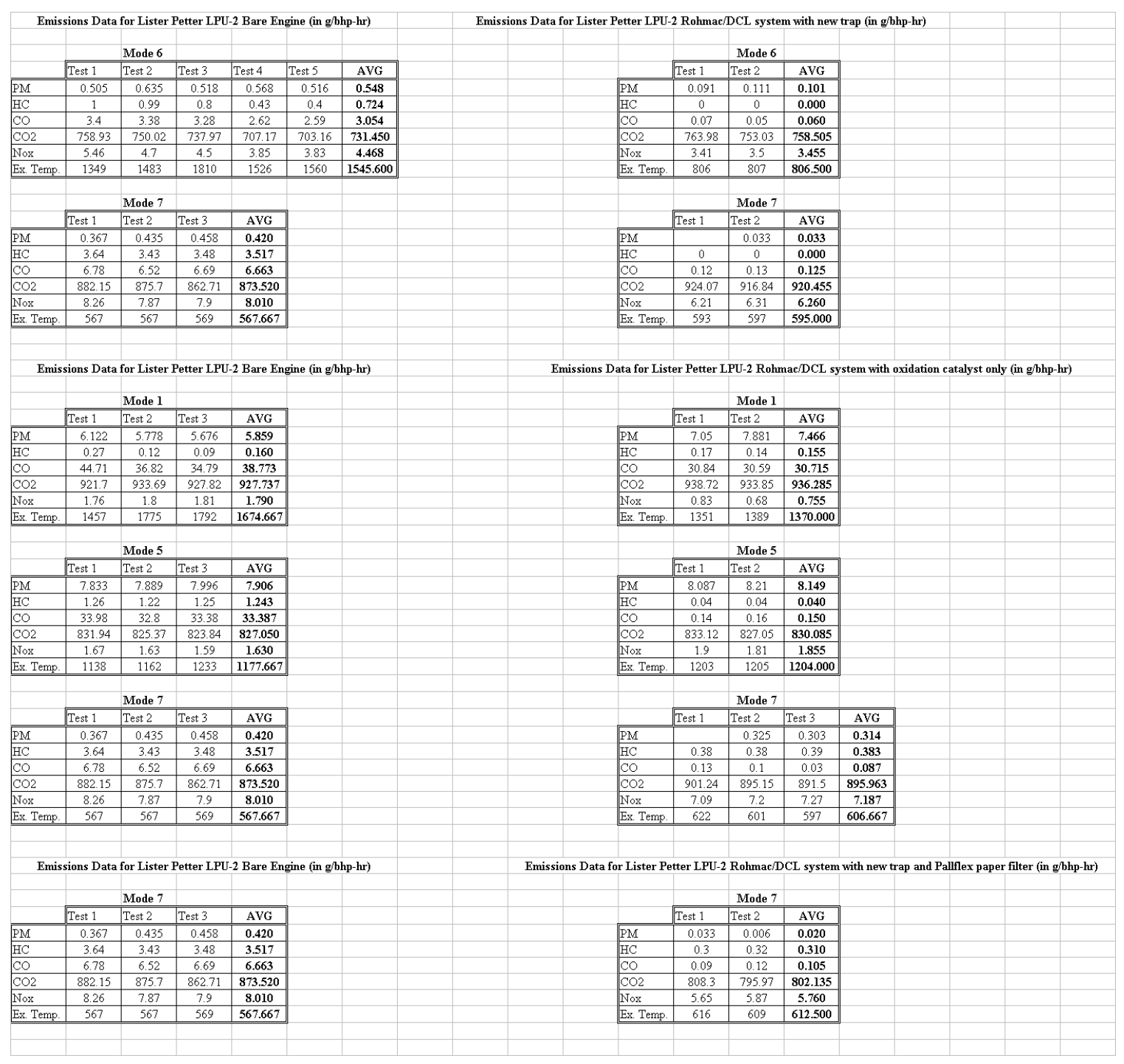




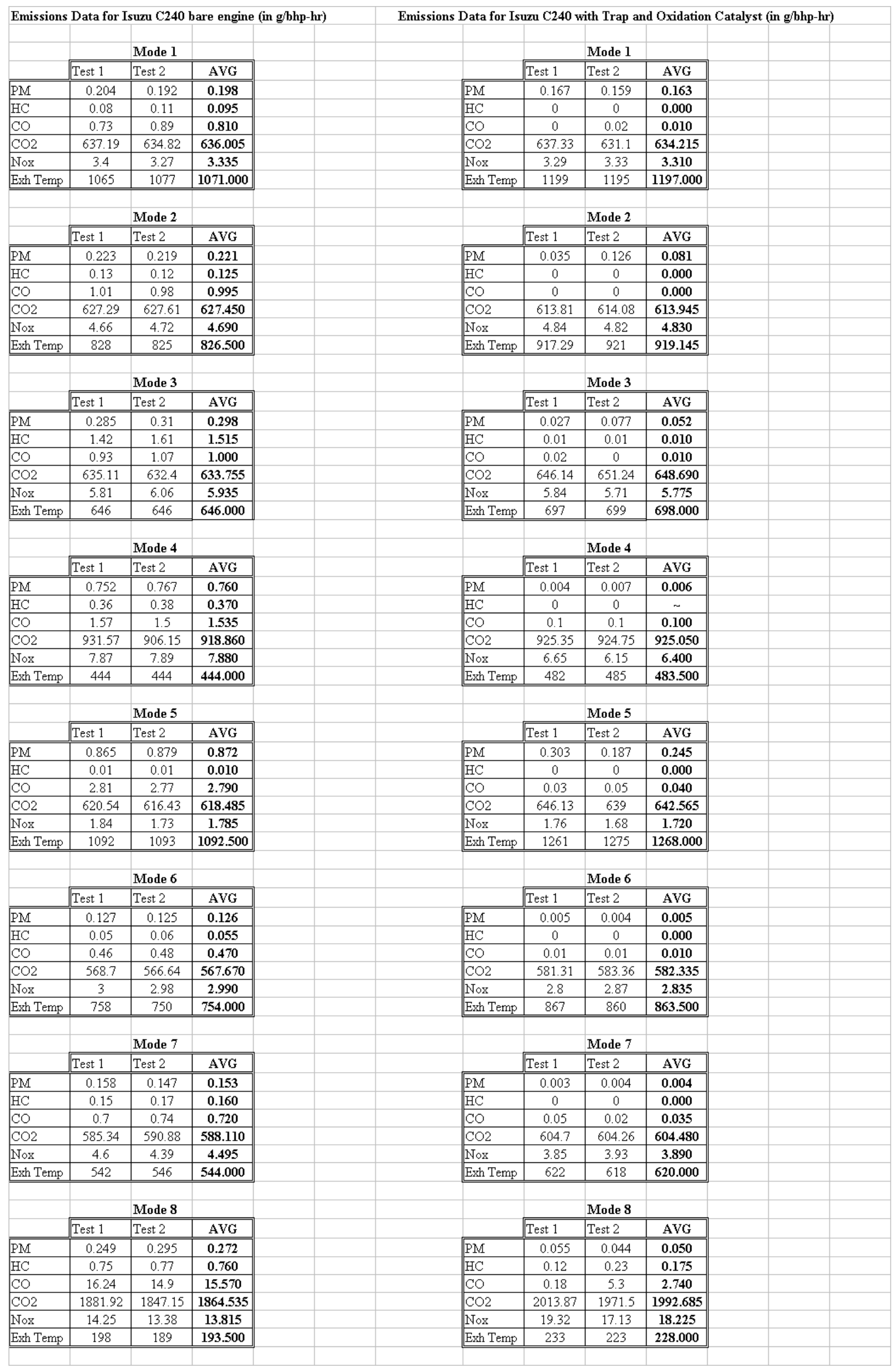




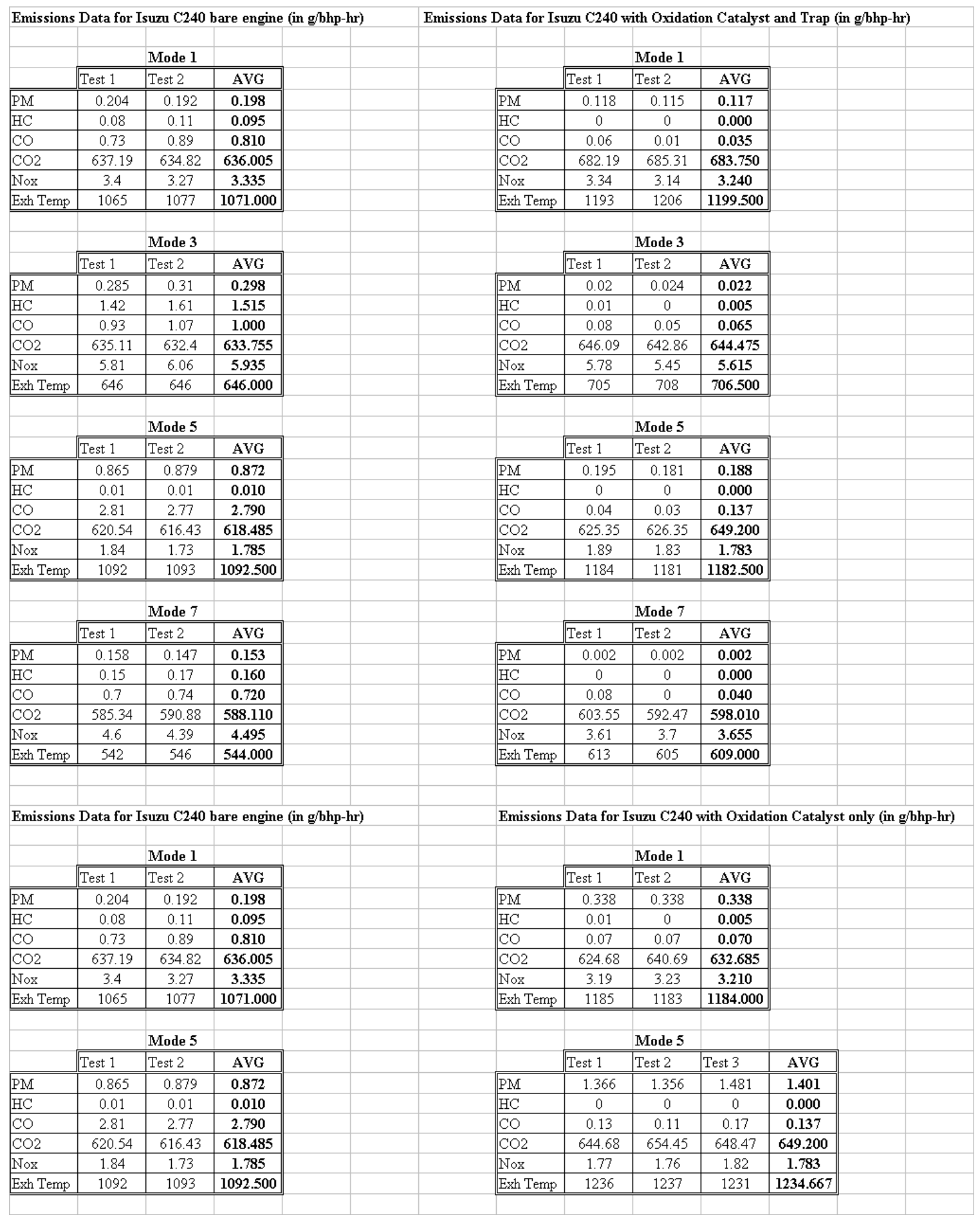




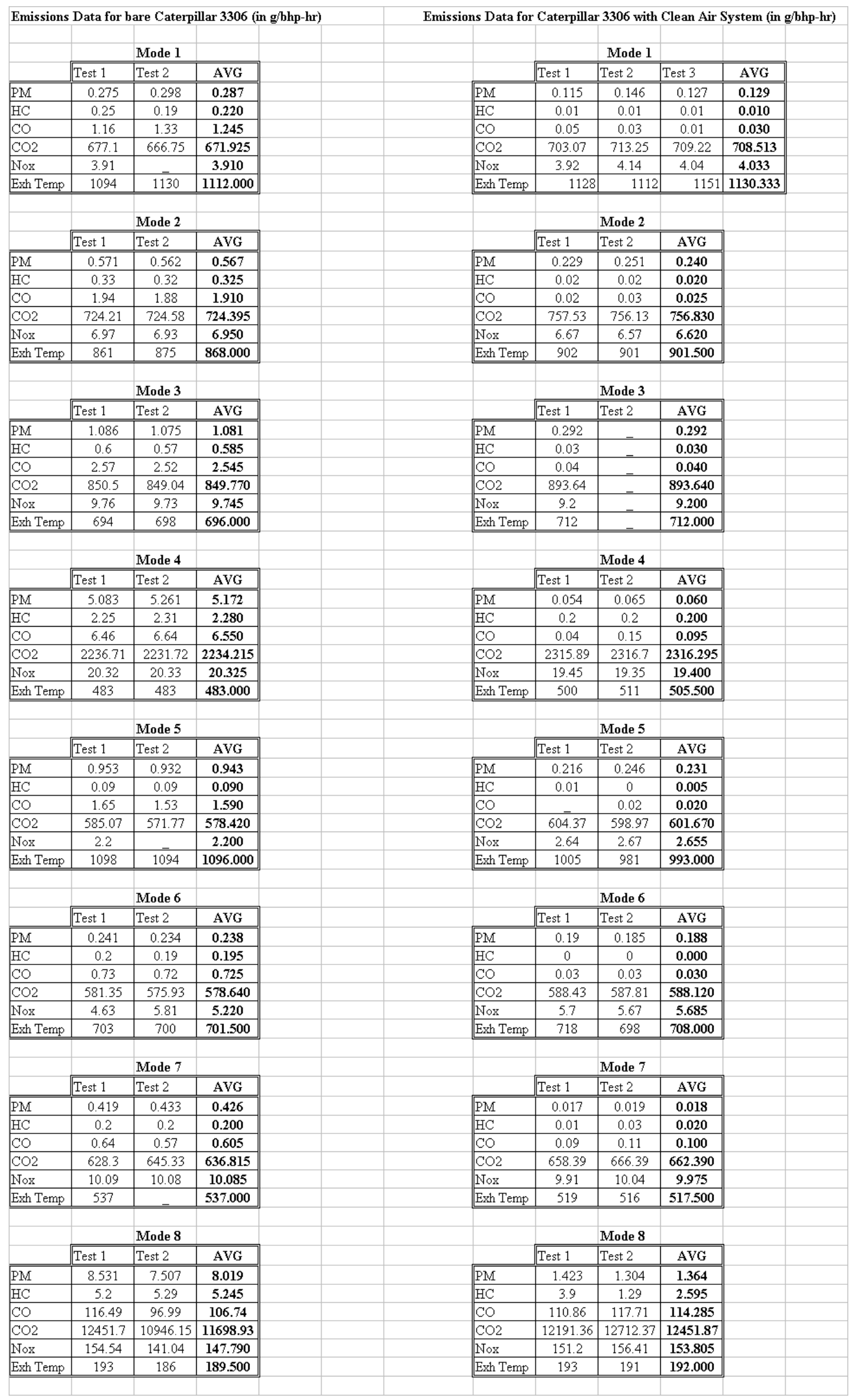




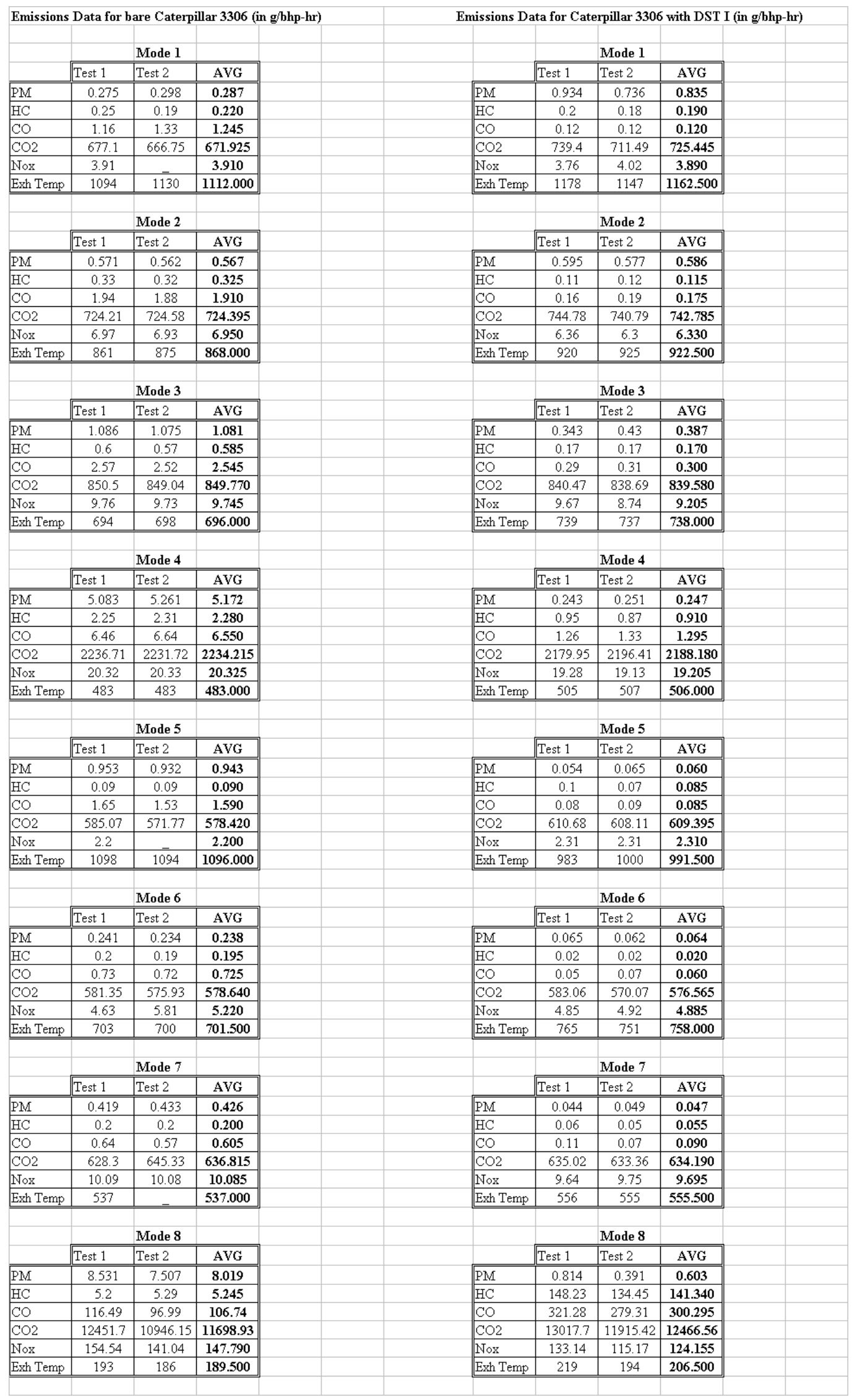




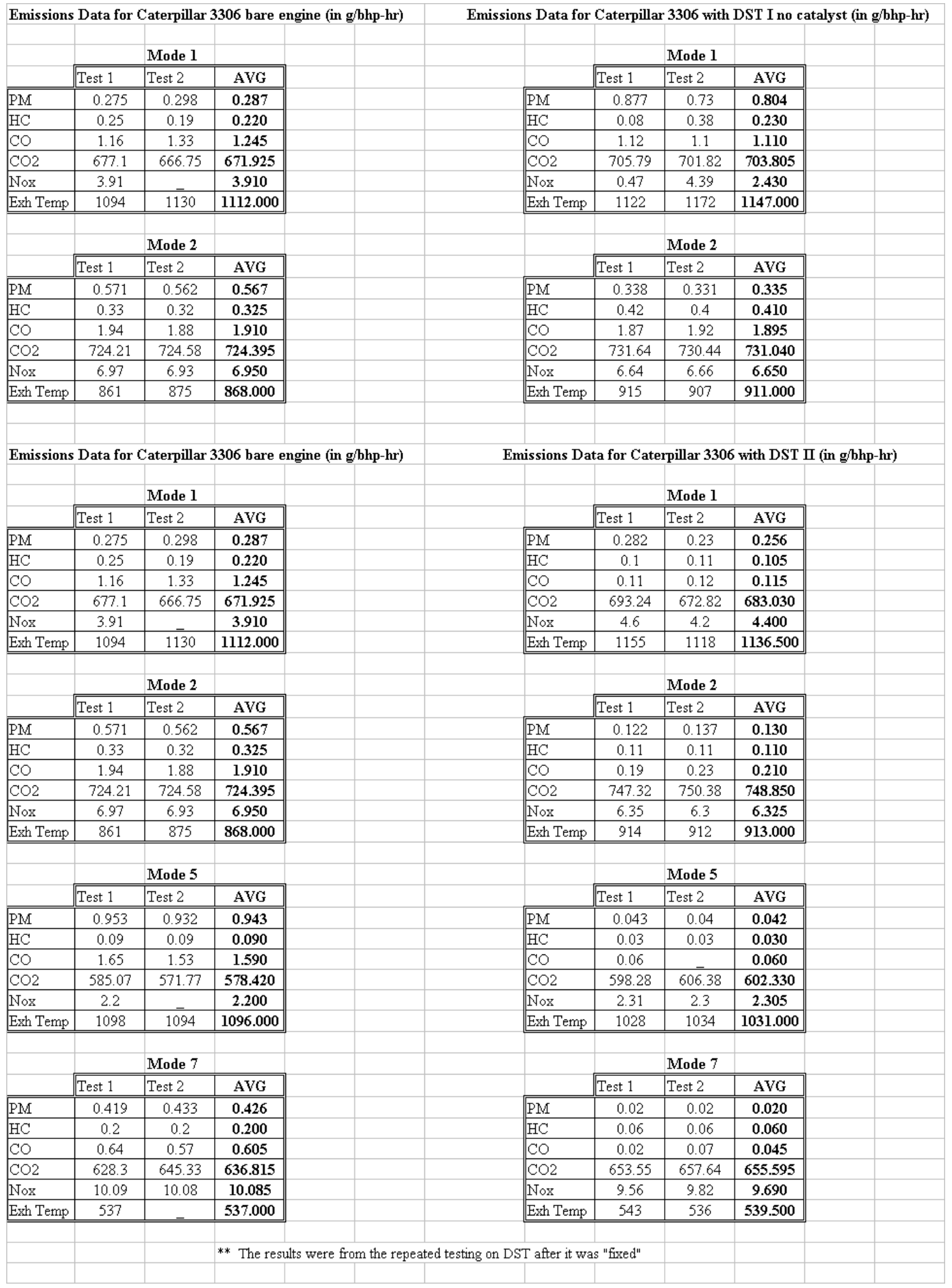




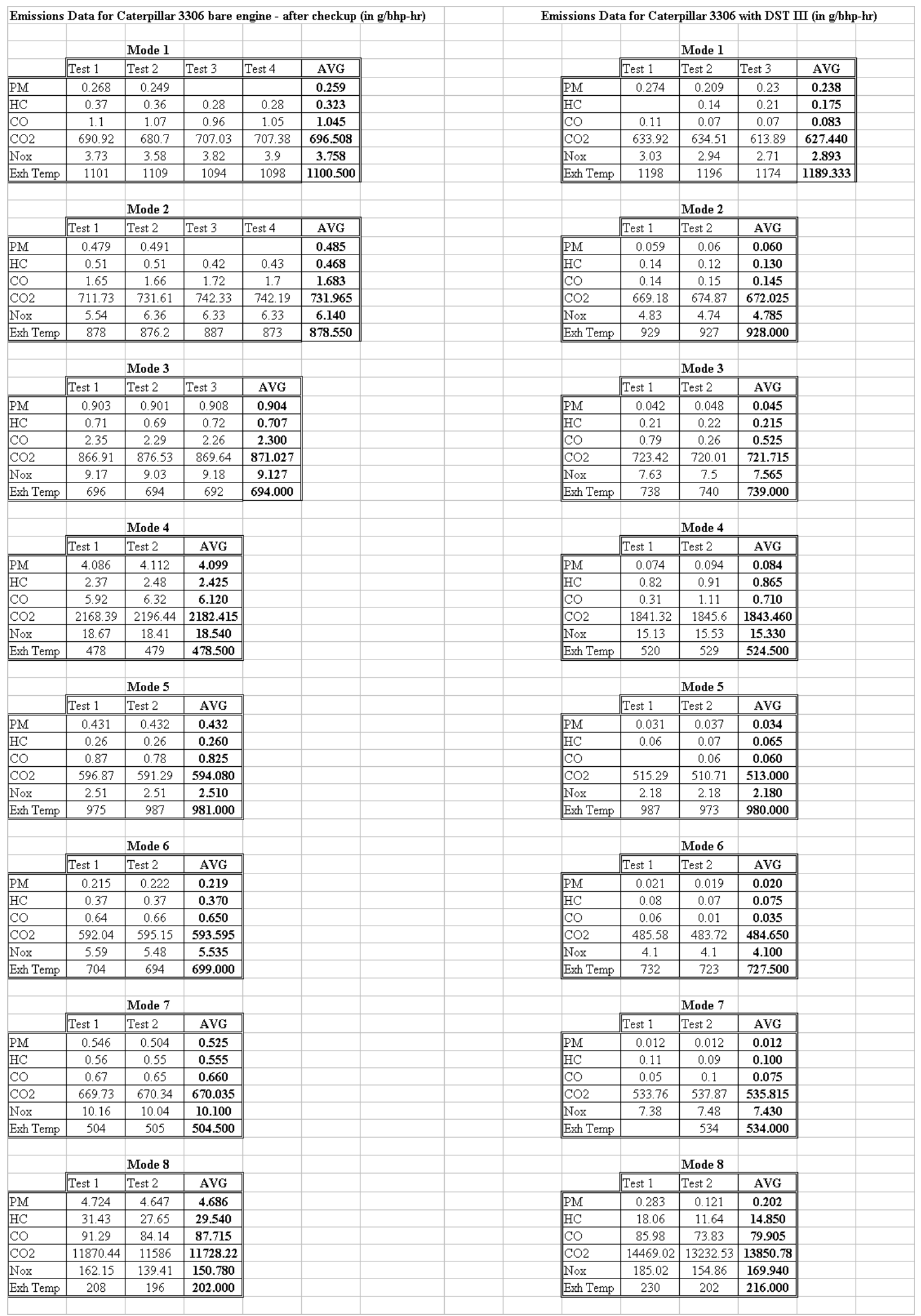


APPENDIX B - EXHAUST MASS EMISSIONS DATA (G/HR) 


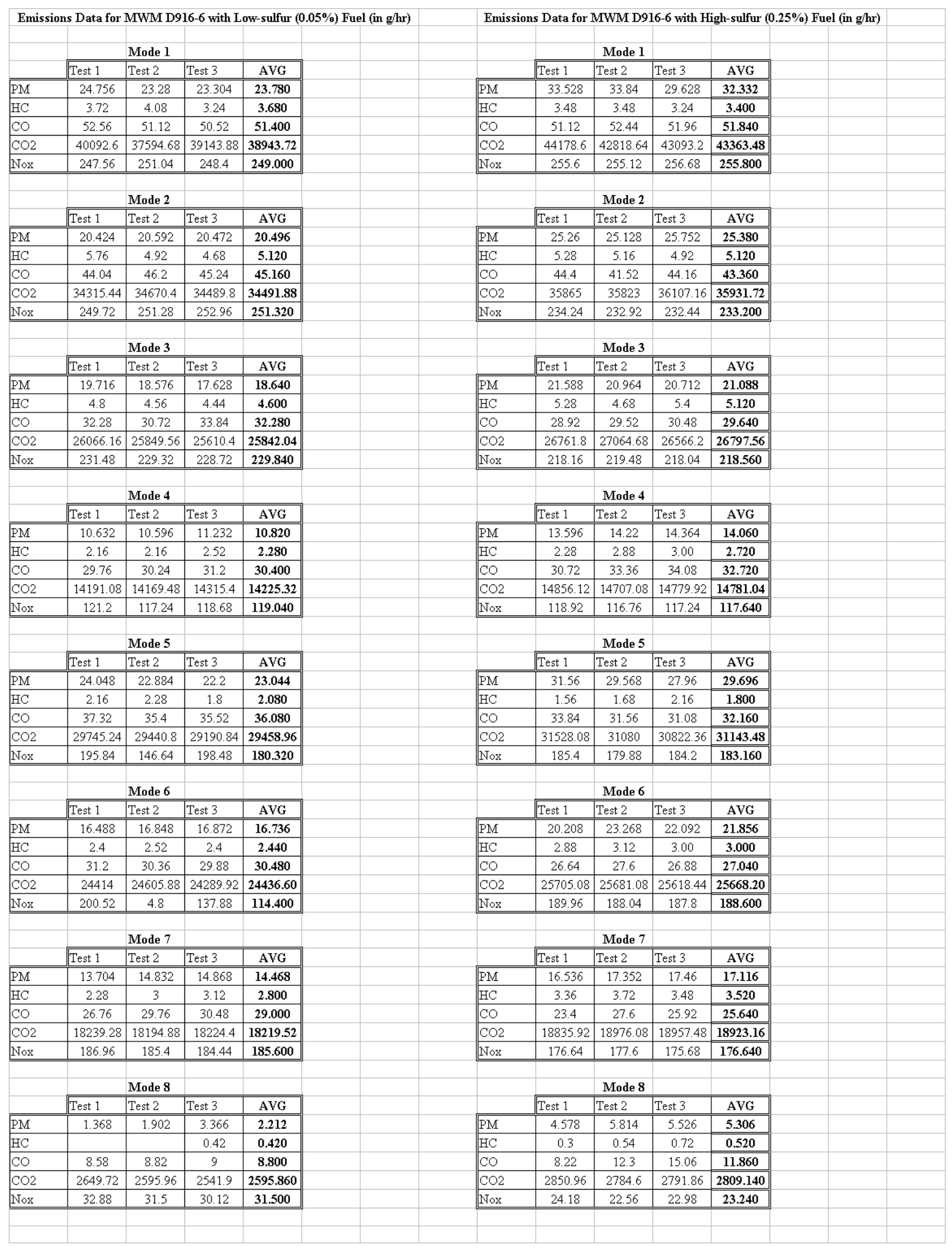




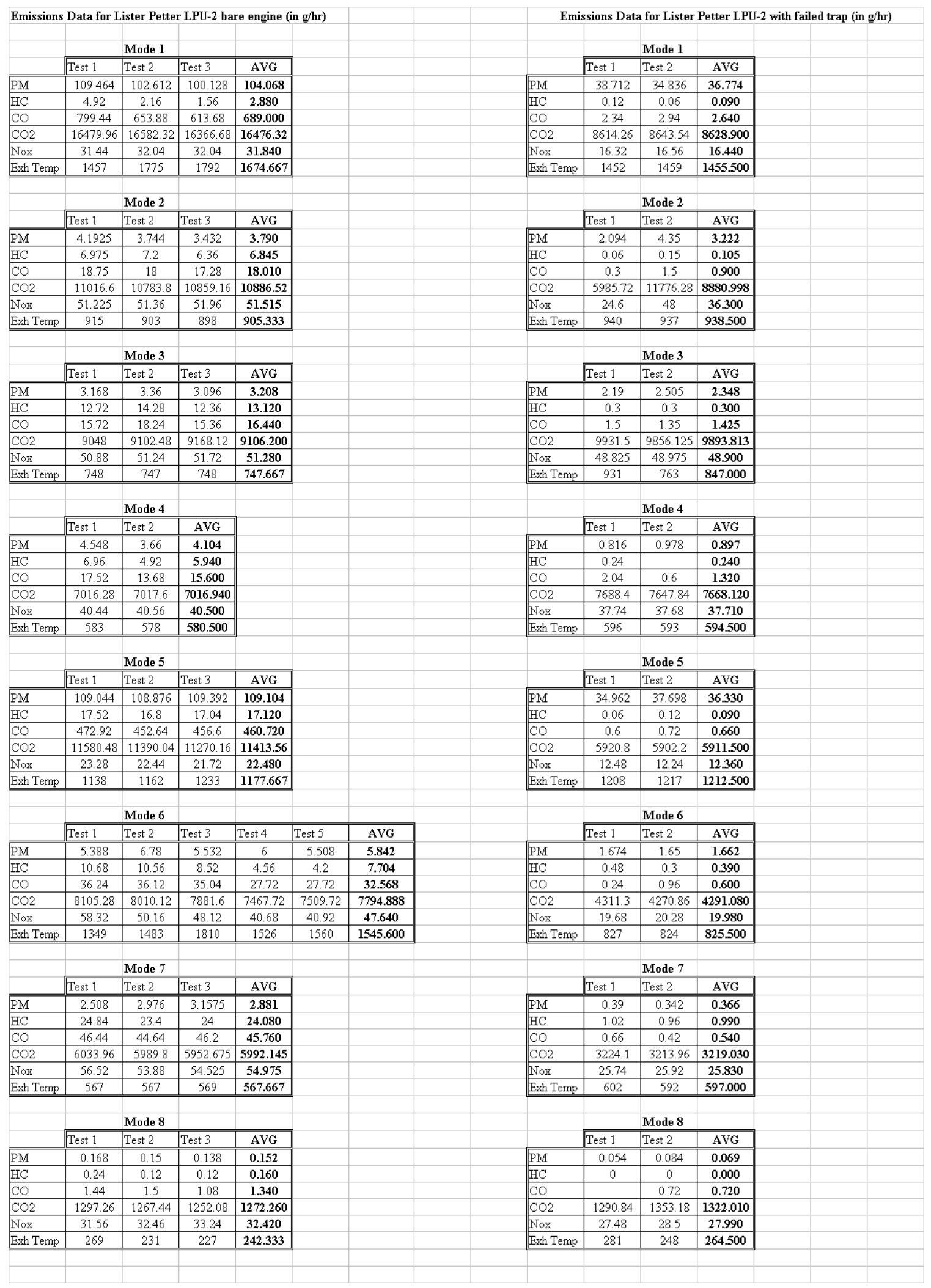




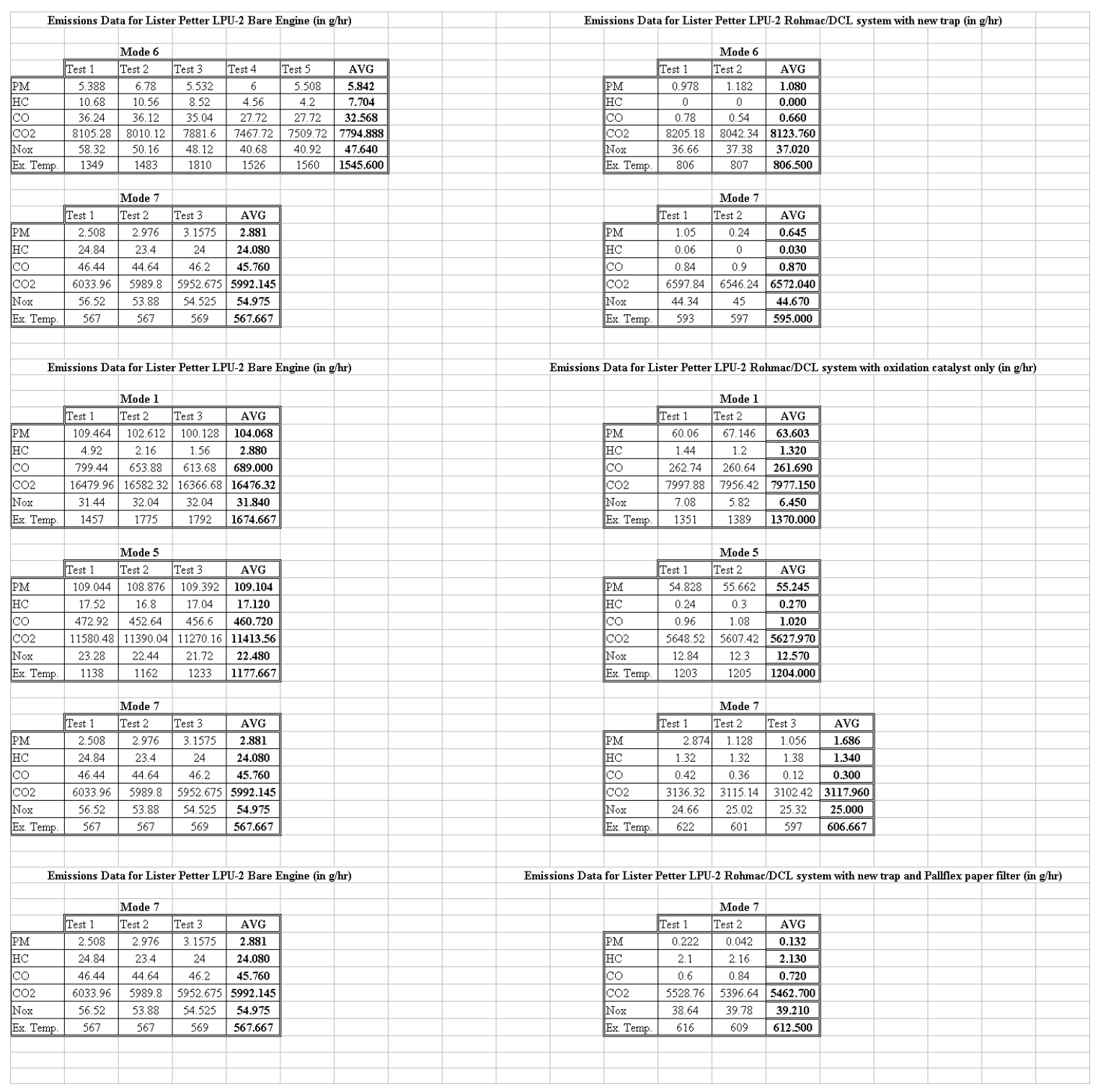




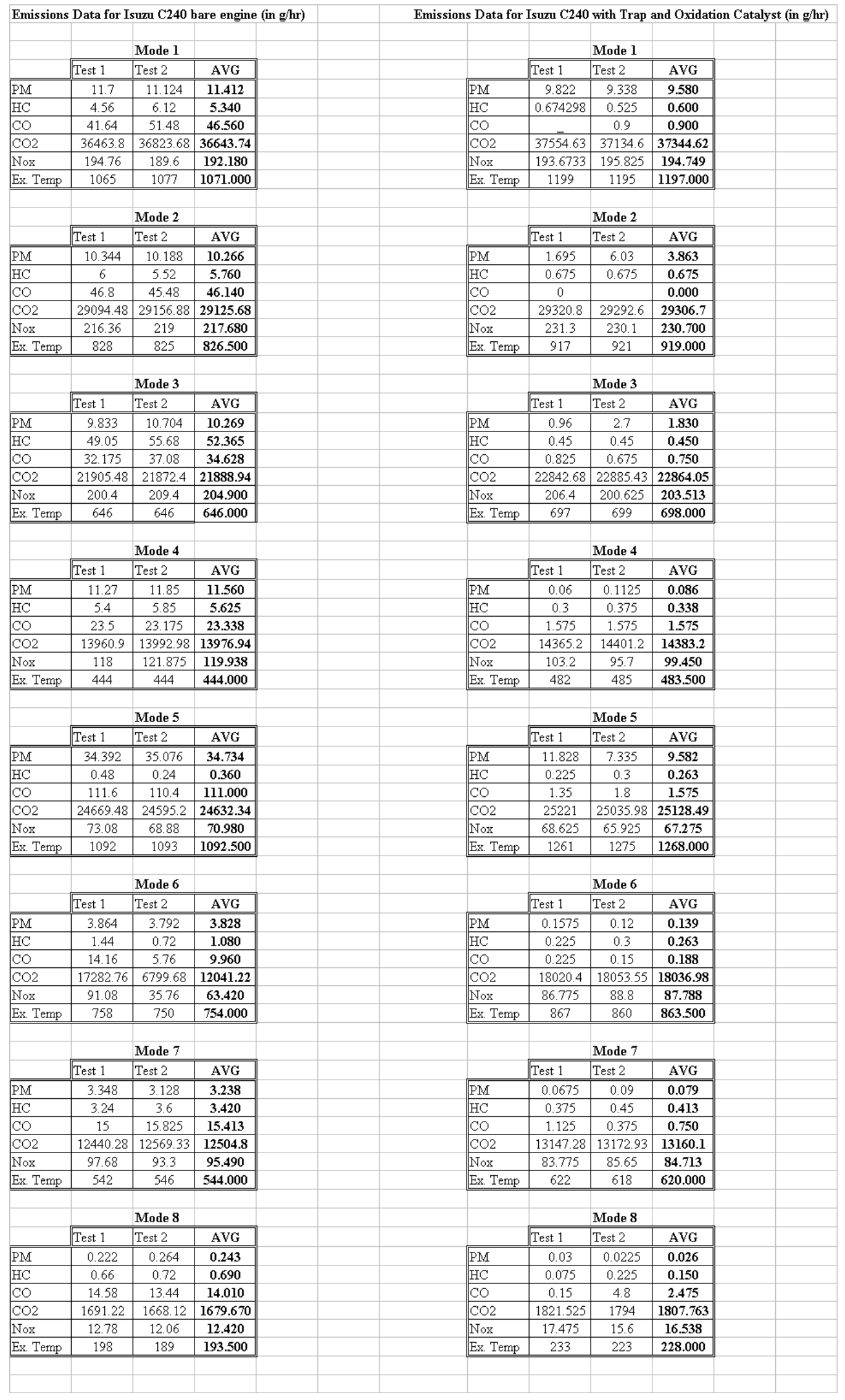




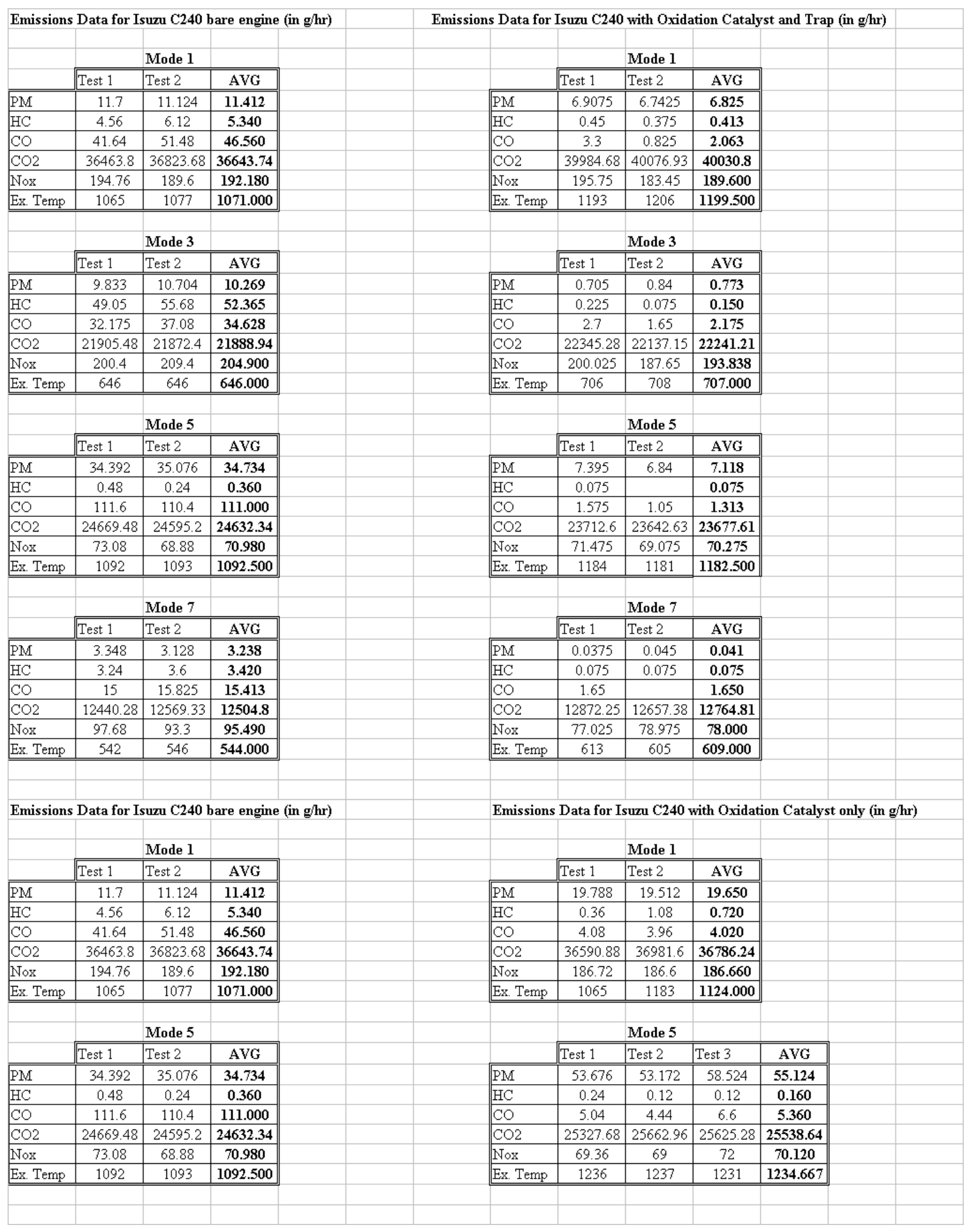




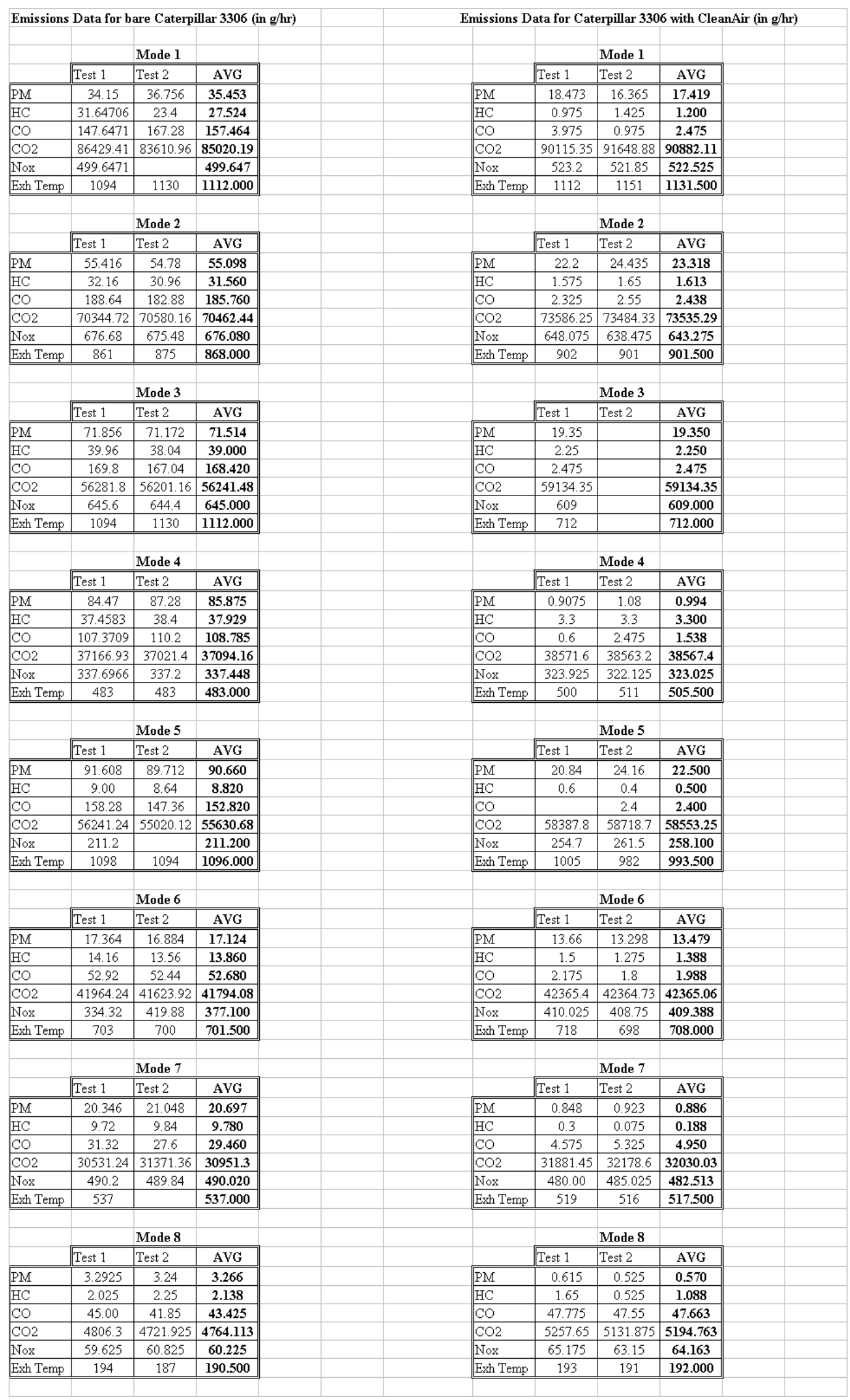




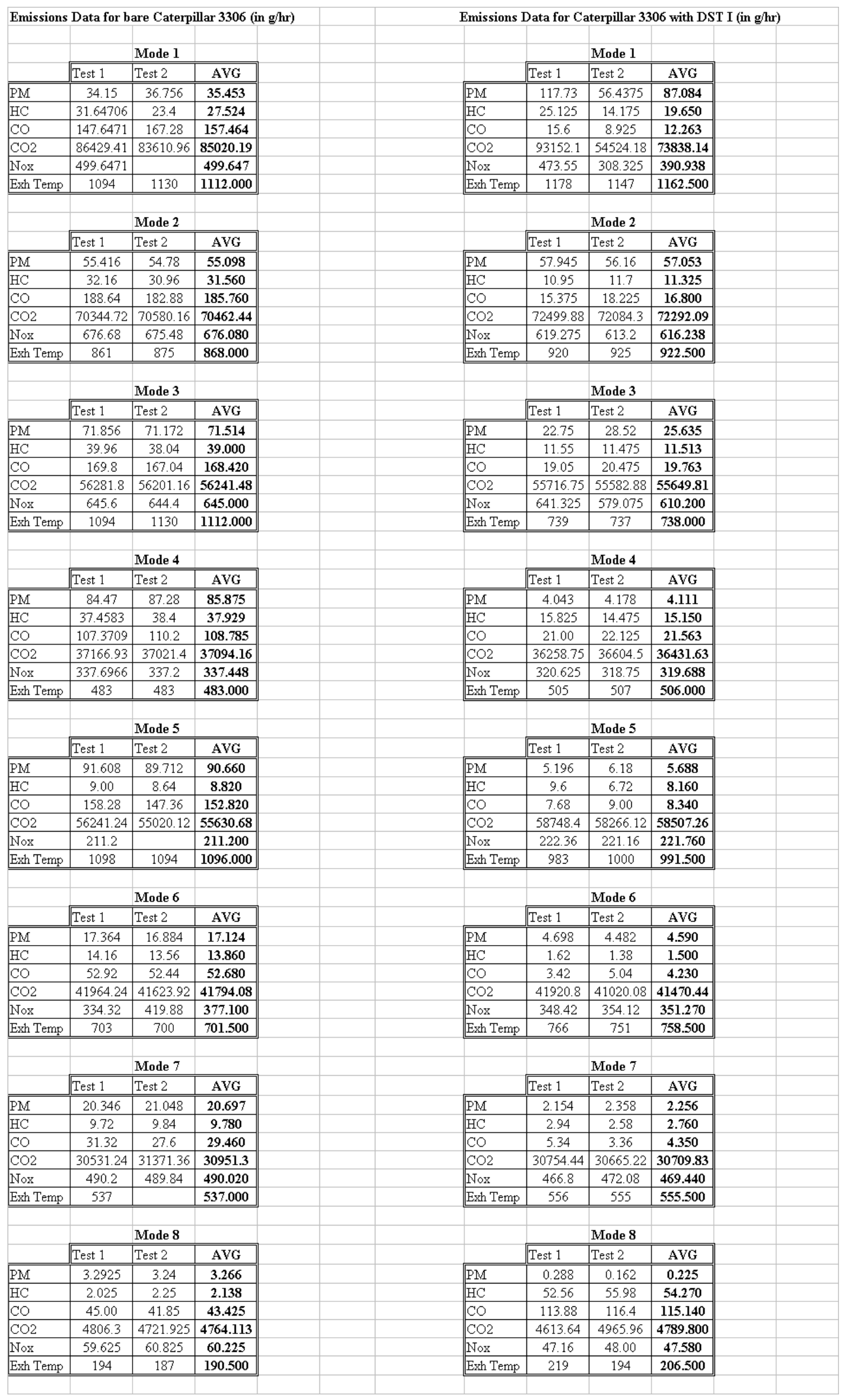




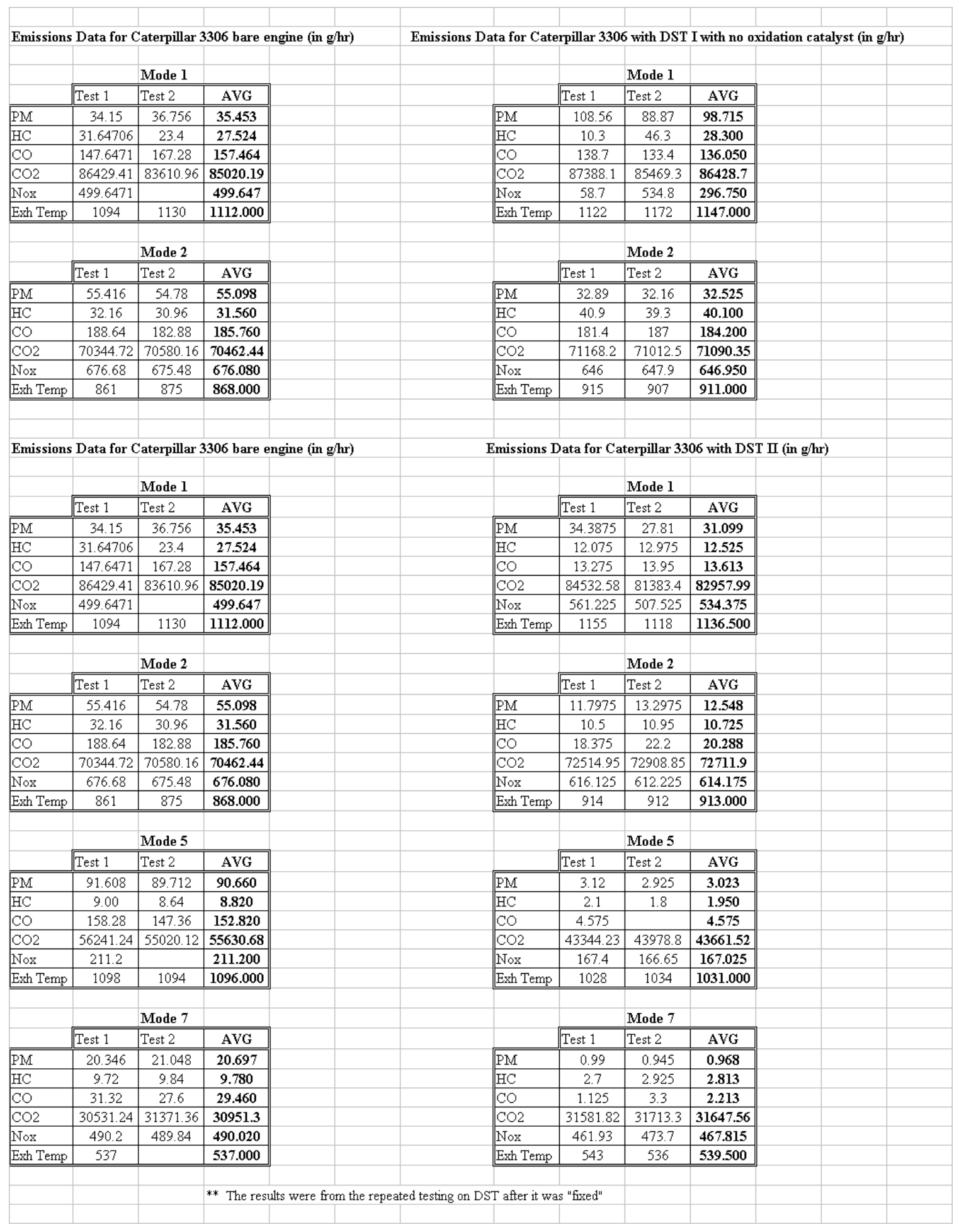




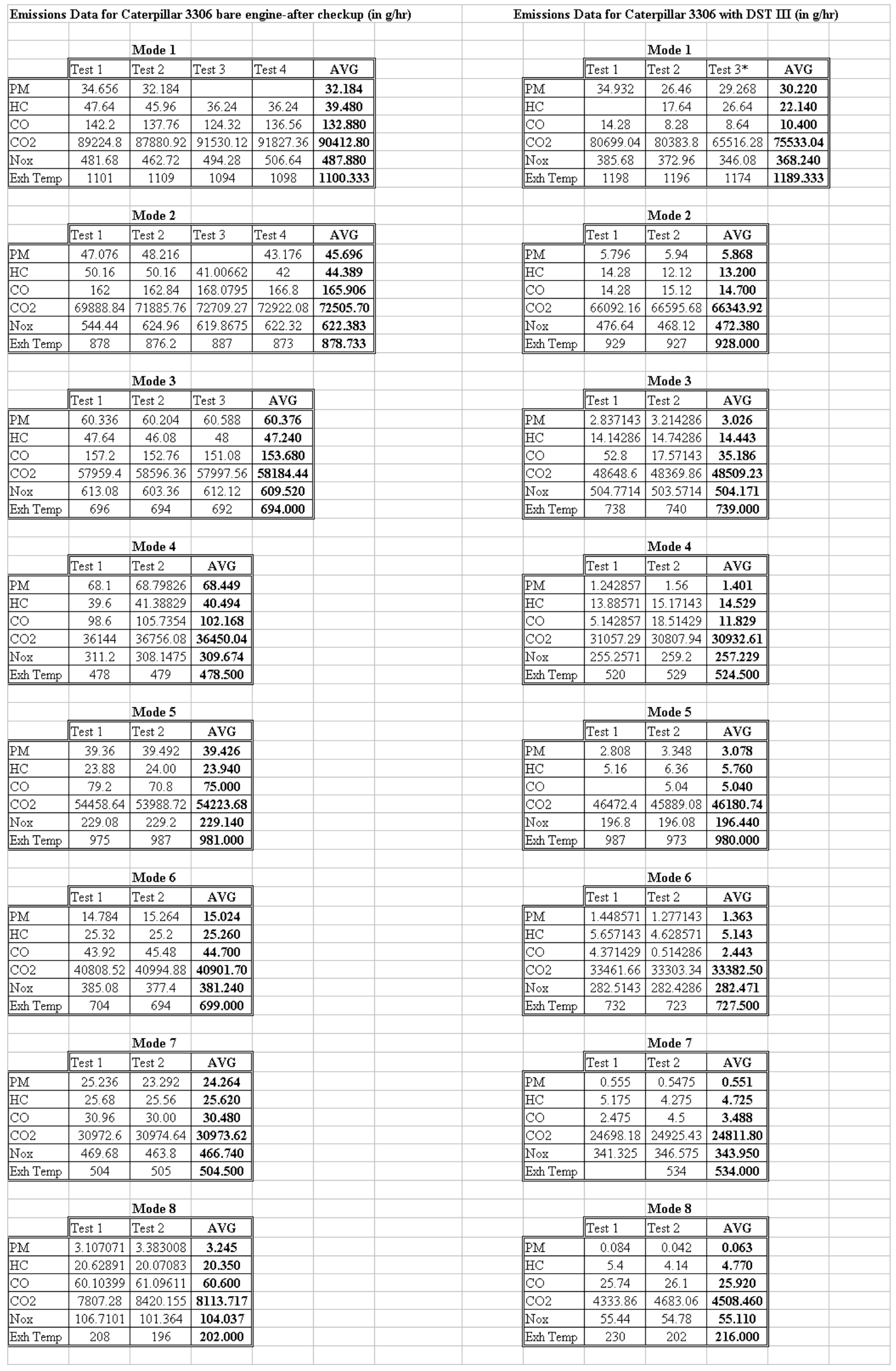

